\title{
Cerebrospinal fluid biochemical studies in patients with Parkinson's disease: toward a potential search for biomarkers for this disease
} \author{
José A. G. Agúndez ${ }^{3,4}$ \\ 1 Section of Neurology, Hospital Universitario del Sureste, Madrid, Spain \\ ${ }^{2}$ Department of Biochemistry and Molecular Biology, University of Extremadura, Cáceres, Spain \\ ${ }^{3}$ AMGenomics, Cáceres, Spain \\ ${ }^{4}$ Department of Pharmacology, University of Extremadura, Cáceres, Spain
}

Félix J. Jiménez-Jiménez ${ }^{1 *}$, Hortensia Alonso-Navarro ${ }^{1}$, Elena García-Martín ${ }^{2,3}$ and

Edited by:

Ramon Santos El-Bachá,

Universidade Federal da Bahia, Brazil

Reviewed by:

Ana I. Duarte, University of

Coimbra, Portugal

Victor P. Andreev, Arbor Research

Collaborative for Health, USA

Naruhiko Sahara, National Institute

of Radiological Sciences, Japan

\section{*Correspondence:}

Félix J. Jiménez-Jiménez, Section of Neurology, Hospital Universitario del Sureste, Ronda del Sur 10, E-28500, Arganda del Rey, Madrid, Spain e-mail:

fjavier.jimenez@salud.madrid.org; felix.jimenez@sen.es
The blood-brain barrier supplies brain tissues with nutrients and filters certain compounds from the brain back to the bloodstream. In several neurodegenerative diseases, including Parkinson's disease (PD), there are disruptions of the blood-brain barrier. Cerebrospinal fluid (CSF) has been widely investigated in PD and in other parkinsonian syndromes with the aim of establishing useful biomarkers for an accurate differential diagnosis among these syndromes. This review article summarizes the studies reported on CSF levels of many potential biomarkers of PD. The most consistent findings are: (a) the possible role of CSF urate on the progression of the disease; (b) the possible relations of CSF total tau and phosphotau protein with the progression of PD and with the preservation of cognitive function in PD patients; (c) the possible value of CSF beta-amyloid 1-42 as a useful marker of further cognitive decline in PD patients, and (d) the potential usefulness of CSF neurofilament (NFL) protein levels in the differential diagnosis between PD and other parkinsonian syndromes. Future multicentric, longitudinal, prospective studies with long-term follow-up and neuropathological confirmation would be useful in establishing appropriate biomarkers for PD.

Keywords: Parkinson's disease, cerebrospinal fluid, biological markers, neurotransmitters, oxidative stress, tau protein, alpha-synuclein, beta-amyloid

\section{INTRODUCTION}

The diagnosis of Parkinson's disease (PD) in live patients is fundamentally clinical, and is based on the presence of its cardinal signs (rest tremor, rigidity, bradykinesia, and postural instability), and the absence of atypical data for idiopathic PD. The final confirmation of the diagnosis is made by post-mortem neuropathological analysis. To date, there are no definitive biomarkers to make an accurate differential diagnosis with other parkinsonian syndromes.

Because the cerebrospinal fluid (CSF) is in close contact with the extracellular space of the brain, it is believed that many of the biochemical modifications in the brain should be reflected in the CSF. Therefore, CSF has been widely investigated in PD and in other parkinsonian syndromes with the aim of acquiring knowledge on the pathogenesis of this disease. This article summarizes the data on analyses performed in the CSF of patients diagnosed with PD compared with controls, with regard to: (1) concentrations of neurotransmitters (mainly monoamines and their metabolites), neuromodulators, and related substances as possible biological markers of the disease itself or its complications; (2) concentrations of endogenous neurotoxins; (3) status of oxidative stress markers or substances which could be related with the induction of oxidative stress or with "neuroprotection" against it; (4) status of inflammation and immunological markers, neurotrophic and growth factors, and (5) concentrations of proteins related with the pathogenesis of $\mathrm{PD}$ or other compounds.

The aim of this review is to provide an extensive descriptive overview of studies published on this issue (including references to many reports in the last six decades which have historical interest).

\section{SEARCH STRATEGY}

References for this review were identified by searching in PubMed from 1966 until June 20, 2014. The term "Parkinson's disease" was crossed with "cerebrospinal fluid" and "blood brain barrier," and the related references were selected. Table 1 summarizes a classification of the diverse types of compounds which have been analyzed in the CSF of PD patients in accordance with the search.

\section{NEUROTRANSMITTERS, NEUROMODULATORS, AND RELATED SUBSTANCES DOPAMINE METABOLITES}

Because the main neurochemical finding in $\mathrm{PD}$ is the depletion of dopamine (DA) in the nigroestriatal system (Benito-León et al., 2008), it is to be expected that the CSF concentrations of the main metabolites of DA, dihydroxyphenyl-acetyc acid (DOPAC) 
Table 1 | Relation and classification of compounds measured in CSF of PD.

(A) Neurotransmitters, neuromodulators, and related substances

(1) Dopamine (DA) metabolites: dihydroxyphenylacetic acid (DOPAC) and homovanillic acid (HVA), 3-orthomethylDOPA (3-OMD)

(2) Serotonin (5-hydroxytryptamine or 5-HT) metabolites or precursors: 5-hydroxytryptophan (5-HTP), 5-hydroxyindoleacetic acid (5-HIAA), kynurenine, 3-hydroxykynurenine

(3) Noradrenalin (norepinephrine or NE) metabolites or precursors: 3-methoxy-4-hydroxy-phenylethylenglycol (MHPG), dopamine-beta-hydroxylase (DBH)

(4) Acetylcholine (Ach) and related substances: choline, acetylcholine-esterase (AchE), butiryl-cholin-esterase (BchE)

(5) Neurotransmitter amino acids: gamma-amino butyric acid (GABA), glutamate, aspartate, glycine

(6) Neuropeptides: substantia P (SP), cholecystokinin-8 (CCK-8), met-enkephalin (MET-ENK), leu-enkephalin (LEU-ENK), dynorphin A(1-8), somatostatin, neuropeptide $Y$ (NPY), beta-endorphin, arginine-vasopressine (AVP), vasoactive intestinal peptide (VIP), delta sleep-inducing peptide (DSIP), alpha-melanocyte-stimulating hormone-like, diazepam-binding inhibitor, neurokinin $A$, corticotropin-releasing hormone $(\mathrm{CRH})$, adrenocorticotropin hormone $(\mathrm{ACTH})$, beta-lipotropine, angiotensin, chromogranins $A$ and $B$, secretogranin II, orexin-A/hypocretin-1

(7) Other neurotransmitters: endogenous cannabinoids, $\beta$-phenylethylamine

(8) Cyclic nucleotides: cyclic adenosine $3^{\prime} 5^{\prime}$ monophosphate (cAMP), cyclic guanosine $3^{\prime} 5^{\prime}$ monophosphate (cGMP)

(9) Biopterin derivatives and other cofactors

(B) Endogenous neurotoxins

(1) Tetrahydroisoquinolin (TIO) derivatives: 2-methyl-6,7-dihydroxy1,2,3,4-TIO (2-MDTIO), 1-MDTIQ (salsolinol). 1-benzyl-1,2,3,4-TIO

(2) $\beta$-carbolinium cations (BC+s)

(C) Oxidative stress markers

(1) Lipid peroxidation markers: Malonyl-dialdehyde (MDA) (E)-4-hydroxynonenal (HNE) Low density lipoprotein (LDL) oxidation products Schiff bases, conjugated dienes, oxidized proteins, and aldehyde polymers

(2) DNA oxidation markers: 8'-hydroxy-2'deoxyguanine (8-OHdG) 8-hydrosyguanosine (8-OHG) 8-OHdG/8-OHG ratio

(3) Transition metals and related proteins: iron, ferritin, transferring, copper, cerulopasmin, ferroxidase, manganese, zinc

(4) Other metals: selenium, chromium, magnesium, calcium, aluminum, silicon, cobalt, tin, lead, barium, bismuth, cadmium, mercury, molibdenum, nichel, antimony, strontium, thallium, vanadium, wolfram, and zirconium

(D) Inflamatory and immunological markers

(1) Inteleukins (IL)

(2) Tumor necrosis alpha (TNF- $\alpha$ )

(3) Other: leukotrienes. $\alpha$-1-antichymotrypsin

(E) Growth and neurotrophic factors

(1) Brain-derived neurotrophic factor (BDNF)

(2) Transforming Growth Factors: TGF- $\alpha$, TGF- $\beta 1$, TGF- $\beta 2$

(3) Insulin-like growth factor-1 (IGF-1) and IGF-binding proteins (IGFBPs)

(4) Neuroregulins (Epidermal Growth Factor or EGF family)

(F) Proteins involved in the pathogenesis of PD

(1) Microtubular-Associated Protein Tau (MAPT)

(2) Alpha-synuclein

(3) Amiloyd beta

(4) Neurofilament proteins

(5) Other proteins: DJ-1, UCH-L1

(G) Other compounds

and homovanillic acid (HVA), should be decreased. Indeed, many classical studies have shown variable degrees of decrease in the CSF HVA levels of PD patients compared with controls (Bernheimer et al., 1966; Guldberg et al., 1967; Johansson and Roos, 1967; Olsson and Roos, 1968; Gottfries et al., 1969; Curzon et al., 1970; van Woert and Bowers, 1970; Godwin-Austen et al., 1971; Mones et al., 1972; Papeschi et al., 1972; Pullar et al., 1972; Cox et al., 1973; Voto Bernales et al., 1973; Weiner and Klawans, 1973; Granerus et al., 1974; Davidson et al., 1977; Tabaddor et al.,
1978; Lovenberg et al., 1979; Cunha et al., 1983; Mann et al., 1983; Cramer et al., 1984; Mena et al., 1984; Pezzoli et al., 1984; Burns et al., 1985; Gibson et al., 1985; Jolkkonen et al., 1986; Liu, 1989; Hartikainen et al., 1992; Strittmatter and Cramer, 1992; Chia et al., 1993; Mashige et al., 1994; Eldrup et al., 1995; Cheng et al., 1996; Strittmatter et al., 1996; Kanemaru et al., 1998; Goldstein et al., 2008). Engelborghs et al. (2003) reported normal CSF DA and HVA, and decreased DOPAC levels. González-Quevedo et al. (1993) described normal CSF HVA levels, Espino et al. (1994) 
found decreased HVA only in advanced but not in early PD, Parkinson Study Group DATATOP Investigators found normal levels in early PD (LeWitt et al., 2011). Zubenko et al. (1986) described a non-significant trend toward decreased CSF HVA levels in demented PD patients compared with controls. Tohgi et al. (1993a) found correlation of CSF DA and HVA levels with akinesia and freezing of gait.

Although levodopa treatment usually increases CSF HVA levels according to the majority of studies, this is not related with clinical improvement, with some exceptions (Durso et al., 1989), and pre-treatment CSF HVA levels does not predict levodopa response (Weiner et al., 1969; Chase, 1970; Curzon et al., 1970; Bertler et al., 1971; Casati et al., 1973; Cox et al., 1973; Mones, 1973; Weiner and Klawans, 1973; Granerus et al., 1974; Davidson et al., 1977; Liu, 1989; Nishi et al., 1989; Strittmatter et al., 1996; Antkiewicz-Michaluk et al., 1997; Durso et al., 1997; Krygowska-Wajs et al., 1997), except in one study which described an association between relatively high pre-treatment CSF HVA levels and a better response to levodopa (Gumpert et al., 1973). One study failed to show changes in ventricular CSF HVA levels after a single acute administration of levodopa (Moussa et al., 1992). On the other hand, dopamine agonists such as piribedil and bromocriptine decreased significantly both the basal level (McLellan et al., 1975; Rinne et al., 1977) and probenecid-induced accumulations of HVA in CSF (Rinne et al., 1975, 1977), indicating that the drugs reduced the turnover of endogenous dopamine. Amantadine did not change HVA levels (Cox et al., 1973). Tetrahydrobiopterin (Dissing et al., 1989) and L-threo-3,4-dihydroxyphenylserine (precursor or noraderenalin or norepinephrine-NE) (Maruyama et al., 1994) increased CSF HVA levels in PD patients, but to a lesser extent than levodopa.

Friedman et al. (Friedman, 1985) reported an HVA/5-HIAA ratio in PD patients who developed levodopa-induced dyskinesias (LID) which was significantly higher than in PD patients under levodopa therapy and in controls, but Lunardi et al. (2009) found similar HVA/DA ratios in patients with and without LID. CSF DA, levodopa, and HVA levels were similar in PD patients treated with levodopa with wearing-off motor fluctuations to those without this complication of levodopa therapy, while CSF 3-ortho-methyldopa (3-OMD) levels were higher in the fluctuating patients (Tohgi et al., 1991a). CSF DOPAC and HVA were similar in PD patients with and without depression (Kuhn et al., 1996a), and in patients with major depression with PD than in those without PD (Pålhagen et al., 2010). CSF HVA levels were correlated with striatal uptake in PD patients measured with PET imaging with carbon-11labeled $2 \beta$-carbomethoxy-3 $\beta$-(4-fluorophenyl)-tropane ( $\left.{ }^{11} \mathrm{C}-\mathrm{FT}\right)$ (Ishibashi et al., 2010).

Tohgi et al. (1991b, 1997) found a significant increase in tyrosine, and a significant decrease in CSF levodopa, DA, and 3OMD in PD patients, which was related with levodopa dosage, and described an additional decrease in 3-OMD in subjects treated with tolcapone (Tohgi et al., 1995a). Other authors reported increased CSF 3-OMD related with levodopa therapy (Antkiewicz-Michaluk et al., 1997; Krygowska-Wajs et al., 1997). On the other hand, Chia et al. (1993) found normal CSF 3OMD concentrations. Moser et al. (1996) described increased
CSF levodopa/3-OMD ratio in PD patients with hallucinations. Iacono et al. (1997) found similar HVA levels in PD patients with postural instability and gait disorders to $\mathrm{PD}$ patients without these symptoms.

Although many of the studies of DA metabolites were performed on patients with different types of parkinsonism, with different degrees of severity, and the fact that many of these studies were made using small sample sizes, there is a general consensus that CSF HVA levels are decreased in untreated PD patients and rise after levodopa therapy starts (decreased HVA may not be present in early stages of PD). It is to be expected that low CSF HVA levels should be a reflection of DA depletion in the nigroestriatal system. However, CSF DA metabolite levels are not useful to distinguish between different parkinsonian syndromes and could be normal in early stages of the disease. To our knowledge, no studies have been published regarding the correlation of CSF DA metabolite levels and brain DA levels, although the observation of a correlation between CSF HVA levels and striatal uptake of DA markers in PET imaging (Ishibashi et al., 2010), suggests this correlation.

\section{SEROTONIN (5-HYDROXYTRYPTAMINE OR 5-HT) METABOLITES}

Several studies have described neuronal loss, and presence of Lewy body in serotonergic raphe nuclei in PD patients (BenitoLeón et al., 2008). Tohgi et al. (1993b,c, 1997) reported a 15-20\% reduction of CSF 5-HT, tryptophan (precursor of 5-HT), kynurenine and 3-hydroxykynurenine (metabolites of tryptophan) levels in PD patients. CSF 5-HT levels showed a negative correlation with the severity of bradykinesia, rigidity and freezing of the gait, and decreased after levodopa therapy. This group also found a correlation between CSF 5-HIAA levels and akinesia and freezing of gait (Tohgi et al., 1993a). In contrast, Engelborghs et al. (2003) described increased 5-HT levels. LeWitt et al. (2013) described increased CSF 3-hydroxykynurenine levels, and Widner et al. (2002) described an increased CSF kynurenine/tryptophan ratio in $\mathrm{PD}$ patients.

Several studies have shown reduced CSF levels of 5hydroxyindoleacetic acid (5-HIAA), the main metabolite of 5-HT, in PD patients (Guldberg et al., 1967; Johansson and Roos, 1967, 1971; Olsson and Roos, 1968; Gottfries et al., 1969; Chase, 1970; Rinne and Sonninen, 1972; Rinne et al., 1973; Davidson et al., 1977; Mayeux et al., 1984, 1986, 1988; Kostić et al., 1987; Tohgi et al., 1993c, 1997; Mashige et al., 1994; Strittmatter et al., 1996; Engelborghs et al., 2003). Other authors report normal CSF 5HIAA levels (Papeschi et al., 1970, 1972; Godwin-Austen et al., 1971; Granerus et al., 1974; Davidson et al., 1977; Tabaddor et al., 1978; Cramer et al., 1984; Burns et al., 1985; Chia et al., 1993; González-Quevedo et al., 1993; Volicer et al., 1985; Fukuda et al., 1989). Liu et al. (1999) described lower ventricular CSF 5-HIAA levels in patients with rigid-akinetic $\mathrm{PD}$ than in patients with tremoric PD, and a negative correlation between CSF 5-HIAA levels and PD severity.

CSF 5-HIAA levels seem to be unchanged by therapy with levodopa (Godwin-Austen et al., 1971; Davidson et al., 1977), bromocriptine (Gumpert et al., 1973), or piribedil (Gumpert et al., 1973), or were found decreased by levodopa therapy (Casati et al., 1973). Gumpert et al. (1973) described an 
association between relatively low pre-treatment CSF 5-HIAA levels with a good response to levodopa, while Davidson et al. (1977) reported this association with higher CSF 5-HIAA levels, and others found no such relation (Granerus et al., 1974). Tetrahydrobiopterin increased (Dissing et al., 1989), and L-threo3,4-dihydroxyphenylserine decreased (Maruyama et al., 1994) CSF 5-HIAA levels.

Some authors have described decreased CSF 5-HIAA (Mayeux et al., 1984, 1986, 1988; Mena et al., 1984; Kostić et al., 1987) and 5-HT levels (Mena et al., 1984) in PD patients with depression, while others have described normal CSF 5-HIAA in depressed PD patients (Granerus et al., 1974; Kuhn et al., 1996a), and others still have reported similar CSF 5-HIAA levels in patients with major depression with PD tothose without PD (Pålhagen et al., 2010). Moser et al. (1996) described increased CSF 5-HIAA in PD patients with hallucinations. Iacono et al. (1997) found higher CSF 5-HT and 5-HIAA and lower 5-HTP levels in PD patients with postural instability and gait disorders than in PD patients without these symptoms.

Studies on the correlation of CSF 5-HT metabolite levels and brain 5-HT levels are lacking. The majority of studies report results on CSF 5-HIAA levels, with the controversial results based on short series of cohorts of patients with PD or other parkinsonian syndromes. Current data do not lend support to the role of CSF 5-HIAA as an unequivocal marker of depression linked to PD.

\section{NORADRENALIN (NOREPINEPHRINE OR NE) METABOLITES}

Neurons containing NE in the brain, mainly in the dorsal nuclei of vagus nerve, are involved in the degenerative process of $\mathrm{PD}$ (Benito-León et al., 2008). CSF NE levels have been found normal (Turkka et al., 1987; Chia et al., 1993; Kuhn et al., 1996a; Engelborghs et al., 2003) or decreased (Martignoni et al., 1992; Eldrup et al., 1995) in PD patients. CSF levels of 3-methoxy-4hydroxy-phenylethyleneglycol (MHPG), the main metabolite of NE, have been reported to be normal (Wilk and Mones, 1971; Davidson et al., 1977; Mann et al., 1983; Mena et al., 1984; Hartikainen et al., 1992; Martignoni et al., 1992; Chia et al., 1993; González-Quevedo et al., 1993; Mashige et al., 1994; Kuhn et al., 1996a; Engelborghs et al., 2003) or decreased (Granerus et al., 1974) in PD patients. CSF MHPG levels do not increase either after treatment with levodopa (Wilk and Mones, 1971; Davidson et al., 1977) or with the NE precursor L-Threo-3,4dihydroxyphenylserine (L-threo-DOPS) (Yamamoto et al., 1986; Teelken et al., 1989), while L-threo-DOPS increases CSF NE levels (Tohgi et al., 1990, 1993d).

Several authors have described a negative correlation between CSF MHPG levels and cognitive functioning (Mann et al., 1983) and bradyphrenia (Mayeux et al., 1987) in PD patients, and others have described a relationship between CSF NE levels with severity of PD assessed by Hoehn \& Yahr staging, akinesia scores, and freezing of the gait (Tohgi et al., 1993a). Pålhagen et al. reported decreased CSF MHPG levels in patients with major depression with PD compared to those without PD (Pålhagen et al., 2010).

CSF activity of dopamine- $\beta$-hydroxylase (DBH), an enzyme involved in NE synthesis, has been found decreased in PD patients when compared with controls (Matsui et al., 1981; Hurst et al., 1985).

The normality of CSF MHPG levels found in nearly all studies with PD or other parkinsonian syndromes indicates that this is not a useful marker of PD. The correlation between CSF MHPG and brain NE is unknown.

\section{ACETYLCHOLINE (Ach) AND RELATED SUBSTANCES}

CSF levels of Ach (Duvoisin and Dettbarn, 1967; Welch et al., 1976; Yamada et al., 1996) and its precursor choline (Aquilonius et al., 1972; Welch et al., 1976; Nasr et al., 1993) have been reported to be similar in PD patients to controls with the exception of one study in which lower CSF choline levels were described in PD patients (Manyam et al., 1990).

CSF activity of acetylcholine-esterase (AchE), the main enzyme involved in Ach degradation, has been reported to be similar in PD patients and controls (Jolkkonen et al., 1986; Ruberg et al., 1986; Zubenko et al., 1986; Sirviö et al., 1987; Yoshinaga et al., 1989; Manyam et al., 1990; Hartikainen et al., 1992), although there are studies which have described increased (Ruberg et al., 1986), decreased (Konings et al., 1995), or normal activity (Zubenko et al., 1986; Sirviö et al., 1987) in demented patients, and decreased activity only in those patients with the most severe disease (Hartikainen et al., 1992).

CSF activity of butirylcholine-esterase (BchE) have been found to be similar in PD patients and controls (Ruberg et al., 1986; Sirviö et al., 1987), but increased in demented PD patients in a single study (Ruberg et al., 1986). Data on CSF Ach and related substances are scarce and based on short series of patients, and do not permit valid conclusions.

\section{GAMMA-AMINO BUTYRIC ACID (GABA) AND OTHER NEUROTRANSMITTER AMINO ACIDS}

CSF GABA levels in PD patients have been found to be decreased, when compared with controls, by many authors (Lakke and Teelken, 1976; Manyam et al., 1980, 1988; Kuroda et al., 1982; Manyam, 1982; Teychenné et al., 1982; Kuroda, 1983; de Jong et al., 1984; Araki et al., 1986; Tohgi et al., 1991c), while others have found this value to be normal (Enna et al., 1977; Abbott et al., 1982; Bonnet et al., 1987; Perschak et al., 1987; Mally et al., 1997; Engelborghs et al., 2003) or even increased (Jiménez-Jiménez et al., 1996). Manyam and Tremblay (1984) found reduced CSF free GABA levels and normality of conjugated levels. Abbot et al. (Perschak et al., 1987) found decreased CSF GABA levels in PD patients treated with levodopa, but not in "de novo" $\mathrm{PD}$ patients, while other authors found decreased CSF GABA in untreated PD patients (Manyam, 1982; de Jong et al., 1984), with CSF GABA normal (de Jong et al., 1984; Tohgi et al., 1991c) or slightly decreased (Manyam, 1982) in PD patients under levodopa therapy, suggesting that levodopa increases CSF levels. Teychenné et al. (1982) described low CSF GABA especially in $\mathrm{PD}$ patients with poor response to therapy or suffering from "on-off" motor fluctuations.

Normality of CSF glutamate levels has been reported by most investigators (Van Sande et al., 1971; Gjessing et al., 1974; Lakke and Teelken, 1976; Lakke et al., 1987; Perschak et al., 1987; Espino et al., 1994; Jiménez-Jiménez et al., 1996; Kuiper et al., 
2000), although 3 groups described decreased CSF glutamate levels (Gründig and Gerstenbrand, 1980; Tohgi et al., 1991c; Mally et al., 1997), while CSF glutamine (the main precursor of glutamate) has been found to be normal (Gjessing et al., 1974; Lakke and Teelken, 1976; Manyam et al., 1988; Jiménez-Jiménez et al., 1996) or increased (Mally et al., 1997).

CSF aspartate levels have been reported as normal (Lakke and Teelken, 1976; Manyam, 1982; Araki et al., 1986; Perschak et al., 1987; Mally et al., 1997; Jiménez-Jiménez et al., 1996; Engelborghs et al., 2003), except in the study by Tohgi et al. (1991c) who reported decreased CSF aspartate; CSF asparagine (the main metabolite of aspartate) has been found normal (Lakke and Teelken, 1976; Manyam, 1982; Araki et al., 1986; Perschak et al., 1987; Jiménez-Jiménez et al., 1996; Mally et al., 1997; Engelborghs et al., 2003).

The results on CSF glycine levels have been reported as normal by most investigators (Gjessing et al., 1974; Perschak et al., 1987; Manyam et al., 1988; Jiménez-Jiménez et al., 1996; Mally et al., 1997; Engelborghs et al., 2003), although two groups found them increased (Lakke and Teelken, 1976; Araki et al., 1986; Lakke et al., 1987), and another decreased (Tohgi et al., 1991c). In agreement with Tohgi et al. (1991c), our group reported lower glycine levels in untreated PD patients when compared with PD patients under levodopa therapy or with controls (Jiménez-Jiménez et al., 1996).

Data regarding other (non-neurotransmitter) amino acids are even more controversial. CSF levels of neutral and basic amino acids have been reported to be both increased (Van Sande et al., 1971; Lakke and Teelken, 1976; Lakke et al., 1987), and decreased (Molina et al., 1997a). Two groups reported decreased (Molina et al., 1997a; Engelborghs et al., 2003) and another increased CSF levels of taurine (Lakke and Teelken, 1976; Araki et al., 1986; Lakke et al., 1987). Ornithine, citruline, and arginine (implicated in the urea cycle, and the two latter in the synthesis of nitric oxide) have been found to be increased (Van Sande et al., 1971; Lakke and Teelken, 1976; Lakke et al., 1987), normal (Kuiper et al., 2000), or decreased (Molina et al., 1997a). Another group described increased CSF levels of total homocysteine but normal ones of free homocysteine in PD patients (Isobe et al., 2005), with an additional increase after treatment with levodopa, while total methionine levels decreased after this therapy (Isobe et al., 2010a).

In general, the results on CSF amino acid levels in PD patients are inconclusive, because they might be influenced by selection of study subjects, sample size, lack of adequate matching between cases and controls in many studies, differences in antiparkinsonian therapy, and differences in study techniques, storage and handling of the samples (Jiménez-Jiménez et al., 1996; Molina et al., 1997a).

\section{NEUROPEPTIDES}

Neuropeptides modulate neuronal communication by acting on cell surface receptors. Many of them are co-released with classical neurotransmitters. There have been reports of a number of changes in the concentrations of several neuropeptides in PD brain, which are mainly significant decreases in (JiménezJiménez, 1994): (a) met-enkephalin (MET-ENK), substantia $\mathrm{P}$ (SP), and cholecystokinine 8 (CCK-8) in the substantia nigra; (b) MET-ENK and leu-enkephalin (LEU-ENK) in the putamen and globus pallidus; (c) MET-ENK in the ventral tegmental area; (d) SP, somatostatin and neurotensin in the neocortex, and (e) somatostatin and neurotensin in the hippocampus. It is likely that many of these changes are related with dopaminergic deficit, and the only clear relationship between a neuropeptide and a clinical feature of PD is that of somatostatin with the presence of cognitive impairment (Jiménez-Jiménez, 1994). Table 2 summarizes the findings of classical studies on CSF neuropeptide levels in PD patients. Most of these studies enrolled limited series of patients.

In recent years, there has been increased interest in the possible role of orexin-A/hypocretin-1, a neuropeptide hormone implicated in the pathogenesis of narcolepsia, on the development of excessive daytime sleepiness in PD patients. Since the first report by Drouot et al. (2003), who described decreased ventricular CSF orexin levels in PD patients, which were related with the severity of the disease, other authors have confirmed decreased CSF orexin in PD (Fronczek et al., 2007; Asai et al., 2009) and in other neurodegenerative parkinsonisms (Yasui et al., 2006), and the relation of CSF orexin with severity of PD (Asai et al., 2009), and with the presence of sleep attacks (Asai et al., 2009). In contrast, Compta et al. (2009a) found no significant differences in CSF orexin levels between demented PD patients, non-demented PD patients, and healthy controls, and found no relation between CSF orexine and Epworth sleepiness scale or Mini-Mental State Examination. Drouot et al. (2011) found a lack of association between low ventricular CSF orexin and sleepiness in PD, and a relation between high levels of orexin-A in PD associated with loss of REM muscle atonia (Bridoux et al., 2013), while Wienecke et al. (2012) reported association between low CSF orexin levels and sleepiness in PD. Finally, Pålhagen et al. (2010) described similar CSF orexin levels in patients with major depression with or without concomitant PD. The results regarding orexin $\mathrm{A}$ are controversial, and await confirmation.

\section{OTHER NEUROTRANSMITTERS}

Pisani et al. $(2005,2010)$ found increased CSF levels of the endogenous cannabinoid anandamide in untreated PD patients, which were unrelated to the severity of the disease (Pisani et al., 2005) and reversed by chronic dopaminergic replacement (Pisani et al., 2010). Zhou et al. (1997) found decreased CSF $\beta$-phenylethylamine (PEA) levels in PD patients which were correlated negatively with Hoehn \& Yahr stage.

\section{CYCLIC NUCLEOTIDES}

These compounds act as intracellular second messengers of neurotransmitters or other compounds such as nitric oxide (NO). The most important are cyclic adenosine $3^{\prime} 5^{\prime}$ monophosphate (cAMP) and cyclic guanosine $3^{\prime} 5^{\prime}$ monophosphate (cGMP). Belmaker et al. (1978) reported a 40-50\% decrease of CSF cAMP and an $80-90 \%$ decrease of CSF cGMP levels in PD patients who were not related with levodopa therapy. Decreased CSF cAMP levels in PD have also been reported in another study (Volicer et al., 1986), while others found this value to be normal (Cramer et al., 1973, 1984; Covicković-Sternić et al., 1987; Oeckl et al., 2012), both in PD patients with and without dementia (Oeckl et al., 2012). Four further studies described normal CSF cGMP levels (Volicer et al., 1986; Covicković-Sternić et al., 1987; Ikeda et al., 
Table 2 | Alterations in CSF neuropeptide levels in PD patients compared with controls.

\begin{tabular}{|c|c|c|c|}
\hline Neuropeptide & References & $\begin{array}{l}\text { PD patients/ } \\
\text { Controls }\end{array}$ & Cerebrospinal fluid levels \\
\hline \multirow[t]{2}{*}{ Substantia P (SP) } & Pezzoli et al., 1984 & $12 / 10$ & Increased 5-fold \\
\hline & Cramer et al., 1991 & $23 / 9$ & Decreased by $30 \%$ (controls were essential tremor patients) \\
\hline $\begin{array}{l}\text { Cholecystokinin-8 } \\
\text { (CCK-8) }\end{array}$ & Lotstra et al., 1985 & $20 / 68$ & Decreased by $50 \%$ \\
\hline \multirow[t]{3}{*}{$\begin{array}{l}\text { Met-enkephalin } \\
\text { (MET-ENK) }\end{array}$} & Pezzoli et al., 1984 & $12 / 10$ & $\begin{array}{l}\text { Increased 3-fold in PD patients with slight or moderate disability } \\
(n=6)\end{array}$ \\
\hline & Yaksh et al., 1990 & $8 / 9$ & Decreased by $37 \%$ \\
\hline & Baronti et al., 1991 & $16 / 19$ & Decreased by $31.7 \%$ \\
\hline $\begin{array}{l}\text { Leu-enkephalin } \\
\text { (LEU-ENK) }\end{array}$ & Liu, 1989 & $22 / 19$ & $\begin{array}{l}\text { Increased by } 122 \% \text { in untreated PD patients without further } \\
\text { modification by levodopa therapy }\end{array}$ \\
\hline \multirow[t]{8}{*}{ Somatostatin } & Jolkkonen et al., 1986 & $35 / 19$ & Decreased by $22 \%$ ( $p<0.01)$, especially in demented patients \\
\hline & $\begin{array}{l}\text { Strittmatter and Cramer, } \\
1992\end{array}$ & $38 / 12$ & Decreased by $27.5 \%(p<0.01)$ \\
\hline & Strittmatter et al., 1996 & $35 / 11$ & $\begin{array}{l}\text { Decreased } p<0.05 \text {, similar in untreated vs. treatment with } \\
\text { levodopa }\end{array}$ \\
\hline & Cramer et al., 1989 & $15 / 9$ & Decreased by $39 \%$ \\
\hline & Dupont et al., 1982 & $39 / 29$ & Decreased by $40 \%$ \\
\hline & Christensen et al., 1984 & $48 / 32$ & Decreased by $40 \%$ \\
\hline & Cramer et al., 1985 & $50 / 6$ & Decreased by $34 \%$ (controls were patients with essential tremor) \\
\hline & Masson et al., 1990 & $35 / 11$ & $\begin{array}{l}\text { Decreased }(p<0.02) \text {, especially in untreated patients and in those } \\
\text { with more severe disease }\end{array}$ \\
\hline \multirow[t]{2}{*}{ Neuropeptide Y (NPY) } & Martignoni et al., 1992 & $10 / 20$ & Decreased by $31 \%$ \\
\hline & Yaksh et al., 1990 & $8 / 9$ & Normal \\
\hline \multirow[t]{2}{*}{ Beta-endorphin } & Nappi et al., 1985 & $24 / 15$ & $\begin{array}{l}\text { Decreased }(p<0.005) \text { both in } 14 \text { untreated and } 10 \text { treated PD } \\
\text { patients }\end{array}$ \\
\hline & Jolkkonen et al., 1987 & $36 / 35$ & Normal \\
\hline \multirow{2}{*}{$\begin{array}{l}\text { Arginine-vasopressine } \\
\text { (AVP) }\end{array}$} & Sundquist et al., 1983 & $11 / 21$ & Decreased by $68 \%$ \\
\hline & Olsson et al., 1987 & $12 / 32$ OND & Decreased by $71 \%$ \\
\hline $\begin{array}{l}\text { Vasoactive intestinal } \\
\text { peptide (VIP) }\end{array}$ & Sharpless et al., 1984 & $19 / 12$ & Normal \\
\hline $\begin{array}{l}\text { Delta sleep-inducing } \\
\text { peptide (DSIP) }\end{array}$ & Ernst et al., 1987 & $9 / 20$ & Decreased by $28.7 \%$ (Ferrero et al., 1988) \\
\hline $\begin{array}{l}\text { Alpha-melanocyte- } \\
\text { stimulating } \\
\text { hormone-like }\end{array}$ & Rainero et al., 1988 & $9 / 12$ & Increased by 2-fold \\
\hline
\end{tabular}


Table 2 | Continued

\begin{tabular}{|c|c|c|c|}
\hline Neuropeptide & References & $\begin{array}{l}\text { PD patients/ } \\
\text { Controls }\end{array}$ & Cerebrospinal fluid levels \\
\hline \multirow[t]{2}{*}{$\begin{array}{l}\text { Diazepam-binding } \\
\text { inhibitor }\end{array}$} & Ferrero et al., 1988 & $25 / 82$ & $\begin{array}{l}\text { Increased by } 42.5 \% \text { ( } 80 \% \text { in depressed PD patients and normal in } \\
\text { non-depressed PD patients }\end{array}$ \\
\hline & Ferrarese et al., 1990 & 28/10 & Decreased by $50 \%$ in PDD $(n=14)$, normal in PDND $(n=14)$ \\
\hline Neurokinin A & Galard et al., 1992 & $12 / 11$ & Decreased by $24 \%$ \\
\hline ACTH & Nappi et al., 1985 & $24 / 15$ & Normal \\
\hline Beta-lipotropine & Nappi et al., 1985 & $24 / 15$ & Normal \\
\hline $\begin{array}{l}\text { Chromogranin } A \text { and } B \\
\text { and secretogranin II }\end{array}$ & Eder et al., 1998 & $8 / 29$ & Normal \\
\hline
\end{tabular}

OND, other neurological diseases; PDD, Parkinson's disease demented; PDND, Parkinson's disease non-demented.

1995; Oeckl et al., 2012), while another found a non-significant trend toward higher CSF cGMP levels in PD patients when compared with controls and higher levels in levodopa-treated PD patients compared with those without levodopa treatment (Navarro et al., 1998).

\section{BIOPTERIN DERIVATIVES AND OTHER COFACTORS}

Biopterins act as cofactors for aromatic amino acid hydroxylases, which produce a number of neurotransmitters including DA, NE, epinepherine, and 5-HT and are also required for the production of NO. CSF levels of neopterin and biopterin have been found decreased in PD patients by several groups, especially in those with early-onset PD (Fujishiro et al., 1990; Furukawa et al., 1992), and in carriers of the PARK8 mutation (Koshiba et al., 2011), which was negatively correlated with duration of illness in those patients with akinetic-rigid PD (Furukawa et al., 1991). In contrast, another group found increased CSF neopterin in PD (Widner et al., 2002).

CSF concentration of hydroxylase cofactor, predominantly composed of tetrahydrobiopterin $\left(\mathrm{BH}_{4}\right)$, has also been found decreased (Williams et al., 1980a,b).

Thiamine is an essential cofactor for several important enzymes involved in brain oxidative metabolism. Our group found normal CSF levels of thiamine-diphosphate, thiaminemonophosphate, free thiamine, and total thiamine in PD patients (Jiménez-Jiménez et al., 1999).

\section{ENDOGENOUS NEUROTOXINS}

One of the classical etiological hypotheses of PD is related with the presence of endogenous substances which share structural similarities with 1-methyl-4-phenyl-1,2,3,6-tetrahydropyridine (MPTP), a neurotoxin that induces a parkinsonism resembling PD.
Moser et al. (Moser and Kömpf, 1992; Moser et al., 1995) identified two tetrahydroisoquinolin (TIQ) derivatives in the CSF of PD patients, but not in healthy controls, 2-methyl and 1methyl-6,7-dihydroxy1,2,3,4-TIQ (2-MDTIQ and 1-MDTIQ or salsolinol). This group described a relation between high salsolinol levels and the presence of visual hallucinations (Moser et al., 1996), and reported an increased HVA/3OMD ratio in PD patients in which 2-MDTIQ was detected when compared with those PD in which it was not detectable.

CSF salsolinol levels have been reported to be increased in PD patients compared with controls by other groups (Maruyama et al., 1996; Antkiewicz-Michaluk et al., 1997; Krygowska-Wajs et al., 1997; Naoi and Maruyama, 1999), especially in demented PD patients (Antkiewicz-Michaluk et al., 1997), and in those patients with more severe parkinsonism (Krygowska-Wajs et al., 1997), although other authors have described a trend toward decrease in CSF salsolinol levels with the progression of the disease (Maruyama et al., 1999). In contrast, another group reported similar CSF salsolinol (Müller et al., 1999a,b), but higher levels of harman and norharman $\beta$-carbolines (structural analogs of MPTP as well) in PD patients than in controls (Kuhn et al., 1996b). CSF levels of 1-benzyl-1,2,3,4-TIQ have also been found by another group to be increased (Kotake et al., 1995).

Matsubara et al. (1995) measured $\beta$-carbolinium cations $(\mathrm{BC}+\mathrm{s})$ in the lumbar CSF of $22 \mathrm{PD}$ patients and 11 age-matched controls, and found the 2,9-dimethylnorharmanium cation $(2,9-\mathrm{Me} 2 \mathrm{NH}+)$ in $12 \mathrm{PD}$ patients but not in controls. This group described decreased activity of nicotinamide $\mathrm{N}$-methyltranserase (NNMT), an enzyme that catalyzes the N-methylation of nicotinamide and other pyridines in the CSF of younger PD patients compared with younger controls, and a trend toward decrease with aging in PD patients (Aoyama et al., 2001). 
The results of studies on neurotoxins related with the risk for $\mathrm{PD}$ are based on small series and are not conclusive.

\section{OXIDATIVE STRESS MARKERS}

Because there is much evidence on the contribution of oxidative stress in the pathogenesis of PD (Figure 1) (Alonso-Navarro et al., 2008), the measurement of oxidative stress markers and substances related with oxidative and defense against oxidative phenomena in the CSF of PD patients is useful. Data regarding lipid peroxidation markers are controversial, while DNA oxidation markers have been found to be increased (Table 3).

Transition metals such as iron, copper, and manganese, act as prooxidant agents, although copper is also essential for the

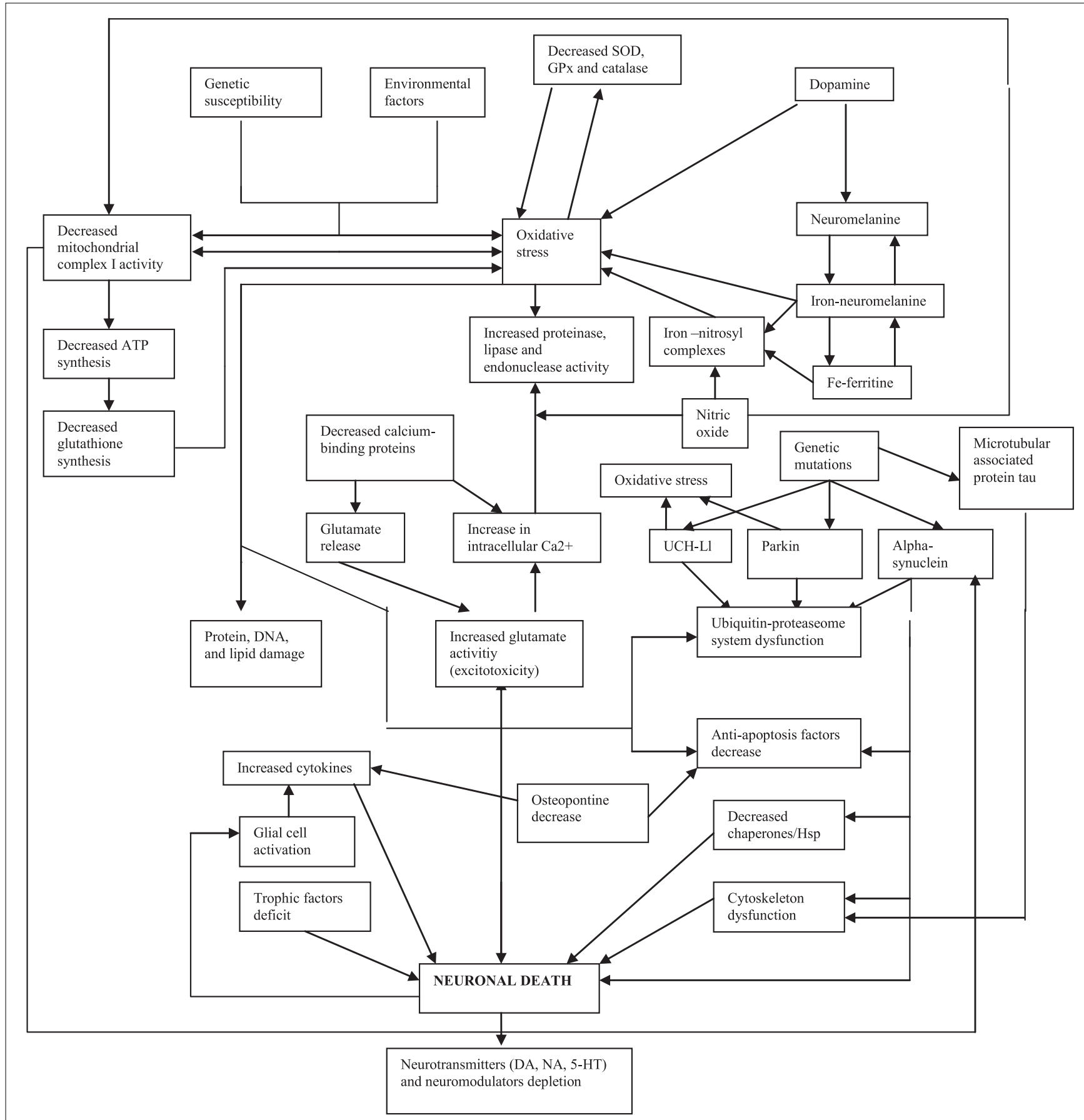

FIGURE 1 | Pathogenical mechanisms proposed for Parkinson's disease (modified from Alonso-Navarro et al., 2008). 
antioxidant function of the protein ceruloplasmin, and copper and manganese are constituents of the cytosolic $\mathrm{Cu}^{+2} / \mathrm{Zn}^{+2}$ and the mitochondrial $\mathrm{Mn}^{+2}$-superoxide-dismutases (SOD, protective against oxidative processes). Zinc has antioxidant activity and is a constituent of $\mathrm{Cu}^{+2} / \mathrm{Zn}^{+2}$-SOD (Jiménez-Jiménez et al., 1998). The results of studies with CSF levels of iron and copper are controversial (Table 3), but a recent meta-analysis showed similar values in PD patients to controls (Mariani et al., 2013), thus suggesting that these metals are not useful as markers of PD.

Together with its role in glutamate excitotoxity, NO could contribute to oxidative stress mechanisms in the pathogenesis of $\mathrm{PD}$ by interacting with ferritin to release iron, inducing mitochondrial complex I damage (Molina et al., 1998), and by inducing nitrosylation of proteins (Fernández et al., 2013). However, studies on CSF levels of nitrates and nitrites have given controversial results (Table 3 ).

Among other antioxidant enzymes and substances (Table 3), one study involving an important number of early PD patients showed the relationship between the presence of relatively higher levels of urate and the slower rates of clinical decline (Ascherio et al., 2009), despite the fact that CSF urate levels were found to be similar in PD patients and controls in the same study.

\section{INFLAMMATORY AND IMMUNOLOGICAL MARKERS}

CSF interleukin (IL) $1-\beta$ levels were found to be normal in one study (Pirttila et al., 1994) and increased in three (BlumDegen et al., 1995; Mogi et al., 1996a; Mogi and Nagatsu, 1999), CSF IL-2 normal (Blum-Degen et al., 1995) or increased (Mogi et al., 1996a; Mogi and Nagatsu, 1999), IL-4 increased (Mogi and Nagatsu, 1999), and CSF IL-10, IL-12, and interferon-gamma levels have been reported to be similar in PD patients and controls (Rota et al., 2006). CSF IL-6 levels have been found to be decreased in PD patients with major depression in comparison with patients with major depression without PD in one study (Palhagen et al., 2010), while another 4 found higher CSF IL-6 in PD patients than in healthy controls (Blum-Degen et al., 1995; Mogi et al., 1996a; Müller et al., 1998; Mogi and Nagatsu, 1999), and in one of them CSF IL-6 was correlated with PD severity (Müller et al., 1998). CSF tumor necrosis $\alpha$ (TNF- $\alpha$ ) levels have been found to be increased (Mogi et al., 1994; Mogi and Nagatsu, 1999), leukotriene 4 (Irkeç et al., 1989), and $\alpha$-1-antichymotrypsin normal (Pirttila et al., 1994), and $\beta$ 2-microglobuline decreased in PD (Mogi et al., 1989; Mogi and Nagatsu, 1999). The CSF levels of the cytokine fractalkine have been found to be normal in PD patients and increased in multiple system atrophy (MSA), and Flt3 ligand normal in these two diseases (Shi et al., 2011). The presence of certain syalilated isoforms of Serpin A1 in the CSF has been related with the development of dementia in PD patients (Jesse et al., 2012).

CSF levels of pros-methylimidazol acetic acid, an isomer of the histamine metabolite tele-methylimidazol acetic acid, have been found to be decreased in PD (Prell et al., 1991), and were highly positively correlated with the severity of the disease (Prell and Green, 1991).

CSF complement $3\left(\mathrm{C}_{3}\right)$ and factor $\mathrm{H}(\mathrm{FH})$ levels were reported to be normal in one study (Wang et al., 2011), while another described a decrease in several isoforms of $\mathrm{C}_{3 \mathrm{~b}}, \mathrm{C}_{4 \mathrm{~b}}, \mathrm{FH}$, and factor B (Finehout et al., 2005), and another normal $\mathrm{C}_{4 \mathrm{~d}}$
(Yamada et al., 1994). CSF levels of heat shock proteins Hsp65 and Hsp70 have been found to be increased (Fiszer et al., 1996), and PD patients have shown higher HLA-DR expression in CSF monocytes in comparison with controls (Fiszer et al., 1994a).

Oligoclonal IgG bands have not been detected in the CSF of PD patients (Chu et al., 1983), but antibodies against DA neurons have been detected in $78 \%$ of PD patients and in only $3 \%$ of controls (Carvey et al., 1991), and the CSF of PD patients has shown a higher proportion of gamma-delta- $\mathrm{T}+$ cells than in controls (Fiszer et al., 1994b).

The results of studies on inflammatory and immunological markers in PD have a low number of patients and controls enrolled, and are inconclusive.

\section{GROWTH AND NEUROTROPHIC FACTORS}

CSF Brain Derived Neurotrophic Factor (BDNF) levels have been found to be similar in PD patients with major depression to those in patients with major depression without PD in one study (Pålhagen et al., 2010), while another described this value as increased in PD patients compared with controls (Salehi and Mashayekhi, 2009). CSF Transforming Growth Factor $\alpha$ (TGF- $\alpha$ ) has been found to be increased in juvenile parkinsonism (Mogi and Nagatsu, 1999). TGF- $\beta 1$ has been found to be increased (Mogi et al., 1995, 1996a; Vawter et al., 1996; Mogi and Nagatsu, 1999) or normal (Rota et al., 2006), and TGF- $\beta 2$ increased (Vawter et al., 1996). CSF insulin-like growth factor-1 (IGF-1) and IGF binding proteins (IGFBPs) expression is increased in PD patients (Mashayekhi et al., 2010). Finally, a single study found a non-significant trend toward increased CSF levels of neuroregulins (which belong to the Epidermal Growth Factor or EGF family) in PD patients (Pankonin et al., 2009). The results of studies on growth and neurotrophic factors in PD, involving a low number of patients and controls, do not permit definitive conclusions.

\section{PROTEINS INVOLVED IN THE PATHOGENESIS OF PARKINSON'S DISEASE \\ MICROTUBULAR ASSOCIATED PROTEIN Tau (MAPT)}

Because MAPT gene is one of the main genes involved in the risk for PD (Alonso-Navarro et al., 2014), the measurement of CSF protein tau levels are hypothetically useful as a marker of this disease. Tau protein is important for maintaining the stability of axonal microtubules involved in the mediation of fast axonal transport of synaptic constituents. Hyperphosphorylation of tau causes reduces binding affinity for microtubules, leading to their malfunction. Following neuronal damage, tau is released into extracellular space and may be increased in the CSF. Tau is an important component of the neurofibrillary tangles (pairwise, helical protein filaments which are found in the cytoskeleton or neuronal cells in Alzheimer's disease (AD) brains. CSF tau protein levels are increased in $\mathrm{AD}$ patients, and so are a useful marker for this disease. The high risk of PD patients of developing cognitive impairment or dementia patients makes measurement of CSF tau reasonable as a possible marker of this disease.

Many studies have shown similar CSF total tau and phosphorylated tau (phosphotau) in PD patients to controls (Blennow et al., 1995; Molina et al., 1997c; Jansen Steur et al., 1998; Sjögren et al., 2002; Mollenhauer et al., 2006; Parnetti et al., 2008, 2011, 
Table 3 | Alterations in the CSF levels of oxidative stress markers and substances related with oxidative stress in PD patients compared with controls.

\begin{tabular}{|c|c|c|c|c|}
\hline & & References & PD/Controls & Cerebrospinal fluid levels \\
\hline & & Ilic et al., 1999 & $33 / 16$ & Increased $(p<0.001)$ \\
\hline & & Shukla et al., 2006 & $21 / 20$ & Normal \\
\hline & $\begin{array}{l}\text { Low density lipoprotein } \\
\text { (LDL) oxidation products }\end{array}$ & Buhmann et al., 2004 & 70/60 OND/31 HC & $\begin{array}{l}\text { Increased 3-fold with -SH } \\
\text { decreased 1.5-fold }\end{array}$ \\
\hline & $\begin{array}{l}\text { Schiff bases, conjugated } \\
\text { dienes, oxidized proteins, } \\
\text { and aldehyde polymers }\end{array}$ & Boll et al., 2008 & $22 / 41$ & $\begin{array}{l}\text { Increased 1,5 fold (lsobe et al., } \\
\text { 2010b) }\end{array}$ \\
\hline & $\begin{array}{l}\text { 8-hydrosyguanosine } \\
\text { (8-OHG) }\end{array}$ & Kikuchi et al., 2002 & $48 / 22$ & Increased \\
\hline & & Abe et al., 2003 & $24 / 15$ & Increased 3-fold ( $p<0.001)$ \\
\hline & 8-OHdG/8-OHG ratio & Kikuchi et al., 2002 & $48 / 22$ & Increased 2-fold ( $p<0.0005)$ \\
\hline \multirow{21}{*}{$\begin{array}{l}\text { Transition metals } \\
\text { and related } \\
\text { proteins }\end{array}$} & Iron & Campanella et al., 1973 & $13 / 5$ & Normal \\
\hline & & Pall et al., 1987 & $24 / 34$ & Normal \\
\hline & & Gazzaniga et al., 1992 & $11 / 22$ & Normal \\
\hline & & Takahashi et al., 1994 & $20 / 25$ & Normal \\
\hline & Ferritin & Campanella et al., 1973 & $13 / 5$ & Normal \\
\hline & & Dexter et al., 1990 & $26 / 11$ & Normal \\
\hline & & Pall et al., 1990 & $24 / 21$ & Normal \\
\hline & & Kuiper et al., 1994a & $72 \mathrm{PDND} / 15 \mathrm{PDD} / 20 \mathrm{HC}$ & Normal \\
\hline & Transferrin & Loeffler et al., 1994 & $12 / 11$ & Normal \\
\hline & Copper & Campanella et al., 1973 & $13 / 5$ & Normal \\
\hline & & Gazzaniga et al., 1992 & $11 / 22$ & Normal \\
\hline & & Takahashi et al., 1994 & $20 / 25$ & Normal \\
\hline & & Pan et al., 1997 & NS/NS & Increased $(p<0.05)$ \\
\hline & & $\begin{array}{l}\text { Jiménez-Jiménez et al., } \\
1998\end{array}$ & $37 / 37$ & Normal \\
\hline & & Forte et al., 2004 & $26 / 13$ & Normal \\
\hline & & Alimonti et al., 2007 & $42 / 20$ & Normal \\
\hline & & Qureshi et al., 2006 & $36 / 21$ & Normal \\
\hline & & Boll et al., 2008 & $22 / 41$ & Increased 2-fold \\
\hline & & Pall et al., 1987 & $24 / 34$ & Increased $(p<0.001)$ \\
\hline & & Hozumi et al., 2011 & $20 / 15$ & Increased 2 -fold $(p<0.01)$ \\
\hline & & Boll et al., 1999 & 49/26 (35 PD untreated) & Increased 1,5 fold \\
\hline
\end{tabular}


Table 3 | Continued

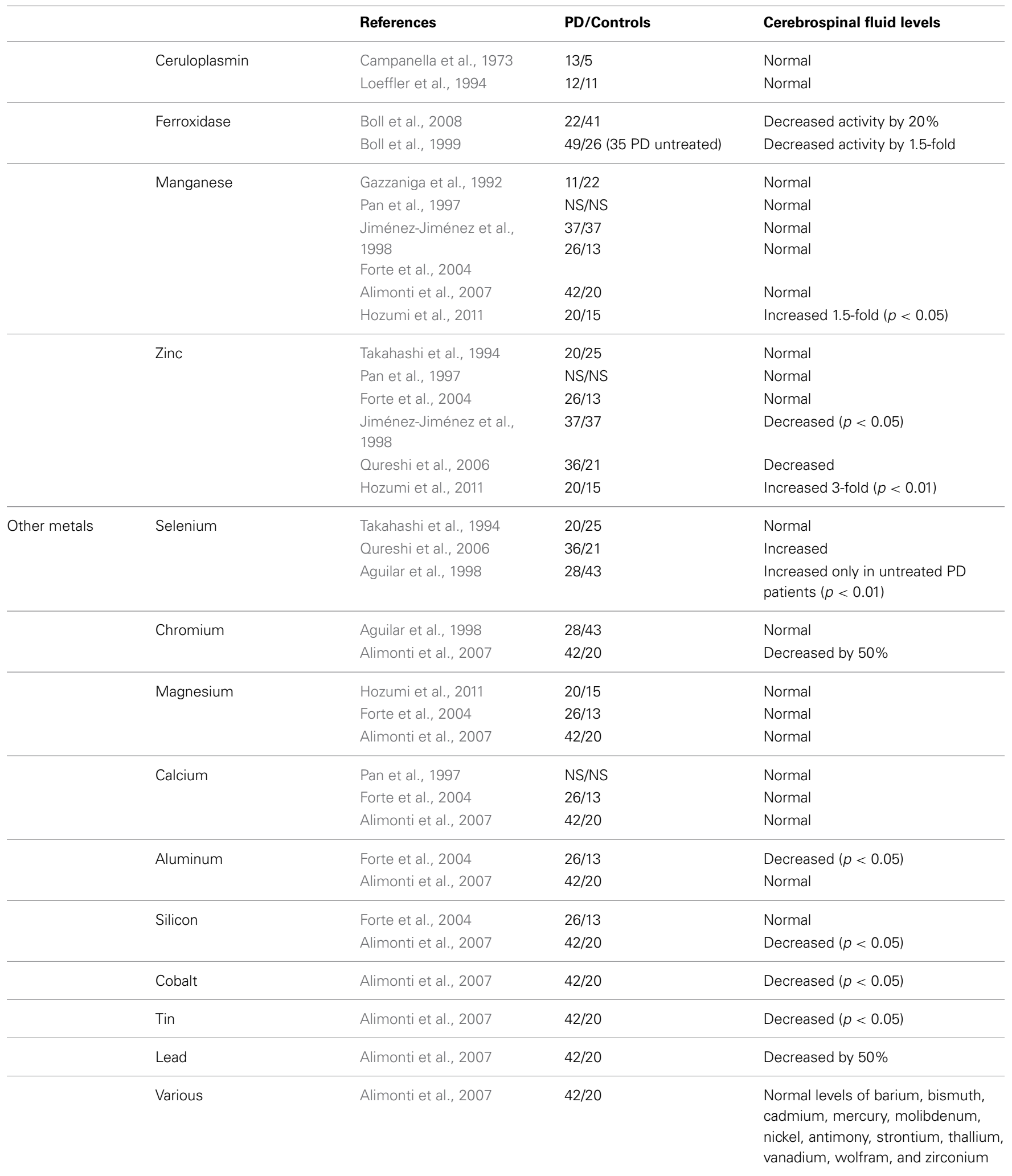


Table 3 | Continued

\begin{tabular}{|c|c|c|c|c|}
\hline & & References & PD/Controls & Cerebrospinal fluid levels \\
\hline \multirow{13}{*}{$\begin{array}{l}\text { Nitric oxide } \\
\text { metabo- } \\
\text { lites/nitroxidative } \\
\text { stress }\end{array}$} & Nitrates & Ikeda et al., 1995 & $11 / 17$ & Normal \\
\hline & & Molina et al., 1996 & $31 / 38$ & Normal \\
\hline & & Kuiper et al., 1994b & $103 / 20$ & Decreased \\
\hline & & Boll et al., 2008 & $22 / 41$ & Increased 2-fold \\
\hline & Nitrites & Ikeda et al., 1995 & $11 / 17$ & Normal \\
\hline & & Ilic et al., 1999 & $33 / ?$ & Normal \\
\hline & & Kuiper et al., 1994b & $103 / 20$ & Normal \\
\hline & & Boll et al., 2008 & $22 / 41$ & Increased 2-fold \\
\hline & & Qureshi et al., 1995 & $16 / 14$ & Increased 2-fold both in untreated \\
\hline & & & & $(n=6)$ and in levodopa-treated $(n=10)$ \\
\hline & & & & PD patients. Controls were young \\
\hline & Nitrotyrosine-containing & Fernández et al., 2013 & $54 / 40$ & Increased $(p<0.01)$ \\
\hline & & Aovama et al 2000 & $10 / 6$ & Increased 18-fold \\
\hline \multirow{24}{*}{$\begin{array}{l}\text { Antioxidant } \\
\text { enzymes or } \\
\text { substances }\end{array}$} & Total & Marttila et al., 1988 & 26/26 OND & Normal \\
\hline & $\begin{array}{l}\text { superoxide-dismutase } \\
\text { (SOD) }\end{array}$ & & & \\
\hline & & De Deyn et al., 1998 & $12 / 58$ & Normal \\
\hline & $\mathrm{Cu} / \mathrm{Zn}-\mathrm{SOD}(\mathrm{SOD}-1)$ & Ilić et al., 1998 & $31 / 16$ & Increased $(p<0.05)$ \\
\hline & & Ilic et al., 1999 & $33 / 16$ & Increased $(p<0.05)$ \\
\hline & & Boll et al., 2008 & $22 / 41$ & Decreased $(p=0.021)$ \\
\hline & Mn-SOD (SOD-2) & Aoyama et al., 2000 & $10 / 6$ & Normal \\
\hline & Catalase & Marttila et al., 1988 & 26/26 OND & Normal \\
\hline & $\begin{array}{l}\text { Glutathione peroxidase } \\
(\mathrm{GPx})\end{array}$ & Marttila et al., 1988 & 26/26 OND & Normal \\
\hline & Glutathione reductase (GR) & Ilić et al., 1998 & $31 / ?$ & Increased \\
\hline & & Ilic et al., 1999 & $33 / ?$ & Increased \\
\hline & Reduced glutathione (GSH) & Marttila et al., 1988 & 26/26 OND & Normal \\
\hline & & Tohgi et al., 1995b & $22 / 15$ & $\begin{array}{l}\text { Increased }(p<0.02) \text { in L-dopa treated } \\
\text { patients }(n=8)\end{array}$ \\
\hline & & Konings et al., 1999 & 71 PD/13 PDND/21 & Normal \\
\hline & & & $\mathrm{HC}$ & \\
\hline & $\begin{array}{l}\text { Oxidized glutathione } \\
\text { (GSSG) }\end{array}$ & LeWitt et al., 2013 & $48 / 57$ & Decreased $(p<0.01)$ \\
\hline & & Tohgi et al., 1995b & $22 / 15$ & $\begin{array}{l}\text { Decreased }(p<0.001) \text { in untreated } \\
\text { patients }(n=14)\end{array}$ \\
\hline & $\begin{array}{l}\text { Alpha-tocopherol (vitamin } \\
\text { E) }\end{array}$ & Buhmann et al., 2004 & 70/60 OND/31 HC & Decreased by $44-48 \%$ \\
\hline & & Tohgi et al., 1995b & $22 / 15$ & Normal \\
\hline & & Molina et al., 1997b & $34 / 47$ & Normal \\
\hline & Alpha-tocopherol-quinone & Tohgi et al., 1995b & $22 / 15$ & $\begin{array}{l}\text { Decreased }(p<0.001) \text { in untreated } \\
\text { patients }(n=15)\end{array}$ \\
\hline & Urate & Tohgi et al., 1993e & $11 / 14$ & Normal \\
\hline & & $\begin{array}{l}\text { Constantinescu et al., } \\
2013\end{array}$ & $6 / 18$ & Normal \\
\hline & & Ascherio et al., 2009 & $713 / 0$ & $\begin{array}{l}\text { Relation of higher CSF levels of urate } \\
\text { with slower rates of clinical decline }\end{array}$ \\
\hline
\end{tabular}




\begin{tabular}{llll}
\hline & References & PD/Controls & Cerebrospinal fluid levels \\
\hline $\begin{array}{l}\text { Xantine (uric acid } \\
\text { precursor) }\end{array}$ & LeWitt et al., 2011 & $217 / 26$ & Normal \\
\hline Ascorbate & Buhmann et al., 2004 & $70 / 60$ OND/31 HC & Normal \\
\hline Carnitine & $\begin{array}{l}\text { Jiménez-Jiménez et al., } \\
1997\end{array}$ & $29 / 29$ & Normal \\
\hline Oxidized coenzyme & Isobe et al., 2010b & $20 / 20$ & Increased 18\% ( $p<0.05)$ \\
\hline Q10/total Q10 ratio & Isobe et al., 2007 & $20 / 20$ & Increased 18\% $(p<0.05)$ \\
\hline Osteopontine & Maetzler et al., 2007 $(p<0.002)$ & $30 / 30$ &
\end{tabular}

OND, other neurological controls; HC, healthy controls; PDND, Parkinson's disease non-demented.

2014a,b; Ohrfelt et al., 2009; Compta et al., 2009b; Alves et al., 2010; Montine et al., 2010; Aerts et al., 2011; van Dijk et al., 2013a; Herbert et al., 2014). Several of these studies have shown increased CSF tau in demented PD patients (Mollenhauer et al., 2006; Compta et al., 2009b). The $33 \mathrm{KDa} / 55 \mathrm{KDa}$ tau isoforms ratio have also been found to be normal in PD (Borroni et al., 2008, 2009), but decreased in progressive supranuclear palsy (PSP), and normal in patients with diffuse Lewy body disease (DLBD), demented PD patients (PDD), AD, and frontotemporal dementia (FTD) (Borroni et al., 2008, 2009).

Some authors have found decreased CSF total tau and phosphotau levels when compared with controls (Mollenhauer et al., 2011; Shi et al., 2011; Kang et al., 2013) and similar levels in PD to PSP, DLBD, and MSA (Mollenhauer et al., 2011), while others found higher CSF tau in DLBD compared with PDD patients (Andersson et al., 2011), and still others higher CSF total tau in MSA than in PD patients (Herbert et al., 2014). Hall et al. (2012) reported decreased CSF total tau and normal phosphotau both in PD and PDD, while total tau was increased in CBD and normal in PSP, DLBD, and MSA, and phosphotau was decreased in PSP and MSA in comparison with controls.

Přikrylová Vranová et al. (2010) found increased CSF tau levels in PD patients with less than 2 years of evolution, and increased CSF tau levels which were higher in patients with PDD than in $\mathrm{PD}$, and in PD than in controls, and similar CSF tau in DLDB than in controls (Vranová et al., 2014). This group and others found increased CSF total tau levels in patients with non-tremor variants of PD as compared to tremor-dominant PD and controls (Jellinger, 2012; Přikrylová Vranová et al., 2012). Compta et al. (2011) described increased CSF tau levels in PD patients carrying the allele rs242557A. Siderowf et al. (2010) showed a lack of association between baseline CSF tau levels and cognitive decline in PD patients. Patients with corticobasal degeneration (CBD) and PSP have shown higher CSF total and phospotau levels (Aerts et al., 2011), and patients with DLBD showed similar CSF tau levels to PD patients in one study (Ohrfelt et al., 2009), while other authors found higher CSF tau levels in AD than in DLBD, in $\mathrm{DLDB}$ higher than in $\mathrm{PDD}$, and in $\mathrm{PDD}$ higher than in $\mathrm{PD}$ (Parnetti et al., 2008).
Baseline CSF levels of total and phosphotau in the DATATOP study, involving 403 early PD patients, were negatively correlated with disease progression assessed with the Unified PD Rating Scale (UPDRS) (Zhang et al., 2013).

Beyer et al. (2013) reported a lack of correlation between CSF levels of total and phosphotau, and ventricular size in 73 nondemented PD patients and 18 PD patients with mild cognitive impairment.

The results of the studies reported on CSF tau levels in $\mathrm{PD}$ are summarized in Table 4. Although these results are not conclusive, CSF tau levels could be related to the progression of the disease (Zhang et al., 2013), and to the preservation of cognitive function in $\mathrm{PD}$ patients (Stewart et al., 2014).

\section{ALPHA-SYNUCLEIN}

Alpha-synuclein ( $\alpha$-synuclein) is a 140 amino acid-long presynaptic protein, which is the major component of the Lewy bodies (the neuropatologic hallmark of PD), and has been implicated in the pathogenesis of $\mathrm{PD}$ and in synucleinopathies such as MSA and DLBD. Mutations of the $\alpha$-synuclein (SNCA) gene are related with early-onset monogenic familial PD and are associated with increased risk for sporadic PD (Alonso-Navarro et al., 2014). Although early studies failed to detect the native form of $\alpha$-synuclein in the CSF of PD and control patients (Jakowec et al., 1998), later studies have detected monomeric SNC in the CSF, with similar levels in PD patients and controls (Borghi et al., 2000). Several studies have found similar CSF total $\alpha$ synuclein levels in PD patients and in controls (Woulfe et al., 2002; Ohrfelt et al., 2009; Park et al., 2011; Parnetti et al., 2011; Tateno et al., 2012) and others decreased CSF $\alpha$-synuclein in PD (Tokuda et al., 2006; Hong et al., 2010; Mollenhauer et al., 2011, 2013; Hall et al., 2012; Wang et al., 2012; Kang et al., 2013; Wennström et al., 2013; Parnetti et al., 2014a,b; Mondello et al., 2014; van Dijk et al., 2014), DLBD (Parnetti et al., 2011; Wennström et al., 2013), MSA (Wang et al., 2012; Mondello et al., 2014), and PSP (Wang et al., 2012). Four studies have reported increased CSF oligomeric $\alpha$-synuclein levels in PD compared with controls (Tokuda et al., 2010; Park et al., 2011; Parnetti 
Table 4 | Results of studies on CSF tau and phosphotau levels in PD, other parkinsonian syndromes and controls.

\begin{tabular}{lll}
\hline References & Cases/Controls & Main findings \\
\hline Blennow et al., 1995 & 44 AD, 31 controls, 17 VAD, 11 FTD, 15 PDND, & CSF total tau and phosphorylated tau (phosphotau) \\
& major depression & higher in AD than in controls, VAD, FTD, PDND, and \\
& & major depression (PDND similar than controls)
\end{tabular}

Molina et al., 1997c

Jansen Steur et al., 1998

Sjögren et al., 2002

Mollenhauer et al., 2006
26 PDND, 25 controls

115 PD (48 with MMSE lower than 25) 15 controls

CSF total tau similar in PD and controls

CSF total and phosphotau similar in PD (not related with MMSE scores) and controls

19 AD, 14 FTD, 11 ALS, 15 PD, 17 controls

CSF total tau and phosphotau increased in AD compared with FTD $(p<0.001)$, ALS $(p<0.001)$, PD $(p<0.001)$, and controls $(p<0.001)$

73 PDD, 23 PDND, 41 controls (non-demented neurological patients)

CSF total tau significantly higher in PDD than in PDND and controls. This observation was most marked ( $p<0.05$ ) in a subgroup of patients with PDD carrying the apolipoprotein genotype epsilon3/epsilon3

Parnetti et al., 2008

19 DLBD, 18 PDD, 23 AD, 20 PDND, 20 controls

CSF total tau of DLBD patients significantly lower than in $A D$ patients, but twofold to threefold higher than in PDD, PDND, or control subjects CSF total tau levels similar in PDD and PDND Phosphotau increased in the AD group only

Borroni et al., 2008 21 PSP, 20 CBD, 44 FTD, 29 AD, 10 PDND, 15 DLBD, 27 controls

CSF tau 33/55 kDa ratio significantly reduced in PSP when compared to controls and to patients with other neurodegenerative conditions

CSF tau 33/55 kDa ratio decrease correlated significantly with brainstem atrophy

Borroni et al., 2009

78 patients with neurodegenerative disorders and 26 controls

Ohrfelt et al., 2009

$66 \mathrm{AD}, 15 \mathrm{PD}, 15 \mathrm{DLBD}, 55$ controls

Compta et al., 2009b

20 PDND, 20 PDD, 30 controls patients

Alves et al., 2010

109 PDND, 36 controls, 20 mild AD

Montine et al., 2010

150 controls ( $115>50$ years; 24 amnestic Mild Cognitive Impairment (aMCl), 49 AD, 49 PD, 11 PDD 62 PD-CIND (cognitive imparment non-demented)
CSF tau 33/55 kDa ratio significantly decreased in patients with PSP $(0.46 \pm 0.16)$ when compared to healthy controls $(p=0.002), \mathrm{AD}(P<0.001)$, FTD, CBD, PD, and DLBD (values in PD similar to those of controls)

CSF total tau and phosphotau increased significantly in $A D$, similar levels in PD, DLBD, and controls

CSF total tau and phosphotau higher in PDD than in PDND and controls $(P<0.05)$. High CSF total tau and phospho-tau were associated with impaired memory and naming

CSF total tau and phosphotau similar in PD and controls

CSF tau did not correlate with cognitive measures

CSF total tau and phospho181-tau significantly increased in $\mathrm{AD}$ and $\mathrm{aMCl}$ in comparison with the other groups

Total tau similar in PDD, PDD and PD-CIND and controls

Phospho181-tau slightly decreased when compared with controls $>50$ years 
Table 4 | Continued

\begin{tabular}{lll}
\hline References & Cases/Controls & Main findings \\
\hline Přikrylová Vranová et al., 2010 & 32 PD, 30 controls & CSF total tau and total tau/beta-amyloid (1-42) ratio \\
& & $\begin{array}{l}\text { higher in PD than in controls }(p=0.045 \text { and } 0.033, \\
\text { respectively) }\end{array}$
\end{tabular}

Siderowf et al., $2010 \quad 45$ PD, longitudinal follow-up at least 1 year

No association between CSF total tau and phospo181-tau and cognitive decline

\begin{tabular}{|c|c|c|}
\hline Aerts et al., 2011 & 21 PSP, 12 CBD, 28 PD, 49 controls & $\begin{array}{l}\text { CSF total tau } \mathrm{CBD}>\mathrm{PSP}>\mathrm{PD}=\text { controls } \\
\mathrm{CSF} \text { phospotau } \mathrm{CBD}>\mathrm{PSP}=\mathrm{PD}=\text { controls }\end{array}$ \\
\hline Parnetti et al., 2011 & $\begin{array}{l}38 \text { PD, } 32 \text { DLBD, } 48 \text { AD, } 31 \text { FTD, } 32 \text { controls with } \\
\text { other neurological diseases }(n=32)\end{array}$ & $\begin{array}{l}\text { CSF total tau and phosphotau AD }>\text { FTD }>\text { DLBD }= \\
\text { PD }=\text { controls }\end{array}$ \\
\hline Shi et al., 2011 & 137 controls, 126 PD, 50 AD and 32 MSA & $\begin{array}{l}\text { CSF total tau and phosphotau } A D>\text { controls }>P D= \\
\text { MSA }\end{array}$ \\
\hline Mollenhauer et al., 2011 & $\begin{array}{l}\text { Cross-sectional cohort: } 51 \text { PD, } 29 \text { MSA, } 55 \text { DLBD, } \\
62 \text { AD, and } 72 \text { neurological controls }\end{array}$ & CSF total tau $A D>D L B D>P D=$ controls $=$ MSA \\
\hline
\end{tabular}

Mollenhauer et al., $2011 \quad$ Validation cohort: 275 PD, 15 MSA, 5566 DLBD, 8

CSF total tau MSA $<$ DLBD $=$ PD $<$ DLBD $<$ controls $\mathrm{PSP}, 22$ normal pressure hydrocephalus (NPH) and 23 neurological controls

Andersson et al., $2011 \quad 47$ DLBD, 17 PDD $(n=17)$

CSF total-tau higher in DLBD than in PDD

CSF phosphotau similar in DLBD and PDD

Compta et al., 201138 PD patients (19 PDD, 19 PDND). All cases were genotyped for a series of tau gene polymorphisms rs1880753, rs1880756, rs1800547, rs1467967, rs242557, rs2471738, and rs7521

The A-allele rs242557 polymorphism was the only tau gene variant significantly associated with higher CSF tau and phospho-tau levels, under both dominant and dose-response model. This association depended on the presence of dementia, and was only observed in individuals with low $(<500 \mathrm{pg} / \mathrm{mL}$ ) CSF A $\beta$ levels

Hall et al., 2012

MSA, 12 CBD, 107 controls

Přikrylová Vranová et al., 2012

48 PD (17 early-onset PD, 15 tremor dominant, 16 non-tremor-dominant), 19 neurological controls, 18 AD

Jellinger, 2012

12 PD (6 tremor-dominant PD and 6 non-tremor-dominant PD), $27 \mathrm{AD}, 17$ controls

van Dijk et al., 2013a

$52 \mathrm{PD}, 50$ controls

63 PD, 39 controls

Kang et al., 2013

403 early stage PD patients enrolled in the DATATOP study
CSF total tau $\mathrm{AD}>\mathrm{MSA}=\mathrm{CBD}>\mathrm{PSP}=$ Controls $=$ DLBD $>$ PDND $=$ PDD

CSF phosphotau increased in $A D, A D>P D D=$ $\mathrm{DLBD}=$ controls $=\mathrm{CBD}>\mathrm{PDND}>\mathrm{PSP}=\mathrm{MSA}$

CSF tau and index tau/amiloid beta42 increased in non-tremor-dominant PD compared with controls, and other PD groups, and siminar to those of $A D$

CSF total tau higher in AD compared with the other groups, and higher in tremor-dominant PD compared with non-tremor dominant PD and controls

CSF total tau and phosphotau similar in PD and controls

CSF total tau and phosphotau181 significantly lower in PD than in controls

Baseline CSF phosphotau/total tau and phosphotau/amyloid beta significantly and negatively correlated with the rates of the Unified Parkinson Disease Rating Scale change

No associations between CSF total tau and phosphotau and hippocampal atrophy 
Table 4 | Continued

\begin{tabular}{lcc}
\hline References & Cases/Controls & Main findings \\
\hline Herbert et al., 2014 & 43 PD, 23 MSA, 30 controls & CSF total tau significantly lower in PD than in MSA, \\
& & but similar to those of controls \\
CSF phosphotau similar in PD, MSA and controls
\end{tabular}

Parnetti et al., 2014a

71 PD (8 of 44 carriers of a mutation in the beta-glucocerebrosidase gene (GBA1) 45 controls

with other neurological disases

Parnetti et al., 2014b
44 PD and 25 controls with other neurological diseases
CSF phosphotau similar in PD, MSA and controls

CSF total tau and phosphotau similar in PD and controls
CSF total tau and phosphotau similar in PD and controls, and unrelated with prognosis and cognitive impairment

Vranová et al., 2014

27 PDND, 14 PDD, 14 DLBD, 17 AD 24 controls

CSF total tau $\mathrm{AD}>\mathrm{PDD}>\mathrm{PDND}>\mathrm{DLBD}=$ controls

AD, Alzheimer's disease; PD, Parkinson's disease; VAD, vascular dementia; FTD, frontotemporal dementia; PDND, PD non-demented; PD, PD demented; MMSE, MiniMental State Examination; DLBD, diffuse Lewy body disease; PSP, progressive supranuclear palsy; CBD, corticobasal degeneration; MSA, multiple system atrophy; aMCl, Amnestic Mild Cognitive Impairment; PD-CIND, PD with cognitive imparment non-demented; NPH, normal pressure hydrocephalus.

et al., 2014a,b), and one of them showed increased CSF $\alpha$ Syn in PD patients compared with patients with PSP and AD (Tokuda et al., 2010). Wang et al. (2012) found increased CSF levels of the phosphorylated $\alpha$-synuclein phospho-Ser129 (PS129) in PD patients when compared with controls, but lower levels in MSA and PSP of this protein than in PD patients and controls.

Aerts et al. (2012) found similar CSF $\alpha$-synuclein levels in PD patients to DLBD, PSP, and MSA. Hall et al. (2012) found higher CSF $\alpha$-synuclein in PSP than in PD, PDD, DLBD, and MSA. Tateno et al. (2012) reported similar CSF $\alpha$-synuclein levels in PD, MSA, DLBD, and controls but higher CSF $\alpha$ synuclein levels in AD patients, while Ohrfelt et al. (2009) found higher CSF $\alpha$-Syn levels in AD than in DLDB and PD, and in DLBD than in PD patients. Foulds et al. (2012) found similar post-mortem CSF total $\alpha$-synuclein levels in PD, MSA, DLBD, and PSP, but increased CSF levels of phosforylated oligomers in MSA.

van Dijk et al. (2014) reported a lack of relation between CSF $\alpha$-synuclein levels and striatal dopaminergic deficit measured by dopamine transporter binding and single photon emission computed tomography. In addition, a recent study by Shi et al. (2012) described a lack of relation between the loss of striatal dopaminergic function, assessed by positron emission tomography (PET), and CSF $\alpha$-synuclein levels, in asymptomatic carriers of mutations in the LRRK2 gene. CSF neurosin (a protease that degrades $\alpha$-synuclein) levels have been found to be decreased (Wennström et al., 2013).

Lower baseline CSF $\alpha$-synuclein levels in the DATATOP study predicted a better preservation of cognitive function in early $\mathrm{PD}$ patients with up to 8 years of follow-up (Stewart et al., 2014).

The results of the studies reported on CSF $\alpha$-synuclein levels in PD are summarized in Table 5. The majority of recent studies have shown decreased CSF $\alpha$-synuclein levels both in PD and in other synucleopathies. Therefore, this should be a useful marker to distinguish this disease from controls, but not to distinguish among synucleopathies.

\section{AMYLOID-BETA}

Amyloid beta $(A \beta)$ are a group of different lengths peptides resulting from the enzymatic cleavage of the amyloid precursor protein (APP). The most common is the 42 amino-acid long $\mathrm{A} \beta 42$. These peptides have a differential trend toward aggregation (specially $A \beta 1-42)$ to form amyloid plaques, one of the pathological hallmarks of $\mathrm{AD}$ and DLBD. The increased risk for developing cognitive impairment and dementia of PD patients in comparison with the general population makes it reasonable to link AD markers such as $A \beta 42$ to PDD. Several studies have shown similar (Holmberg et al., 2003; Mollenhauer et al., 2006; Ohrfelt et al., 2009; Přikrylová Vranová et al., 2010; Aerts et al., 2011; Parnetti et al., 2011; van Dijk et al., 2013a) or decreased (Sjögren et al., 2002; Compta et al., 2009b; Mollenhauer et al., 2011; Shi et al., 2011; Kang et al., 2013; Nutu et al., 2013a; Vranová et al., 2014) CSF A $\beta 1-42$ (A $\beta 1-42)$ in PD patients, with the exception of one study which reports increased levels (Parnetti et al., 2014b). Other found decreased CSF A $\beta$-1-42 (Mollenhauer et al., 2006; Compta et al., 2009b; Alves et al., 2010; Montine et al., 2010; Siderowf et al., 2010) and A $\beta 1-40$ (Alves et al., 2010) and A $\beta 1-38$ (Alves et al., 2010) only in PDD patients or in PD patients with memory impairment.

Baseline CSF A $\beta$ levels in the DATATOP study, were negatively correlated with disease progression assessed with UPDRS (Zhang et al., 2013). Baseline CSF levels of A $\beta 1-42$ in two studies (Siderowf et al., 2010; Parnetti et al., 2014b); and the combination of lower baseline CSF A $\beta$, worse verbal learning, semantic fluency and visuoperceptual scores, and thinner superior-frontal/anterior cingulated in precentral regions by 3Tbrain-Magnetic Resonance Imaging in another (Compta et al., 2013) have been associated with further cognitive decline in PD patients.

CSF A $\beta 1-42$ levels have been reported as decreased (Parnetti et al., 2008; Andersson et al., 2011; Parnetti et al., 2011) or similar (Ohrfelt et al., 2009; Nutu et al., 2013a) in DLBD than in PDD and PD patients, decreased in MSA (Holmberg et al., 2003; Shi et al., 2011), and decreased in DLBD in comparison with PD, 
Table 5 | Results of studies on CSF alpha-synuclein and phosphotau levels in PD, other parkinsonian syndromes and controls.

\begin{tabular}{|c|c|c|}
\hline References & Cases/Controls & Main findings \\
\hline Woulfe et al., 2002 & $5 \mathrm{PD}, 4$ controls & Similar anti- $\alpha$-synuclein antibodies in PD and controls \\
\hline Tokuda et al., 2006 & 33 PD, 38 controls ( 9 healthy and 29 with OND) & $\begin{array}{l}\text { CSF } \alpha \text {-synuclein levels significantly lower in PD than in controls } \\
(p<0.0001)\end{array}$ \\
\hline Ohrfelt et al., 2009 & 66 AD, 15 PD, 15 DLBD, 55 controls & CSF $\alpha$-synuclein AD $>$ Controls $=$ DLBD $=$ PD \\
\hline Hong et al., 2010 & 117 PD, 132 controls, 50 AD & $\begin{array}{l}\text { CSF } \alpha \text {-synuclein PD }<\text { Controls }=\text { AD (after correcting for hemoglobin } \\
\text { levels) }\end{array}$ \\
\hline
\end{tabular}

Tokuda et al., $2010 \quad 32$ PD, 28 controls (12 healthy and 16 with OND)

CSF $\alpha$-synuclein oligomers and oligomers/total- $\alpha$-synuclein ratio in CSF higher in PD group $(p<0.0001)$

Tokuda et al., $2010 \quad 25$ PD, 18 PSP, 35 AD, 43 controls $\quad$ CSF $\alpha$-synuclein PD $>$ PSP $=$ Controls $>$ AD

Parnetti et al., $2011 \quad 38$ PD, 32 DLBD, 48 AD, 31 FTD, 32 controls with $\quad$ CSF $\alpha$-synuclein Controls $>$ PD $>$ DLBD $=$ AD $=$ FTD other neurological diseases $(n=32)$

Mollenhauer et al., 2011 Cross-sectional cohort: 51 PD, 29 MSA, 55 $\mathrm{DLBD}, 62 \mathrm{AD}$, and 72 neurological controls

CSF $\alpha$-synuclein PD $<$ DLBD $<$ MSA $<$ controls $<$ AD

Kang et al., $2013 \quad$ Validation cohort: 275 PD, 15 MSA, 5566 DLBD,
$8 \mathrm{PSP}, 22 \mathrm{NPH}$, and 23 neurological controls Park et al., 2011 PD, 29 neurological controls

CSF $\alpha$-synuclein MSA $<$ DLBD $=\mathrm{PD}<\mathrm{NPH}=\mathrm{PSP}<$ controls

Park et al, 2011

CSF $\alpha$-synuclein oligomer significantly higher in PD than in neurological controls

Kang et al., $2013 \quad 63$ PD, 39 controls

Slightly, but significantly, lower CSF levels of $\alpha$-synuclein in PD compared with healthy controls

Lower levels of CSF $\alpha$-synuclein associated with increased motor severity

\begin{tabular}{ll} 
Hall et al., 2012 & 90 PDND, 33 PDD, 70 DLBD, 48 AD, 45 PSP, 48 \\
& MSA, 12 CBD, 107 controls \\
\hline Tateno et al., 2012 & $\begin{array}{l}9 \text { AD, 6 DLBD, 11 PD, 11 MSA, 11 neurological } \\
\text { controls }\end{array}$
\end{tabular}
CSF $\alpha$-synuclein $\mathrm{AD}>\mathrm{PSP}=$ Controls $>\mathrm{PDD}=\mathrm{DLBD}=\mathrm{MSA}=\mathrm{CBD}$ $=$ PDND

CSF $\alpha$-synuclein levels in AD higher than in controls $(P<0.05)$, and significantly lower in PD $(P<0.001)$, DLBD $(P<0.01)$, and MSA $(P<0.05)$ when compared with $\mathrm{AD}$

Wang et al., 2012

Discovery series: 93 PD, 26 AD, 78 controls, 33 PSP, 16 MSA

CSF Phosphorylated $\alpha$-synuclein (PS-129) PD > Controls > AD > MSA $=\mathrm{PSP}$

Replication series: 116 PD, 50 AD, 126 controls, 27 PSP, 25 MSA

CSF $\alpha$-synuclein MSA $<\mathrm{PD}<\mathrm{PSP}>\mathrm{AD}=$ Controls

CSF PS-199/ $\alpha$-synuclein ratio MSA > PK > AD > PSP $=$ Controls

Aerts et al., 2012

58 PD, 47 MSA, 3 DLBD, 22 Vascular Parkinsonsim, 10 PSP, 2 CBD, 57 controls

CSF $\alpha$-synuclein did not differ significantly among the study groups

Foulds et al., 2012 13 PDND, 10 PD with cognitive impairment, 16 PDD, 17 DLBD, 12 PSP, 8 MSA, 20 controls (ventricular CSF obtained post-mortem)

CSF total $\alpha$-synuclein, oligomeric $\alpha$-synuclein and phosphorylated $\alpha$-synuclein similar in PDND, PDCI, PDD, DLBD, PSP, MSA, and control groups

CSF oligomeric phosphorylated $\alpha$-synuclein significantly higher in MSA $(p<0.001)$ when compared with the other study groups

Shi et al., 2012

8 symptomatic and 18 asymptomatic carriers of the G2019 mutation in the LRRK2 gene

Lack of correlation between PET scan evidence of loss of striatal dopaminergic and CSF $\alpha$-synuclein levels

(Continued) 
Table 5 | Continued

\begin{tabular}{|c|c|c|}
\hline References & Cases/Controls & Main findings \\
\hline $\begin{array}{l}\text { Mollenhauer et al., } \\
2013\end{array}$ & 78 PD (drug naive), 48 controls & CSF $\alpha$-synuclein lower in PD than in controls \\
\hline Wennström et al., 2013 & 52 controls, 46 AD,38 PDND, 22 PDD, 33 DLBD & $A D>$ controls $>$ DLBD $>$ PD $>$ PDD \\
\hline Parnetti et al., 2014a & $\begin{array}{l}71 \text { PD (8 of } 44 \text { carriers of a mutation in the } \\
\text { beta-glucocerebrosidase gene (GBA1) } 45 \\
\text { controls with other neurological diseases }\end{array}$ & $\begin{array}{l}\text { CSF } \alpha \text {-synuclein lower and oligomeric/total } \alpha \text {-synuclein ratio higher in } \\
\text { PD than in controls }\end{array}$ \\
\hline Parnetti et al., 2014b & $\begin{array}{l}44 \text { PD and } 25 \text { controls with other neurological } \\
\text { diseases }\end{array}$ & $\begin{array}{l}\text { CSF total } \alpha \text {-synuclein lower and oligomeric } \alpha \text {-synuclein higher in PD } \\
\text { than in controls. No relation with prognosis and cognitive impairment }\end{array}$ \\
\hline van Dijk et al., 2014 & 53 PD, 50 controls & $\begin{array}{l}\text { CSF } \alpha \text {-synuclein levels reduced in patients with PD, but not correlated } \\
\text { with measures of disease severity, and striatal dopaminergic deficit } \\
\text { assessed with neuroimaging }\end{array}$ \\
\hline Mondello et al., 2014 & 22 controls, 52 PD, 34 MSA, 32 PSP, 12 CBD & CSF $\alpha$-synuclein MSA $<$ PD $<$ PSP $<$ CBD $<$ Controls \\
\hline \multirow[t]{3}{*}{ Stewart et al., 2014} & $\begin{array}{l}304 \text { early PD patients enrolled in the DATATOP } \\
\text { study. Longitudinal follow-up }\end{array}$ & CSF $\alpha$-synuclein showed a longitudinal decrease over follow-up period \\
\hline & & $\begin{array}{l}\text { CSF } \alpha \text {-synuclein was not correlated with the rate of clinical progression } \\
\text { of the motor symptoms }\end{array}$ \\
\hline & & $\begin{array}{l}\text { Lower basal levels of CSF } \alpha \text {-synuclein were associated with better } \\
\text { preservation of cognitive function }\end{array}$ \\
\hline
\end{tabular}

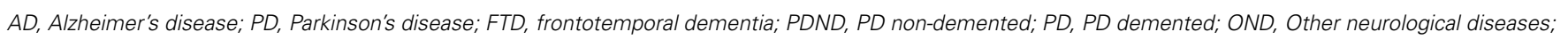

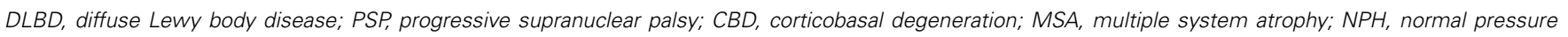
hydrocephalus.

PDD (Hall et al., 2012; Vranová et al., 2014), PSP, MSA, and CBD (Hall et al., 2012).

Alves et al. (2013) reported that patients with PD with the postural instability-gait disorders (PIGD) phenotype had significantly reduced CSF $A \beta 42, A \beta 38, A \beta 42 / 40$, and $A \beta 38 / 40$ levels compared with patients with the tremor-dominant phenotype and controls.

Nutu et al. (2013b) described lower CSF levels of A $\beta 1-15 / 16$ in $\mathrm{PD}, \mathrm{PDD}, \mathrm{PSP}$, and MSA compared to $\mathrm{CBD}, \mathrm{AD}$, and controls.

Beyer et al. (2013) reported a correlation between CSF levels of $A \beta 38, A \beta 40$, and $A \beta 42$, and ventricular size in 73 nondemented PD patients and 18 PD patients with mild cognitive impairment.

The results of the studies reported on CSF A $\beta$ levels in PD are summarized in Table 6. Many of these studies suggest the potential usefulness of CSF A $\beta 1-42$ levels to predict cognitive impairment in $\mathrm{PD}$ patients.

\section{NEUROFILAMENT PROTEINS}

Abnormal accumulation in the cytoplasm of neurofilaments (NF), members of the cytoskeleton proteins expressed by neurons, have been detected in neurodegenerative diseases including $\mathrm{AD}, \mathrm{MSA}, \mathrm{DLBD}$, and $\mathrm{PD}$. CSF levels of neurofilament light (NFL) proteins have been found normal in PD patients (Constantinescu et al., 2010; Hall et al., 2012), and increased in patients with PSP (Holmberg et al., 1998; Constantinescu et al., 2010; Hall et al., 2012), MSA (Holmberg et al., 1998; Constantinescu et al., 2010; Hall et al., 2012), CBD
(Constantinescu et al., 2010; Hall et al., 2012), and PDD (Hall et al., 2012).

CSF neuronal thread protein (NTP) levels have been found increased when compared with controls and decreased when compared with $\mathrm{AD}$ patients in one study (de la Monte et al., 1992), and similar to those of controls in another (Yamada et al., 1993). CSF annexine V has been found to be decreased in PD (Vermes et al., 1999). Glial fibrilar acidic protein (GFAP) has been found to be normal in the CSF of PD, MSA, PSP, and CBD patients (Constantinescu et al., 2010). CSF levels of the glial activation marker YKL-40 have been found to be decreased in PD, MS, PSP, and CBD (Olsson et al., 2013).

\section{OTHER PROTEINS}

Defects in the gene encoding DJ-1 protein cause an autosomal recessive early-onset PD, PARK7 (Alonso-Navarro et al., 2014). This protein is also a marker of oxidative stress. CSF levels of DJ-1 protein have been found to be increased in PD in 2 studies (Waragai et al., 2006; Herbert et al., 2014) and decreased in another 2 (Shi et al., 2011; Hong et al., 2010). One of these studies described decreased CSF DJ-1 in MSA as well (Shi et al., 2011), and other increased DJ-1 in MSA compared with PD and with controls (Herbert et al., 2014). Shi et al. (2012) described a lack of relation between the loss of striatal dopaminergic function and CSF DJ-1 levels in asymptomatic carriers of mutations in the LRRK2 gene (PARK8). The results on DJ-1 are, therefore, inconsistent and should not be considered as a marker of PD. 
Table 6 | Results of studies on CSF amiloyd beta (A $\beta$ ) levels in PD, other parkinsonian syndromes and controls.

\begin{tabular}{|c|c|c|}
\hline References & Cases/Controls & Main findings \\
\hline Mollenhauer et al., 2006 & $\begin{array}{l}73 \text { PDD, } 23 \text { PDND, } 41 \text { controls } \\
\text { (non-demented neurological patients) }\end{array}$ & $\begin{array}{l}\text { CSF A } \beta 42 \text { lower in the PDD patients compared to PDND patients } \\
\text { and controls. This observation was most marked }(p<0.05) \text { in a } \\
\text { subgroup of patients with PDD carrying the apolipoprotein genotype } \\
\text { epsilon3/epsilon3 }\end{array}$ \\
\hline
\end{tabular}

Parnetti et al., 2008 19 DLBD, 18 PDD, 23 AD, 20 PDND, 20 controls

Ohrfelt et al., 2009

66 AD patients, 15 PD patients, 15 patients with dementia with Lewy bodies (DLBD) and 55 cognitively normal controls

Compta et al., 2009b

20 PDND, 20 PDD, 30 controls patients

Alves et al., 2010

109 PDND, 36 controls, 20 mild AD
DLBD showed the lowest mean CSF A 42 levels, with a negative association to dementia duration. PDD patients had mean CSF A $\beta 42$ similar to those seen in PD patients

CSF A 442 AD $<D L B D<P D=$ Controls

CSF A 42 ranged from high (controls) to intermediate (PDND) and low (PDD) levels $(P<0.001)$. In all PD and PDD patients, in PDND, CSF $A \beta 42$ was related with phonetic fluency

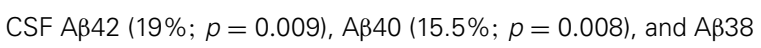
$(23 \% ; p=0.004)$ significantly decreased in PD compared with controls

CSF A $A 42$ reductions in PD less marked than in $A D(53 \%$;

$p=0.002$ )

Associations between CSF levels of $A \beta 42(\beta=0.205 ; p=0.019)$, $\mathrm{A} \beta 40(\beta=0.378 ; p<0.001)$, and $A \beta 38(\beta=0.288 ; p=0.001)$ and memory impairment, but not executive-attentional or visuospatial dysfunction

Montine et al., 2010

150 controls ( $115>50$ years; 24 amnestic Mild Cognitive Impairment (aMCl), $49 \mathrm{AD}$, 49 PD, 11 PDD 62 PD-CIND (cognitive imparment non-demented)

CSF A 442 levels reduced in AD $(p<0.001)$, PD-CIND $(P<0.05)$, and PDD $(P<0.01)$, and similar to those of controls in PD

$32 \mathrm{PD}, 30$ controls

Přikrylová Vranová et al., $2010 \quad 32$ PD, 30 controls

Siderowf et al., 2010

$45 \mathrm{PD}$, longitudinal follow-up at least 1 year

CSF A 1 1-42 similar in PD and controls

Lower baseline CSF A 1-42 associated with more rapid cognitive decline

Subjects with CSF A $\beta 1-42$ levels $=192 \mathrm{pg} / \mathrm{mL}$ declined an average of 5.85 (95\% confidence interval 2.11-9.58, $p=0.002$ ) points per year more rapidly on the DRS- 2 than subjects above that cutoff, after adjustment for age, disease duration, and baseline cognitive status

\begin{tabular}{ll}
\hline Aerts et al., 2011 & 21 PSP, 12 CBD, 28 PD, 49 controls \\
Parnetti et al., 2011 & $\begin{array}{l}\text { 38 PD, 32 DLBD, 48 AD, 31 FTD, 32 } \\
\text { controls with other neurological diseases }\end{array}$ \\
\hline Shi et al., 2011 & 137 controls, 126 PD, 50 AD and 32 MSA \\
\hline Mollenhauer et al., 2011 & $\begin{array}{l}\text { Validation cohort: 275 PD, 15 MSA, 55 66 } \\
\text { DLBD, 8 PSP, 22 NPH, and 23 neurological } \\
\text { controls }\end{array}$
\end{tabular}

Andersson et al., 2011 47 DLBD, 17 PDD

Kang et al., 2013 A 342 lower in DLBD than in PDD

CSF A 1-42 similar in CBD, PSP, PD, and controls CSF A 1 1-42 controls $=\mathrm{PD}>\mathrm{DLBD}=\mathrm{AD}=\mathrm{FTD}$

CSF A $1-42$ controls $=P D=\_M S A>A D$

CSF A 1-42 DLBD $<$ MSA $=\mathrm{NPH}=\mathrm{PD}<$ controls $<\mathrm{PSP}$

Slightly, but significantly, lower levels of $A \beta 1-42$ in PD compared with controls

(Continued) 


\section{Table 6 | Continued}

\begin{tabular}{|c|c|c|}
\hline References & Cases/Controls & Main findings \\
\hline Hall et al., 2012 & $\begin{array}{l}90 \text { PDND, } 33 \text { PDD, } 70 \text { DLBD, } 48 \text { AD, } 45 \\
\text { PSP, } 48 \text { MSA, } 12 \text { CBD, } 107 \text { controls }\end{array}$ & $\begin{array}{l}\text { CSF A } 1-42 \mathrm{AD}<\mathrm{DLBD}=\mathrm{PDD}=\mathrm{PSP}=\mathrm{MSA}=\mathrm{CBD}=\mathrm{PDND}= \\
\text { Controls }\end{array}$ \\
\hline
\end{tabular}

Přikrylová Vranová et al., $2012 \quad 48$ PD (17 early-onset PD, 15 tremor-dominant, 16

CSF $A \beta 42$ lower in $A D$ than in the other groups, and lower in non-tremor-dominant), 19 neurological non-tremor-dominant PD compared with controls

controls, $18 \mathrm{AD}$

\begin{tabular}{ll}
\hline Jellinger, 2012 & 12 PD (6 tremor-dominant PD and 6 \\
& non-tremor-dominant PD), 27 AD, 17 \\
& controls
\end{tabular}

CSF A 342 lower in tremor-dominant PD than in non-tremor-dominant controls

\begin{tabular}{ll}
\hline van Dijk et al., 2013a & 52 PD, 50 controls \\
\hline Zhang et al., 2013 & $\begin{array}{l}403 \text { early stage PD patients enrolled in the } \\
\text { DATATOP study }\end{array}$
\end{tabular}

Beyer et al., 2013

73 PDND, 18 PD with mild cognitive
impairment $P D$ and $A D$, and lower in these three groups than in controls

CSF A $\beta 42$ similar in PD and controls

CSF baseline levels of A 342 weakly but negatively correlated with baseline Unified Parkinson Disease Rating Scale total scores

Association between CSF A $\beta 38, A \beta 40$, and $A \beta 42$ with the radial distance of the occipital and frontal horns of the lateral ventricles in PDND. Negative association between CSF A 338 and A $\beta 42$ with enlargement in occipital and frontal horns of the lateral ventricles in the pooled sample, and with enlargemente of the occipital horns in PD with mild cognitive impairment

Nutu et al., 2013a

\begin{tabular}{ll} 
& controls \\
\hline Compta et al., 2013 & $\begin{array}{l}27 \text { PDND, longitudinal following (11 } \\
\text { developed dementia) }\end{array}$
\end{tabular}

Alves et al., 2013

Nutu et al., 2013b

Parnetti et al., 2014b

Vranová et al., 2014
99 PD de novo (39 with postural instability/gait disorders -PIGD-and 60 tremor-dominant-TD), 46 controls

90 PDND, 32 PDD, 68 DLBD, 48 AD, 45 PSP, 46 MSA, 12 CBD, 107 controls
44 PD and 25 controls with other neurological diseases
CSF $A \beta 1-40$ AD $<$ DLDB $<$ PDD $<$ PDND = controls

CSF $A \beta 1-42 \mathrm{PDD}=\mathrm{DLBD}=\mathrm{PDND}<$ controls $=\mathrm{AD}$

CSF $A \beta 1-40 / A \beta 1-42$ ratio $A D<D L D B<P D D=$ controls $=P D$
Lower CSF amyloid- $\beta$ predicted development of dementia together with worse verbal learning, semantic fluency and visuoperceptual scores, and thinner superior-frontal/anterior cingulate and precentral regions

CSF $A \beta 42, A \beta 38, A \beta 42 / 40$, and $A \beta 38 / 40$ levels significantly reduced in PIGD phenotype compared with TD phenotype and with controls (TD similar to controls)

Significantly lower levels of A 1 1-15/16 were detected in PD, PDD, PSP, and MSA compared to other neurodegenerative diseases and controls

CSF A 442 lower in PD than in controls. This value was related with cognitive impairment

CSF A 342 PDND > PDD > DLBD >AD > controls

$$
\text { controls }
$$

AD, Alzheimer's disease; PD, Parkinson's disease; ALS, amyotrophic lateral sclerosis; FTD, frontotemporal dementia; PDND, PD non-demented; PD, PD demented;

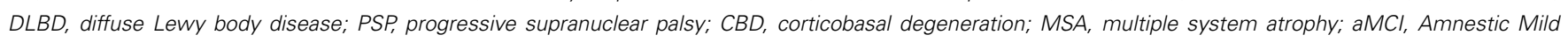
Cognitive Impairment; PD-CIND, PD with cognitive imparment non-demented; NPH, normal pressure hydrocephalus; PIGD, Postural instability and gait disorder; TD, tremor-dominant.

Defects in the gene encoding ubiquitin carboxy-terminal hydrolase 1 (UCH-L1) cause familial PD, PARK5. A recent study found decreased CSF UCH-L1 levels in PD, MSA, and PSP compared with controls (Mondello et al., 2014).

Among proteins related with apoptosis, Bcl-2 protein has not been detected in the CSF of PD patients (Mogi et al., 1996b; Mogi and Nagatsu, 1999). CSF levels of clusterin have been reported to be increased (Přikrylová Vranová et al., 2010; Vranová et al., 2014) or normal (van Dijk et al., 2013a), tissue transglutaminase (Vermes et al., 2004) increased in PD, and cystatin C normal in PD (Přikrylová Vranová et al., 2010; Yamamoto-Watanabe et al., 2010) and decreased in MSA (Yamamoto-Watanabe et al., 2010).

Studies measuring CSF levels of lysosomal hydrolases (involved in the $\alpha$-Syn degradation) found decreased (Balducci 
et al., 2007), normal (van Dijk et al., 2013b), or increased (Parnetti et al., 2014a) $\beta$-hexosaminidase, increased cathepsin E (van Dijk et al., 2013b), decreased $\alpha$-mannosidase (Balducci et al., 2007), decreased (Balducci et al., 2007) or normal $\beta$-mannosidase (Mollenhauer et al., 2011; van Dijk et al., 2013b), decreased $\alpha$-fucosidase (van Dijk et al., 2013b), $\beta$-glucocerebrosidase decreased (Balducci et al., 2007; Parnetti et al., 2014a) or normal (van Dijk et al., 2013b), $\beta$-galactosidase increased (van Dijk et al., 2013b) or normal (Balducci et al., 2007; Parnetti et al., 2014a), and cathepsin D normal (van Dijk et al., 2013b) in PD patients compared with controls.

CSF Prion protein (PrP) (Meyne et al., 2009) and tetranectin (involved in tissue remodeling) (Hong et al., 2010) levels have been found to be decreased, and apolipoprotein A-1 normal (Wang et al., 2010) in PD patients. CSF levels of transthyretin (TTR, a clearance protein produced in the choroid plexus) have been found to be increased in Lewy body diseases, including PD, PDD, and DLBD in relation with controls (Maetzler et al., 2012). CSF levels of the soluble proteoglycan NG2 (sNG2), involved in proliferation, migration, and differentiation of perycites and NG2 cells in the brain, have been found to be similar in PD patients and controls, and decreased in DLBD (Nielsen et al., 2014).

In $\mathrm{PD}$ patients there are reports of decreased CSF postproline cleaving enzyme (Hagihara and Nagatsu, 1987), increased dipeptidyl-aminopeptidase II (Hagihara et al., 1987), normal dipeptidyl-aminopeptidase IV (Hagihara et al., 1987), and normal glutamic oxaloacetic transaminase (GOT) (Steen and Thomas, 1962; Weiss et al., 1975; Qureshi et al., 1995) and glutamic pyruvic transaminase (GPT) (Weiss et al., 1975) levels.

\section{OTHER COMPOUNDS}

In patients with PD there have been reports of normal CSF levels of the proteoglycan $\mathrm{N}$-acetyl neuraminic acid (Lipman and Papadopoulos, 1973), and CSF insulin levels (Jiménez-Jiménez et al., 2000) have been found normal in PD patients.

The CSF levels of corticosterone (Pålhagen et al., 2010) and neuroactive steroids such as allopregnanolone (THP) and $5 \alpha$ dihydroprogesterone (DHP) (di Michele et al., 2003) have been found to be decreased in PD. Björkhem et al. (2013) reported that $10 \%$ of the PD patients were found to have increased CSF levels of 24S-hydroxycholesterol, and that there was a significant correlation between this value and duration of the disease. Lee et al. (2008) described a significant increase in the CSF levels of the polyunsaturated fatty acid eicosapentanoic acid (EPA) in patients with PD and MSA.

Paik et al. (2010) measured several polyamines in the CSF of patients with PD, MSA and controls. These substances are important for cell growth, and act as important modulators of a variety of ion channels, including glutamate NMDA and AMPA receptors. CSF total polyamine, $\mathrm{N}^{1}$ acetyl-cadaverine, and cadaverine levels were increased both in PD and MSA, but PD patients showed higher CSF putrescine and lower CSF spermidine levels than MSA and controls, and MSA patients showed lower CSF $\mathrm{N}^{1}$ acetylputrescine than PD and controls. CSF $\mathrm{N}^{8}$ acetylspermidine levels were higher in $\mathrm{PD}$ patients than in controls, and in MSA than in PD patients and controls.

\section{CONCLUSIONS}

(A) The majority of classical biochemical studies on neurotransmitter and related substances have described decreased CSF HVA, and normal NE, MHPG, ACh, AChE, glutamate, aspartate, and glycine levels in patients with PD. Results on CSF GABA and 5-HIAA levels are controversial. Many of these classical studies included patients with different types of Parkinsonism and had a limited number of patients and controls.

(B) Studies on the possible value of endogenous neurotoxins, oxidative stress markers, inflammatory and immunological markers, and growth and neurotrophic factors as biological markers of PD should be considered as inconclusive. The most consistent finding related with these issues is the possible role of CSF urate on the progression of the disease (Ascherio et al., 2009).

(C) Data regarding the role of CSF total tau and phosphotau as biological markers for PD are inconsistent. The most interesting findings are the possible relations of these markers with the progression of the disease (Zhang et al., 2013), and with the preservation of cognitive function in $\mathrm{PD}$ patients (Stewart et al., 2014).

(D) CSF $\alpha$-synuclein levels have been found to be decreased in most, but not all, studies in PD patients compared with controls. This marker should be useful for the differential diagnosis between synucleopathies and other parkinsonian syndromes, but its usefulness to differentiate among synucleopathies (PD, PDD, DLBD, and MSA), remains to be elucidated.

(E) CSF A $\beta 1-42$ levels could be considered as a useful marker of the presence of further cognitive decline in $\mathrm{PD}$ patients.

(F) CSF NFL protein levels should be useful for the differential diagnosis of PSP, MSA, CBD, and PDD from PD, but not to discriminate between $\mathrm{PD}$ and healthy controls.

\section{FUTURE APPROACHES}

While possible biomarkers for PD in classical studies have been hypothesis-driven, attempts to develop effective procedures for the differential diagnosis of PD in its early stages have led to the performance of CSF multianalyte methods including systematic measurements of patterns of variation in proteins (proteomics) or small molecules (metabolomics). These methods have led to the identification of possible unexpected biomarkers of diseases involved in neurodegenerative processes. However, the results of these types of studies, which are briefly described below, are not clearly established and await replication.

Guo et al. (2009), in a proteomic analysis of the CSF of PD patients and controls, found significantly higher CSF levels of apolipoprotein E, autotoxin, and some SOD1 isoforms, and lower levels of complement $\mathrm{C}_{4}$ when compared with controls, while Pigment epithelium-derived factor (PEDF or serpin F1) was not significantly increased, and complement $\mathrm{C}_{3}$ and haptoglobin were similar in PD patients and controls.

Zhang et al. (2008) performed a proteomics-discovered multianalyte profile (MAP) in CSF on 95 control subjects, 48 patients with probable $\mathrm{AD}$, and 40 patients with probable $\mathrm{PD}$, and concluded that the optimal MAP leading to the correct diagnosis was 
composed of the following proteins in order of contribution: tau, BDNF, IL-8, A $\beta 42, \beta 2$-microglobulin, vitamin D binding protein, apoA2, and apoE.

Maarouf et al. (2012) analyzed ventricular CSF from PD and controls obtained in the immediate post-mortem period using a two-dimensional difference gel electrophoresis (2D-DIGE) coupled with mass spectrophotometry protein identification, and found differences between the 2 groups in 6 molecules: fibrinogen, transthyretin, apoE, clusterin, apoA1, and glutathione-Stransferase-Pi (GSTP).

Trupp et al. (2014) reported a generally lower level of metabolites in PD as compared to controls, with a specific decrease in 3-hydroxyisovaleric acid, tryptophan, and creatinine, a significant decrease in the levels of $A \beta-38$ and $A \beta-42$, and an increase in soluble amyloid peptide precursor $\alpha(\mathrm{APP} \alpha)$ in CSF of patients.

Ideally, future studies should fulfill the following conditions: (a) a multicenter and prospective design; (b) inclusion of patients diagnosed with PD and other types of parkinsonism according to standardized criteria; (c) measurement of multiple potential biological markers in the CSF; (d) a very long-term follow-up period (till death as end-point), with assessment of both clinical features and serial determinations of the biological markers; and (e) final neuropathological confirmation by examination of the brains of patients at death (this is lacking in most of the studies published).

\section{ACKNOWLEDGMENTS}

English grammar was reviewed by Professor James McCue. Natalia Gutiérrez Casado (Librarian of Hospital Universitario del Sureste) contributed in getting many of the classical references. Research at authors' laboratories is financed by grants PI12/00241, PI12/00324, and RETICS RD12/0013/0002 from Fondo de Investigación Sanitaria, Instituto de Salud Carlos III, Spain, Innovation and GR10068 from Junta de Extremadura, Spain. Financed in part with FEDER funds from the European Union.

\section{REFERENCES}

Abbott, R. J., Pye, I. F., and Nahorski, S. R. (1982). CSF and plasma GABA levels in Parkinson's disease. J. Neurol. Neurosurg. Psychiatry 45, 253-256. doi: 10.1136/jnnp.45.3.253

Abe, T., Isobe, C., Murata, T., Sato, C., and Tohgi, H. (2003). Alteration of 8-hydroxyguanosine concentrations in the cerebrospinal fluid and serum from patients with Parkinson's disease. Neurosci. Lett. 336, 105-108. doi: 10.1016/S0304-3940(02)01259-4

Aerts, M. B., Esselink, R. A., Abdo, W. F., Bloem, B. R., and Verbeek, M. M. (2012). CSF $\alpha$-synuclein does not differentiate between parkinsonian disorders. Neurobiol. Aging 33, 430 e1-e3. doi: 10.1016/j.neurobiolaging.2010.12.001

Aerts, M. B., Esselink, R. A., Bloem, B. R., and Verbeek, M. M. (2011). Cerebrospinal fluid tau and phosphorylated tau protein are elevated in corticobasal syndrome. Mov. Disord. 26, 169-173. doi: 10.1002/mds.23341

Aguilar, M. V., Jiménez-Jiménez, F. J., Molina, J. A., Meseguer, I., Mateos-Vega, C. J., González-Muñoz, M. J., et al. (1998). Cerebrospinal fluid selenium and chromium levels in patients with Parkinson's disease. J. Neural Transm. 105, 1245-1251.

Alimonti, A., Bocca, B., Pino, A., Ruggieri, F., Forte, G., and Sancesario, G. (2007). Elemental profile of cerebrospinal fluid in patients with Parkinson's disease. J. Trace Elem. Med. Biol. 21, 234-241. doi: 10.1016/j.jtemb.2007.05.001

Alonso-Navarro, H., Jiménez-Jiménez, F. J., García-Martín, E., and Agúndez, J. A. G. (2014). Genomic and pharmacogenomic biomarkers of Parkinson's disease. Curr. Drug Metab. 15, 129-181. doi: 10.2174/138920021502140327175404

Alonso-Navarro, H., Jiménez-Jiménez, F. J., Pilo de la Fuente, B., and Plaza-Nieto, J. F. (2008). "Mecanismos patogénicos de la enfermedad de Parkinson," in Tratado de los Trastornos del Movimiento, 2nd Edn., Chapter 18, Vol. 1, eds F. J. JiménezJiménez, M. R. Luquin, J. A. Molina, and G. Linazasoro (Barcelona: Viguera Editores, S.L.), 425-485.

Alves, G., Brønnick, K., Aarsland, D., Blennow, K., Zetterberg, H., Ballard, C., et al. (2010). CSF amyloid-beta and tau proteins, and cognitive performance, in early and untreated Parkinson's disease: the Norwegian ParkWest study. J. Neurol. Neurosurg. Psychiatry 81, 1080-1086. doi: 10.1136/jnnp.2009. 199950

Alves, G., Pedersen, K. F., Bloem, B. R., Blennow, K., Zetterberg, H., Borm, G. F., et al. (2013). Cerebrospinal fluid amyloid- $\beta$ and phenotypic heterogeneity in de novo Parkinson's disease. J. Neurol. Neurosurg. Psychiatry 84, 537-543. doi: 10.1136/jnnp-2012-303808

Andersson, M., Zetterberg, H., Minthon, L., Blennow, K., and Londos, E. (2011). The cognitive profile and CSF biomarkers in dementia with Lewy bodies and Parkinson's disease dementia. Int. J. Geriatr. Psychiatry 26, 100-105 doi: 10.1002/gps.2496

Antkiewicz-Michaluk, L., Krygowska-Wajs, A., Szczudlik, A., Romańska, I., and Vetulani, J. (1997). Increase in salsolinol level in the cerebrospinal fluid of parkinsonian patients is related to dementia: advantage of a new highperformance liquid chromatography methodology. Biol. Psychiatry 42, 514-518. doi: 10.1016/S0006-3223(96)00408-8

Aoyama, K., Matsubara, K., Fujikawa, Y., Nagahiro, Y., Shimizu, K., Umegae, N., et al. (2000). Nitration of manganese superoxide dismutase in cerebrospinal fluids is a marker for peroxynitrite-mediated oxidative stress in neurodegenerative diseases. Ann. Neurol. 47, 524-527. doi: 10.1002/15318249(200004)47:43.3.CO;2-X

Aoyama, K., Matsubara, K., Kondo, M., Murakawa, Y., Suno, M., Yamashita, K., et al. (2001). Nicotinamide-N-methyltransferase is higher in the lumbar cerebrospinal fluid of patients with Parkinson's disease. Neurosci. Lett. 298, 78-80. doi: 10.1016/S0304-3940(00)01723-7

Aquilonius, S. M., Nyström, B., Schuberth, J., and Sundwall, A. (1972). Cerebrospinal fluid choline in extrapyramidal disorders. J. Neurol. Neurosurg. Psychiatry 35, 720-725. doi: 10.1136/jnnp.35.5.720

Araki, K., Takino, T., Ida, S., and Kuriyama, K. (1986). Alteration of amino acids in cerebrospinal fluid from patients with Parkinson's disease and spinocerebellar degeneration. Acta Neurol. Scand. 73, 105-110. doi: 10.1111/j.16000404.1986.tb03249.x

Asai, H., Hirano, M., Furiya, Y., Udaka, F., Morikawa, M., Kanbayashi, T., et al. (2009). Cerebrospinal fluid-orexin levels and sleep attacks in four patients with Parkinson's disease. Clin. Neurol. Neurosurg. 111, 341-344. doi: 10.1016/j.clineuro.2008.11.007

Ascherio, A., LeWitt, P. A., Xu, K., Eberly, S., Watts, A., Matson, W. R., et al. (2009). Urate as a predictor of the rate of clinical decline in Parkinson disease. Arch. Neurol. 66, 1460-1468. doi: 10.1001/archneurol.2009.247

Balducci, C., Pierguidi, L., Persichetti, E., Parnetti, L., Sbaragli, M., Tassi, C., et al. (2007). Lysosomal hydrolases in cerebrospinal fluid from subjects with Parkinson's disease. Mov. Disord. 22, 1481-1484. doi: 10.1002/mds.21399

Baronti, F., Conant, K. E., Giuffra, M., Davis, T. L., Brughitta, G., Iadarola, M. J., et al. (1991). Opioid peptides in Parkinson's disease: effects of dopamine repletion. Brain Res. 560, 92-96. doi: 10.1016/0006-8993(91)91219-Q

Beal, M. F., Growdon, J. H., Mazurek, M. F., and Martin, J. B. (1986). CSF somatostatin-like immunoreactivity in dementia. Neurology 36, 294-297. doi: 10.1212/WNL.36.2.294

Belmaker, R. H., Ebstein, R. P., Biederman, J., Stern, R., Berman, M., and van Praag, H. M. (1978). The effect of L-dopa and propranolol on human CSF cyclic nucleotides. Psychopharmacology (Berl.) 58, 307-310. doi: 10.1007/BF004 27396

Benito-León, J., Alonso-Navarro, H., Pascual-Gómez, J., and Jiménez-Jiménez, F. J. (2008). "Neuroquímica de los trastornos del movimiento," in Tratado de los Trastornos del Movimiento, 2nd Edn., Chapter 7, Vol. 1, eds F. J. JiménezJiménez, M. R. Luquin, J. A. Molina, and G. Linazasoro (Barcelona: Viguera Editores, S.L.), 133-149.

Bernheimer, H., Birkmayer, W., and Hornykiewicz, O. (1966). Homovanillic acid in the cerebrospinal fluid: studies in Parkinson's syndrome and other diseases of the CNS. Wien. Klin. Wochenschr. 78, 417-419.

Bertler, A., Jeppsson, P. G., Nordgren, L., and Rosengren, E. (1971). Serial determinations of homovanillinic acid in the cerebrospinal fluid of Parkinson patients treated with L-dopa. Acta Neurol. Scand. 47, 393-402. doi: 10.1111/j.16000404.1971.tb07494.x 
Beyer, M. K., Alves, G., Hwang, K. S., Babakchanian, S., Bronnick, K. S., Chou, Y. Y., et al. (2013). Cerebrospinal fluid A $\beta$ levels correlate with structural brain changes in Parkinson's disease. Mov. Disord. 28, 302-310. doi: $10.1002 / \mathrm{mds} .25282$

Björkhem, I., Lövgren-Sandblom, A., Leoni, V., Meaney, S., Brodin, L., Salveson, L., et al. (2013). Oxysterols and Parkinson's disease: evidence that levels of 24Shydroxycholesterol in cerebrospinal fluid correlates with the duration of the disease. Neurosci. Lett. 555, 102-105. doi: 10.1016/j.neulet.2013.09.003

Blennow, K., Wallin, A., Agren, H., Spenger, C., Siegfried, J., and Vanmechelen, E. (1995). Tau protein in cerebrospinal fluid: a biochemical marker for axonal degeneration in Alzheimer disease? Mol. Chem. Neuropathol. 26, 231-245. doi: 10.1007/BF02815140

Blum-Degen, D., Müller, T., Kuhn, W., Gerlach, M., Przuntek, H., and Riederer, P. (1995). Interleukin-1 beta and interleukin-6 are elevated in the cerebrospinal fluid of Alzheimer's and de novo Parkinson's disease. Neurosci. Lett. 202, 17-20. doi: 10.1016/0304-3940(95)12192-7

Boll, M. C., Alcaraz-Zubeldia, M., Montes, S., and Rios, C. (2008). Free copper, ferroxidase and SOD1 activities, lipid peroxidation and $\mathrm{NO}(\mathrm{x})$ content in the CSF. A different marker profile in four neurodegenerative diseases. Neurochem. Res. 33, 1717-1723. doi: 10.1007/s11064-008-9610-3

Boll, M. C., Sotelo, J., Otero, E., Alcaraz-Zubeldia, M., and Rios, C. (1999). Reduced ferroxidase activity in the cerebrospinal fluid from patients with Parkinson's disease. Neurosci. Lett. 265, 155-158. doi: 10.1016/S0304-3940(99)00221-9

Bonnet, A. M., Tell, G., Schechter, P. J., Grove, J., Saint-Hilaire, M. H., De Smet, Y., et al. (1987). Cerebrospinal fluid GABA and homocarnosine concentrations in patients with Friedreich's ataxia, Parkinson's disease, and Huntington's chorea. Mov. Disord. 2, 117-123. doi: 10.1002/mds.870020206

Borghi, R., Marchese, R., Negro, A., Marinelli, L., Forloni, G., Zaccheo, D., et al. (2000). Full length alpha-synuclein is present in cerebrospinal fluid from Parkinson's disease and normal subjects. Neurosci. Lett. 287, 65-67. doi: 10.1016/S0304-3940(00)01153-8

Borroni, B., Gardoni, F., Parnetti, L., Magno, L., Malinverno, M., Saggese, E., et al. (2009). Pattern of Tau forms in CSF is altered in progressive supranuclear palsy. Neurobiol. Aging 30, 34-40. doi: 10.1016/j.neurobiolaging.2007.05.009

Borroni, B., Malinverno, M., Gardoni, F., Alberici, A., Parnetti, L., Premi, E., et al. (2008). Tau forms in CSF as a reliable biomarker for progressive supranuclear palsy. Neurology 71, 1796-1803. doi: 10.1212/01.wnl.0000335941.68602.39

Bridoux, A., Moutereau, S., Covali-Noroc, A., Margarit, L., Palfi, S., Nguyen, J. P., et al. (2013). Ventricular orexin-A (hypocretin-1) levels correlate with rapideye-movement sleep without atonia in Parkinson's disease. Nat. Sci. Sleep 5, 87-91. doi: 10.2147/NSS.S41245

Buhmann, C., Arlt, S., Kontush, A., Möller-Bertram, T., Sperber, S., Oechsner, M., et al. (2004). Plasma and CSF markers of oxidative stress are increased in Parkinson's disease and influenced by antiparkinsonian medication. Neurobiol. Dis. 15, 160-170. doi: 10.1016/j.nbd.2003.10.003

Burns, R. S., LeWitt, P. A., Ebert, M. H., Pakkenberg, H., and Kopin, I. J. (1985). The clinical syndrome of striatal dopamine deficiency. Parkinsonism induced by 1-methyl-4-phenyl-1,2,3,6-tetrahydropyridine (MPTP). N. Engl. J. Med. 312, 1418-1421. doi: 10.1056/NEJM198505303122203

Campanella, G., Carrieri, P., Romito, D., and Pasqual-Marsettin, E. (1973). Iron, transferrin, copper and ceruloplasmin of the serum and cerebrospinal fluid in extrapyramidal diseases and primary myopathies. Study in basic conditions and in Parkinsonism after treatment with dopaminergic agents (L-dopa, L-dopa + RO 4-4602, amantadine). Acta Neurol. (Napoli) 28, 1-34.

Carvey, P. M., McRae, A., Lint, T. F., Ptak, L. R., Lo, E. S., Goetz, C. G., et al. (1991). The potential use of a dopamine neuron antibody and a striatal-derived neurotrophic factor as diagnostic markers in Parkinson's disease. Neurology 41(5 Suppl. 2), 53-58. discussion: 59-60. doi: 10.1212/WNL.41.5_Suppl_2.53

Casati, C., Agnoli, A., Jori, A., and Dolfini, E. (1973). On the relationship between L-DOPA therapy and CSF monoamine metabolites in Parkinson's disease. Z. Neurol. 204, 149-154.

Chase, T. N. (1970). Cerebrospinal fluid monoamine metabolites and peripheral decarboxylase inhibitors in parkinsonism. Neurology 20(Suppl.), 36-40. doi: 10.1212/WNL.20.12_Part_2.36

Cheng, F. C., Kuo, J. S., Chia, L. G., and Dryhurst, G. (1996). Elevated 5S-cysteinyldopamine/homovanillic acid ratio and reduced homovanillic acid in cerebrospinal fluid: possible markers for and potential insights into the pathoetiology of Parkinson's disease. J Neural Transm 103, 433-446. doi: 10.1007/BF01276419
Chia, L. G., Cheng, F. C., and Kuo, J. S. (1993). Monoamines and their metabolites in plasma and lumbar cerebrospinal fluid of Chinese patients with Parkinson's disease. J. Neurol. Sci. 116, 125-134. doi: 10.1016/0022-510X(93)90316-Q

Christensen, S. E., Dupont, E., Mondrup, K., Olivarius, B. F., and Orskov, H. (1984). Parkinson's disease and benign essential tremor: somatostatin-like immunoreactivity in the cerebrospinal fluid. Adv. Neurol. 40, 325-331.

Chu, A. B., Sever, J. L., Madden, D. L., Iivanainen, M., Leon, M., Wallen, W., et al. (1983). Oligoclonal IgG bands in cerebrospinal fluid in various neurological diseases. Ann. Neurol. 13, 434-439. doi: 10.1002/ana.410130410

Compta, Y., Ezquerra, M., Muñoz, E., Tolosa, E., Valldeoriola, F., Rios, J., et al. (2011). High cerebrospinal tau levels are associated with the rs242557 tau gene variant and low cerebrospinal $\beta$-amyloid in Parkinson disease. Neurosci. Lett. 487, 169-173. doi: 10.1016/j.neulet.2010.10.015

Compta, Y., Martí, M. J., Ibarretxe-Bilbao, N., Junqué, C., Valldeoriola, F., Muñoz, E., et al. (2009b). Cerebrospinal tau, phospho-tau, and beta-amyloid and neuropsychological functions in Parkinson's disease. Mov. Disord. 24, 2203-2210. doi: $10.1002 / \mathrm{mds} .22594$

Compta, Y., Pereira, J. B., Ríos, J., Ibarretxe-Bilbao, N., Junqué, C., Bargalló, N., et al. (2013). Combined dementia-risk biomarkers in Parkinson's disease: a prospective longitudinal study. Parkinsonism Relat. Disord. 19, 717-724. doi: 10.1016/j.parkreldis.2013.03.009

Compta, Y., Santamaria, J., Ratti, L., Tolosa, E., Iranzo, A., Muñoz, E., et al. (2009a). Cerebrospinal hypocretin, daytime sleepiness and sleep architecture in Parkinson's disease dementia. Brain 132, 3308-3317. doi: 10.1093/brain/awp263

Constantinescu, R., Andreasson, U., Holmberg, B., and Zetterberg, H. (2013). Serum and cerebrospinal fluid urate levels in synucleinopathies versus tauopathies. Acta Neurol. Scand. 127, e8-e12. doi: 10.1111/ane.12012

Constantinescu, R., Rosengren, L., Johnels, B., Zetterberg, H., and Holmberg, B. (2010). Consecutive analyses of cerebrospinal fluid axonal and glial markers in Parkinson's disease and atypical Parkinsonian disorders. Parkinsonism Relat. Disord. 16, 142-145. doi: 10.1016/j.parkreldis.2009.07.007

Covicković-Sternić, N., Kostić, V. S., Djuricić, B. M., Bumbasirević-Beslać, L., Nikolić, M., and Mrsulja, B. B. (1987). Cyclic nucleotides in cerebrospinal fluid of drug-free Parkinson patients. Eur. Neurol. 27, 24-28. doi: 10.1159/000116124

Cox, B., Danta, G., Schnieden, H., and Yuill, G. M. (1973). Interactions of L-dopa and amantadine in patients with Parkinsonism. J. Neurol. Neurosurg. Psychiatry 36, 354-361. doi: 10.1136/jnnp.36.3.354

Cramer, H., Jost, S., Reuner, C., Milios, E., Geiger, J., and Mundinger, F. (1991). Ventricular fluid neuropeptides in Parkinson's disease. II. Levels of substance P-like immunoreactivity. Neuropeptides 18, 69-73. doi: 10.1016/01434179(91)90002-Z

Cramer, H., Ng, L. K., and Chase, T. N. (1973). Adenosine 3',5'-monophosphate in cerebrospinal fluid. Effect of drugs and neurologic disease. Arch. Neurol. 29, 197-199. doi: 10.1001/archneur.1973.00490270079014

Cramer, H., Rissler, K., Rösler, N., Strubel, D., Schaudt, D., and Kuntzmann, F. (1989). Immunoreactive substance $P$ and somatostatin in the cerebrospinal fluid of senile parkinsonian patients. Eur. Neurol. 29, 1-5. doi: 10.1159/000116366

Cramer, H., Warter, J. M., and Renaud, B. (1984). Analysis of neurotransmitter metabolites and adenosine 3',5'-monophosphate in the CSF of patients with extrapyramidal motor disorders. Adv. Neurol. 40, 431-435.

Cramer, H., Wolf, A., Rissler, K., Weigel, K., and Ostertag, C. (1985). Ventricular somatostatin-like immunoreactivity in patients with basal ganglia disease. J. Neurol. 232, 219-222. doi: 10.1007/BF00313783

Cunha, L., Gonçalves, A. F., Oliveira, C., Dinis, M., and Amaral, R. (1983) Homovanillic acid in the cerebrospinal fluid of Parkinsonian patients. Can. J. Neurol. Sci. 10, 43-46.

Curzon, G., Godwin-Austen, R. B., Tomlinson, E. B., and Kantamaneni, B. D. (1970). The cerebrospinal fluid homovanillic acid concentration in patients with Parkinsonism treated with L-dopa. J. Neurol. Neurosurg. Psychiatry 33, 1-6. doi: 10.1136/jnnp.33.1.1

Davidson, D. L., Yates, C. M., Mawdsley, C., Pullar, I. A., and Wilson, H. (1977). CSF studies on the relationship between dopamine and 5-hydroxytryptamine in Parkinsonism and other movement disorders. J. Neurol. Neurosurg. Psychiatry 40, 1136-1141. doi: 10.1136/jnnp.40.12.1136

De Deyn, P. P., Hiramatsu, M., Borggreve, F., Goeman, J., D'Hooge, R., Saerens, J., et al. (1998). Superoxide dismutase activity in cerebrospinal fluid of patients with dementia and some other neurological disorders. Alzheimer Dis. Assoc. Disord. 12, 26-32. doi: 10.1097/00002093-19980300000004 
de Jong, P. J., Lakke, J. P., and Teelken, A. W. (1984). CSF GABA levels in Parkinson's disease. Adv. Neurol. 40, 427-430.

de la Monte, S. M., Volicer, L., Hauser, S. L., and Wands, J. R. (1992). Increased levels of neuronal thread protein in cerebrospinal fluid of patients with Alzheimer's disease. Ann. Neurol. 32, 733-742. doi: 10.1002/ana.410320606

Dexter, D. T., Carayon, A., Vidailhet, M., Ruberg, M., Agid, F., Agid, Y., et al. (1990). Decreased ferritin levels in brain in Parkinson's disease. J. Neurochem. 55, 16-20. doi: 10.1111/j.1471-4159.1990.tb08814.x

di Michele, F., Longone, P., Romeo, E., Lucchetti, S., Brusa, L., Pierantozzi, M., et al. (2003). Decreased plasma and cerebrospinal fluid content of neuroactive steroids in Parkinson's disease. Neurol. Sci. 24, 172-173. doi: 10.1007/s10072003-0115-1

Dissing, I. C., Güttler, F., Pakkenberg, H., Lou, H., Gerdes, A. M., Lykkelund, C., et al. (1989). Tetrahydrobiopterin and Parkinson's disease. Acta Neurol. Scand. 79, 493-499. doi: 10.1111/j.1600-0404.1989.tb03820.x

Drouot, X., Moutereau, S., Lefaucheur, J. P., Palfi, S., Covali-Noroc, A., Margarit, L., et al. (2011). Low level of ventricular CSF orexin-A is not associated with objecttive sleepiness in PD. Sleep Med. 12, 936-937. doi: 10.1016/j.sleep.2011.08.002

Drouot, X., Moutereau, S., Nguyen, J. P., Lefaucheur, J. P., Créange, A., Remy, P., et al. (2003). Low levels of ventricular CSF orexin/hypocretin in advanced PD. Neurology 61, 540-543. doi: 10.1212/01.WNL.0000078194.53210.48

Dupont, E., Christensen, S. E., Hansen, A. P., de Fine Olivarius, B., and Orskov, H. (1982). Low cerebrospinal fluid somatostatin in Parkinson disease: an irreversible abnormality. Neurology 32, 312-314. doi: 10.1212/WNL.32.3.312

Durso, R., Evans, J. E., Josephs, E., Szabo, G. K., Evans, B. A., Handler, J. S., et al. (1997). Central levodopa metabolism in Parkinson's disease after administration of stable isotope-labeled levodopa. Ann. Neurol. 42, 300-304. doi: 10.1002/ana.410420305

Durso, R., Szabo, G., Davoudi, H., and Feldman, R. G. (1989). Magnitude of response to levodopa in Parkinson disease as it relates to peripheral and central measurements of levodopa and associated metabolites. Clin. Neuropharmacol. 12, 384-392. doi: 10.1097/00002826-198910000-00003

Duvoisin, R. C., and Dettbarn, W. D. (1967). Cerebrospinal fluid acetylcholine in man. Neurology 17, 1077-1081. doi: 10.1212/WNL.17.11.1077

Eder, U., Leitner, B., Kirchmair, R., Pohl, P., Jobst, K. A., Smith, A. D., et al. (1998). Levels and proteolytic processing of chromogranin A and B and secretogranin II in cerebrospinal fluid in neurological diseases. J. Neural Transm. 105, 39-51. doi: $10.1007 /$ s007020050036

Eldrup, E., Mogensen, P., Jacobsen, J., Pakkenberg, H., and Christensen, N. J. (1995). CSF and plasma concentrations of free norepinephrine, dopamine, 3,4dihydroxyphenylacetic acid (DOPAC), 3,4-dihydroxyphenylalanine (DOPA), and epinephrine in Parkinson's disease. Acta Neurol. Scand. 92, 116-121. doi: 10.1111/j.1600-0404.1995.tb01023.x

Engelborghs, S., Marescau, B., and De Deyn, P. P. (2003). Amino acids and biogenic amines in cerebrospinal fluid of patients with Parkinson's disease. Neurochem. Res. 28, 1145-1150. doi: 10.1023/A:1024255208563

Enna, S. J., Stern, L. Z., Wastek, G. J., and Yamamura, H. I. (1977). Cerebrospinal fluid gamma-aminobutyric acid variations in neurological disorders. Arch. Neurol. 34, 683-685. doi: 10.1001/archneur.1977.00500230053008

Ernst, A., Cramer, H., Strubel, D., Kuntzmann, F., and Schoenenberger, G. A. (1987). Comparison of DSIP- (delta sleep-inducing peptide) and P-DSIPlike (phosphorylated) immunoreactivity in cerebrospinal fluid of patients with senile dementia of Alzheimer type, multi-infarct syndrome, communicating hydrocephalus and Parkinson's disease. J. Neurol. 235, 16-21. doi: 10.1007/BF00314191

Espino, A., Ambrosio, S., Bartrons, R., Bendahan, G., and Calopa, M. (1994). Cerebrospinal monoamine metabolites and amino acid content in patients with parkinsonian syndrome and rats lesioned with MPP+. J. Neural Transm. Park. Dis. Dement. Sect. 7, 167-176 doi: 10.1007/BF02253436

Espino, A., Calopa, M., Ambrosio, S., Ortolà, J., Peres, J., and Navarro, M. A. (1995). CSF somatostatin increase in patients with early parkinsonian syndrome. J. Neural Transm. Park. Dis. Dement. Sect. 9, 189-196. doi: 10.1007/BF02259660

Fernández, E., García-Moreno, J. M., Martín de Pablos, A., and Chacón, J. (2013). May the evaluation of nitrosative stress through selective increase of 3nitrotyrosine proteins other than nitroalbumin and dominant tyrosine-125/136 nitrosylation of serum $\alpha$-synuclein serve for diagnosis of sporadic Parkinson's disease? Antioxid. Redox Signal. 19, 912-918. doi: 10.1089/ars.2013.5250

Ferrarese, C., Appollonio, I., Frigo, M., Meregalli, S., Piolti, R., Tamma, F., et al. (1990). Cerebrospinal fluid levels of diazepam-binding inhibitor in neurodegenerative disorders with dementia. Neurology 40, 632-635. doi: 10.1212/WNL.40.4.632

Ferrero, P., Benna, P., Costa, P., Tarenzi, L., Baggio, G., Bergamasco, B., et al. (1988). Diazepam binding inhibitor-like immunoreactivity (DBI-LI) in human CSF. Correlations with neurological disorders. J. Neurol. Sci. 87, 327-349. doi: 10.1016/0022-510X(88)90257-2

Finehout, E. J., Franck, Z., and Lee, K. H. (2005). Complement protein isoforms in CSF as possible biomarkers for neurodegenerative disease. Dis. Markers 21, 93-101. doi: 10.1155/2005/806573

Fiszer, U., Fredrikson, S., and Członkowska, A. (1996). Humoral response to hsp 65 and hsp 70 in cerebrospinal fluid in Parkinson's disease. J. Neurol. Sci. 139, 66-70. doi: 10.1016/0022-510X(96)00002-0

Fiszer, U., Mix, E., Fredrikson, S., Kostulas, V., and Link, H. (1994a). Parkinson's disease and immunological abnormalities: increase of HLA-DR expression on monocytes in cerebrospinal fluid and of CD45RO+ T cells in peripheral blood. Acta Neurol. Scand. 90, 160-166. doi: 10.1111/j.1600-0404.1994.tb02699.x

Fiszer, U., Mix, E., Fredrikson, S., Kostulas, V., Olsson, T., and Link, H. (1994b). gamma delta+ $\mathrm{T}$ cells are increased in patients with Parkinson's disease. J. Neurol. Sci. 121, 39-45. doi: 10.1016/0022-510X(94)90154-6

Forte, G., Bocca, B., Senofonte, O., Petrucci, F., Brusa, L., Stanzione, P., et al. (2004). Trace and major elements in whole blood, serum, cerebrospinal fluid and urine of patients with Parkinson's disease. J. Neural Transm. 111, 1031-1040. doi: 10.1007/s00702-004-0124-0

Foulds, P. G., Yokota, O., Thurston, A., Davidson, Y., Ahmed, Z., Holton, J., et al. (2012). Post mortem cerebrospinal fluid $\alpha$-synuclein levels are raised in multiple system atrophy and distinguish this from the other $\alpha$-synucleinopathies, Parkinson's disease and Dementia with Lewy bodies. Neurobiol. Dis. 45, 188-195. doi: 10.1016/j.nbd.2011.08.003

Friedman, A. (1985). [Drug-induced dyskinesia during the treatment of Parkinson disease-biochemical studies]. Neurol. Neurochir. Pol. 19, 401-403.

Fronczek, R., Overeem, S., Lee, S. Y., Hegeman, I. M., van Pelt, J., van Duinen, S. G., et al. (2007). Hypocretin (orexin) loss in Parkinson's disease. Brain 130, 1577-1585. doi: 10.1093/brain/awm090

Fujishiro, K., Hagihara, M., Takahashi, A., and Nagatsu, T. (1990). Concentrations of neopterin and biopterin in the cerebrospinal fluid of patients with Parkinson's disease. Biochem. Med. Metab. Biol. 44, 97-100. doi: 10.1016/08854505(90)90049-7

Fukuda, H., Nakamura, S., Hara, K., Udaka, F., and Kameyama, M. (1989). [Study on the concentration of 5-hydroxyindoleacetic acid (5-HIAA) in the lumbar cerebrospinal fluid (CSF) in neurological diseases]. Rinsho Shinkeigaku 29, 1192-1194.

Furukawa, Y., Kondo, T., Nishi, K., Yokochi, F., and Narabayashi, H. (1991). Total biopterin levels in the ventricular CSF of patients with Parkinson's disease: a comparison between akineto-rigid and tremor types. J. Neurol. Sci. 103, 232-237. doi: 10.1016/0022-510X(91)90169-8

Furukawa, Y., Nishi, K., Kondo, T., Mizuno, Y., and Narabayashi, H. (1992). Juvenile parkinsonism: ventricular CSF biopterin levels and clinical features. J. Neurol. Sci. 108, 207-213. doi: 10.1016/0022-510X(92)90053-N

Galard, R., Catalán, R., Montalbán, J., Molins, A., Miquel, F., and Castellanos, J. M. (1992). Neurokinin concentrations in cerebrospinal fluid. A preliminary study in Parkinson's disease. Eur. J. Clin. Chem. Clin. Biochem. 30, 281-284.

Gazzaniga, G. C., Ferraro, B., Camerlingo, M., Casto, L., Viscardi, M., and Mamoli, A. (1992). A case control study of CSF copper, iron and manganese in Parkinson disease. Ital. J. Neurol. Sci. 13, 239-243. doi: 10.1007/BF02224396

Gibson, C. J., Logue, M., and Growdon, J. H. (1985). CSF monoamine metabolite levels in Alzheimer's and Parkinson's disease. Arch. Neurol. 42, 489-492. doi: 10.1001/archneur.1985.04060050091016

Gjessing, L. R., Gjesdahl, P., Dietrichson, P., and Presthus, J. (1974). Free amino acids in the cerebrospinal fluid in old age and in Parkinson's disease. Eur. Neurol. 12, 33-37. doi: 10.1159/000114602

Godwin-Austen, R. B., Kantamaneni, B. D., and Curzon, G. (1971). Comparison of benefit from L-dopa in Parkinsonism with increase of amine metabolites in the CSF. J. Neurol. Neurosurg. Psychiatry 34, 219-223. doi: 10.1136/jnnp.34.3.219

Goldstein, D. S., Holmes, C., Bentho, O., Sato, T., Moak, J., Sharabi, Y., et al. (2008). Biomarkers to detect central dopamine deficiency and distinguish Parkinson disease from multiple system atrophy. Parkinsonism Relat. Disord. 14, 600-607. doi: 10.1016/j.parkreldis.2008.01.010

González-Quevedo, A., García, J. C., Fernández, R., and Fernández Cartaya, L. (1993). Monoamine metabolites in normal human cerebrospinal fluid and in 
degenerative diseases of the central nervous system. Bol. Estud. Med. Biol. 41, 13-19.

Gottfries, C. G., Gottfries, I., and Roos, B. E. (1969). Homovanillic acid and 5 -hydroxyindoleacetic acid in the cerebrospinal fluid of patients with senile dementia, presenile dementia and parkinsonism. J. Neurochem. 16, 1341-1345. doi: 10.1111/j.1471-4159.1969.tb05984.x

Granerus, A. K., Magnusson, T., Roos, B. E., and Svanborg, A. (1974). Relationship of age and mood to monoamine metabolites in cerebrospinal fluid in parkinsonism. Eur. J. Clin. Pharmacol. 7, 105-109. doi: 10.1007/BF00 561323

Gründig, E., and Gerstenbrand, F. (1980). [Comparison between the effects of L-dopa, prodipine and amantadine on the serum and CSF amino acid levels in Parkinson's disease (author's transl)]. Wien. Klin. Wochenschr. 92, 868-871.

Guldberg, H. C., Turner, J. W., Hanieh, A., Ashcroft, G. W., Crawford, T. B., Perry, W. L., et al. (1967). On the occurrence of homovanillic acid and 5-hydroxyindol3 -ylacetic acid in the ventricular C.S.F. of patients suffering from parkinsonism. Confin. Neurol. 29, 73-77. doi: 10.1159/000103680

Gumpert, J., Sharpe, D., and Curzon, G. (1973). Amine metabolites in the cerebrospinal fluid in Parkinson's disease and the response to levodopa. J. Neurol. Sci. 19, 1-12. doi: 10.1016/0022-510X(73)90050-6

Guo, J., Sun, Z., Xiao, S., Liu, D., Jin, G., Wang, E., et al. (2009). Proteomic analysis of the cerebrospinal fluid of Parkinson's disease patients. Cell Res. 19, 1401-1403. doi: 10.1038/cr.2009.131

Hagihara, M., and Nagatsu, T. (1987). Post-proline cleaving enzyme in human cerebrospinal fluid from control patients and parkinsonian patients. Biochem. Med. Metab. Biol. 38, 387-391. doi: 10.1016/0885-4505(87)90103-4

Hagihara, M., Mihara, R., Togari, A., and Nagatsu, T. (1987). Dipeptidylaminopeptidase II in human cerebrospinal fluid: changes in patients with Parkinson's disease. Biochem. Med. Metab. Biol. 37, 360-365. doi: 10.1016/08854505(87)90049-1

Hall, S., Öhrfelt, A., Constantinescu, R., Andreasson, U., Surova, Y., Bostrom, F., et al. (2012). Accuracy of a panel of 5 cerebrospinal fluid biomarkers in the differential diagnosis of patients with dementia and/or parkinsonian disorders. Arch. Neurol. 69, 1445-1452. doi: 10.1001/archneurol.2012.1654

Hartikainen, P., Reinikainen, K. J., Soininen, H., Sirviö, J., Soikkeli, R., and Riekkinen, P. J. (1992). Neurochemical markers in the cerebrospinal fluid of patients with Alzheimer's disease, Parkinson's disease and amyotrophic lateral sclerosis and normal controls. J. Neural Transm. Park. Dis. Dement. Sect. 4, 53-68. doi: 10.1007/BF02257622

Herbert, M. K., Eeftens, J. M., Aerts, M. B., Esselink, R. A., Bloem, B. R., Kuiperij, H. B., et al. (2014). CSF levels of DJ-1 and tau distinguish MSA patients from PD patients and controls. Parkinsonism Relat. Disord. 20, 112-115. doi: 10.1016/j.parkreldis.2013.09.003

Holmberg, B., Johnels, B., Blennow, K., and Rosengren, L. (2003). Cerebrospinal fluid Abeta42 is reduced in multiple system atrophy but normal in Parkinson's disease and progressive supranuclear palsy. Mov. Disord. 18, 186-190. doi: $10.1002 / \mathrm{mds} .10321$

Holmberg, B., Rosengren, L., Karlsson, J. E., and Johnels, B. (1998). Increased cerebrospinal fluid levels of neurofilament protein in progressive supranuclear palsy and multiple-system atrophy compared with Parkinson's disease. Mov. Disord. 13, 70-77. doi: 10.1002/mds.870130116

Hong, Z., Shi, M., Chung, K. A., Quinn, J. F., Peskind, E. R., Galasko, D., et al. (2010). DJ-1 and alpha-synuclein in human cerebrospinal fluid as biomarkers of Parkinson's disease. Brain 133, 713-726. doi: 10.1093/brain/ awq008

Hozumi, I., Hasegawa, T., Honda, A., Ozawa, K., Hayashi, Y., Hashimoto, K., et al. (2011). Patterns of levels of biological metals in CSF differ among neurodegenerative diseases. J. Neurol. Sci. 303, 95-99. doi: 10.1016/j.jns.2011.01.003

Hurst, J. H., LeWitt, P. A., Burns, R. S., Foster, N. L., and Lovenberg, W. (1985). CSF dopamine-beta-hydroxylase activity in Parkinson's disease. Neurology 35, 565-568. doi: 10.1212/WNL.35.4.565

Iacono, R. P., Kuniyoshi, S. M., Ahlman, J. R., Zimmerman, G. J., Maeda, G., and Pearlstein, R. D. (1997). Concentrations of indoleamine metabolic intermediates in the ventricular cerebrospinal fluid of advanced Parkinson's patients with severe postural instability and gait disorders. J. Neural Transm. 104, 451-459. doi: 10.1007/BF01277663

Ikeda, M., Sato, I., Yuasa, T., Miyatake, T., and Murota, S. (1995). Nitrite, nitrate and cGMP in the cerebrospinal fluid in degenerative neurologic diseases. J. Neural Transm. Gen. Sect. 100, 263-267. doi: 10.1007/BF01276464
Ilic, T. V., Jovanovic, M., Jovicic, A., and Tomovic, M. (1999). Oxidative stress indicators are elevated in de novo Parkinson's disease patients. Funct. Neurol. 14, 141-147.

Ilić, T., Jovanović, M., Jovicić, A., and Tomović, M. (1998). Oxidative stress and Parkinson's disease. Vojnosanit. Pregl. 55, 463-468.

Irkeç, C., Ercan, S., and Irkeç, M. (1989). Leukotrienes and neurological diseases. Mikrobiyol. Bul. 23, 342-347.

Ishibashi, K., Kanemaru, K., Saito, Y., Murayama, S., Oda, K., Ishiwata, K., et al. (2010). Cerebrospinal fluid metabolite and nigrostriatal dopaminergic function in Parkinson's disease. Acta Neurol. Scand. 122, 46-51. doi: 10.1111/j.16000404.2009.01255.x

Isobe, C., Abe, T., and Terayama, Y. (2010a). L-Dopa therapy increases homocysteine concentration in cerebrospinal fluid from patients with Parkinson's disease. J. Clin. Neurosci. 17, 717-721. doi: 10.1016/j.jocn.2009.09.034

Isobe, C., Abe, T., and Terayama, Y. (2010b). Levels of reduced and oxidized coenzyme Q-10 and 8-hydroxy-2'-deoxyguanosine in the cerebrospinal fluid of patients with living Parkinson's disease demonstrate that mitochondrial oxidative damage and/or oxidative DNA damage contributes to the neurodegenerative process. Neurosci. Lett. 469, 159-163. doi: 10.1016/j.neulet.2009.11.065

Isobe, C., Murata, T., Sato, C., and Terayama, Y. (2005). Increase of total homocysteine concentration in cerebrospinal fluid in patients with Alzheimer's disease and Parkinson's disease. Life Sci. 77, 1836-1843. doi: 10.1016/j.lfs.2005.02.014

Isobe, C., Murata, T., Sato, C., and Terayama, Y. (2007). Increase of oxidized/total coenzyme Q-10 ratio in cerebrospinal fluid in patients with Parkinson's disease. J. Clin. Neurosci. 14, 340-343. doi: 10.1016/j.jocn.2005.12.023

Jakowec, M. W., Petzinger, G. M., Sastry, S., Donaldson, D. M., McCormack, A., and Langston, J. W. (1998). The native form of alpha-synuclein is not found in the cerebrospinal fluid of patients with Parkinson's disease or normal controls. Neurosci. Lett. 253, 13-16. doi: 10.1016/S0304-3940(98)00599-0

Jansen Steur, E., Vermes, I., and de Vos, R. A. (1998). Cerebrospinal-fluid tau protein and aspartate aminotransferase in Parkinson's disease. Lancet 351, 1105-1106. doi: 10.1016/S0140-6736(05)79387-9

Jellinger, K. A. (2012). CSF biomarkers in different phenotypes of Parkinson disease. J. Neural Transm. 119, 455-456. doi: 10.1007/s00702-011-0736-0

Jesse, S., Lehnert, S., Jahn, O., Parnetti, L., Soininen, H., Herukka, S. K., et al. (2012). Differential sialylation of serpin A1 in the early diagnosis of Parkinson's disease dementia. PLoS ONE 7:e48783. doi: 10.1371/journal.pone.0048783

Jiménez-Jiménez, F. J., Molina, J. A., Aguilar, M. V., Meseguer, I., Mateos-Vega, C. J., González-Muñoz, M. J., et al. (1998). Cerebrospinal fluid levels of transition metals in patients with Parkinson's disease. J. Neural Transm. 105, 497-505.

Jiménez-Jiménez, F. J., Molina, J. A., Hernánz, A., Fernández-Vivancos, E., de Bustos, F., Barcenilla, B., et al. (1999). Cerebrospinal fluid levels of thiamine in patients with Parkinson's disease. Neurosci. Lett. 271, 33-36. doi: 10.1016/S03043940(99)00515-7

Jiménez-Jiménez, F. J., Molina, J. A., Vargas, C., Gómez, P., De Bustos, F., Zurdo, M., et al. (2000). Normal cerebrospinal fluid levels of insulin in patients with Parkinson's disease. J. Neural Transm. 107, 445-449. doi: 10.1007/s0070200 50015

Jiménez-Jiménez, F. J., Molina, J. A., Vargas, C., Gómez, P., Navarro, J. A., BenitoLeón, J., et al. (1996). Neurotransmitter amino acids in cerebrospinal fluid of patients with Parkinson's disease. J. Neurol. Sci. 141, 39-44. doi: 10.1016/0022510X(96)00115-3

Jiménez-Jiménez, F. J., Rubio, J. C., Molina, J. A., Martín, M. A., Campos, Y., Benito-León, J., et al. (1997). Cerebrospinal fluid carnitine levels in patients with Parkinson's disease. J. Neurol. Sci. 145, 183-185. doi: 10.1016/S0022510X(96)00259-6

Jiménez-Jiménez, F. J., Trejo Gabriel y Galán, J. M., and Fuentes, J. A. (1994). Neuropéptidos y enfermedad de Parkinson. Rev. Neurol. 22, 5-11

Johansson, B., and Roos, B. E. (1967). 5-hydroxyindoleacetic and homovanillic acid levels in the cerebrospinal fluid of healthy volunteers and patients with Parkinson's syndrome. Life Sci. 6, 1449-1454. doi: 10.1016/00243205(67)90193-2

Johansson, B., and Roos, B. E. (1971). 5-Hydroxyindoleacetic acid in cerebrospinal fluid of patients with Parkinson's syndrome treated with L dopa. Eur. J. Clin. Pharmacol. 3, 232-235. doi: 10.1007/BF00565012

Jolkkonen, J. T., Soininen, H. S., and Riekkinen, P. J. (1987). beta-Endorphinlike immunoreactivity in cerebrospinal fluid of patients with Alzheimer's disease and Parkinson's disease. J. Neurol. Sci. 77, 153-159. doi: 10.1016/0022510X(87)90118-3 
Jolkkonen, J., Soininen, H., Halonen, T., Ylinen, A., Laulumaa, V., Laakso, M., et al. (1986). Somatostatin-like immunoreactivity in the cerebrospinal fluid of patients with Parkinson's disease and its relation to dementia. J. Neurol. Neurosurg. Psychiatry 49, 1374-1377. doi: 10.1136/jnnp.49.12.1374

Jost, S., Reuner, C., Mohadjer, M., Mundinger, F., and Cramer, H. (1990). Ventricular fluid neuropeptides in Parkinson's disease. I. Levels and distribution of somatostatin-like immunoreactivity. Neuropeptides 15, 219-225. doi: 10.1016/0143-4179(90)90016-R

Kanemaru, K., Mitani, K., and Yamanouchi, H. (1998). Cerebrospinal fluid homovanillic acid levels are not reduced in early corticobasal degeneration. Neurosci. Lett. 245, 121-122. doi: 10.1016/S0304-3940(98)00181-5

Kang, J. H., Irwin, D. J., Chen-Plotkin, A. S., Siderowf, A., Caspell, C., Coffey, C. S., et al. (2013). Association of cerebrospinal fluid $\beta$-amyloid 1-42, T-tau, Ptau181, and $\alpha$-synuclein levels with clinical features of drug-naive patients with early Parkinson disease. JAMA Neurol. 70, 1277-1287. doi: 10.1001/jamaneurol.2013.3861

Kikuchi, A., Takeda, A., Onodera, H., Kimpara, T., Hisanaga, K., Sato, N., et al. (2002). Systemic increase of oxidative nucleic acid damage in Parkinson's disease and multiple system atrophy. Neurobiol. Dis. 9, 244-248. doi: 10.1006/nbdi.2002.0466

Konings, C. H., Kuiper, M. A., Bergmans, P. L., Grijpma, A. M., van Kamp, G. J., and Wolters, E. C. (1994). Increased angiotensin-converting enzyme activity in cerebrospinal fluid of treated patients with Parkinson's disease. Clin. Chim. Acta 231, 101-106. doi: 10.1016/0009-8981(94)90259-3

Konings, C. H., Kuiper, M. A., Mulder, C., Calliauw, J., and Wolters, E. C. (1995). CSF acetylcholinesterase in Parkinson disease: decreased enzyme activity and immunoreactivity in demented patients. Clin. Chim. Acta 235, 101-105. doi: 10.1016/0009-8981(95)06004-9

Konings, C. H., Kuiper, M. A., Teerlink, T., Mulder, C., Scheltens, P., and Wolters, E. C. (1999). Normal cerebrospinal fluid glutathione concentrations in Parkinson's disease, Alzheimer's disease and multiple system atrophy. J. Neurol. Sci. 168, 112-115. doi: 10.1016/S0022-510X(99)00167-7

Koshiba, S., Tokuoka, H., Yokoyama, T., Horiuchi, E., Ichinose, H., and Hasegawa, K. (2011). Biopterin levels in the cerebrospinal fluid of patients with PARK8 (I2020T). J. Neural Transm. 118, 899-903 doi: 10.1007/s00702-011-0587-8

Kostić, V. S., Djuricić, B. M., Covicković-Sternić, N., Bumbasirević, L., Nikolić, M., and Mrsulja, B. B. (1987). Depression and Parkinson's disease: possible role of serotonergic mechanisms. J. Neurol. 234, 94-96. doi: 10.1007/BF00314109

Kotake, Y., Tasaki, Y., Makino, Y., Ohta, S., and Hirobe, M. (1995). 1-Benzyl-1,2,3,4tetrahydroisoquinoline as a parkinsonism-inducing agent: a novel endogenous amine in mouse brain and parkinsonian CSF. J. Neurochem. 65, 2633-2638. doi: 10.1046/j.1471-4159.1995.65062633.x

Krygowska-Wajs, A., Szczudlik, A., Antkiewicz-Michaluk, L., Romańska, I., and Vetulani, J. (1997). Salsolinol, 3-O-methyl-dopa and homovanillic acid in the cerebrospinal fluid of Parkinson patients. Neurol. Neurochir. Pol. 31, 875-885.

Kuhn, W., Müller, T., Gerlach, M., Sofic, E., Fuchs, G., Heye, N., et al. (1996a). Depression in Parkinson's disease: biogenic amines in CSF of "de novo" patients. J. Neural Transm. 103, 1441-1445. doi: 10.1007/BF01271258

Kuhn, W., Müller, T., Grosse, H., and Rommelspacher, H. (1996b). Elevated levels of harman and norharman in cerebrospinal fluid of parkinsonian patients. J. Neural Transm. 103, 1435-1440. doi: 10.1007/BF01271257

Kuiper, M. A., Mulder, C., van Kamp, G. J., Scheltens, P., and Wolters, E. C. (1994a). Cerebrospinal fluid ferritin levels of patients with Parkinson's disease, Alzheimer's disease, and multiple system atrophy. J. Neural Transm. Park. Dis. Dement. Sect. 7, 109-114. doi: 10.1007/BF02260965

Kuiper, M. A., Teerlink, T., Visser, J. J., Bergmans, P. L., Scheltens, P., and Wolters, E. C. (2000). L-glutamate, L-arginine and L-citrulline levels in cerebrospinal fluid of Parkinson's disease, multiple system atrophy, and Alzheimer's disease patients. J. Neural Transm. 107, 183-189. doi: 10.1007/s007020050016

Kuiper, M. A., Visser, J. J., Bergmans, P. L., Scheltens, P., and Wolters, E. C. (1994b). Decreased cerebrospinal fluid nitrate levels in Parkinson's disease, Alzheimer's disease and multiple system atrophy patients. J. Neurol. Sci. 121, 46-49. doi: 10.1016/0022-510X(94)90155-4

Kuroda, H. (1983). Gamma-aminobutyric acid (GABA) in cerebrospinal fluid. Acta Med. Okayama 37, 167-177.

Kuroda, H., Ogawa, N., Yamawaki, Y., Nukina, I., Ofuji, T., Yamamoto, M., et al. (1982). Cerebrospinal fluid GABA levels in various neurological and psychiatric diseases. J. Neurol. Neurosurg. Psychiatry 45, 257-260. doi: 10.1136/jnnp.45.3.257
Lakke, J. P., and Teelken, A. W. (1976). Amino acid abnormalities in cerebrospinal fluid of patients with parkinsonism and extrapyramidal disorders. Neurology 26, 489-493. doi: 10.1212/WNL.26.5.489

Lakke, J. P., Teelken, A. W., vd Voet, H., and Wolthers, B. G. (1987). Amino acid abnormalities in cerebrospinal fluid and blood serum of patients with Parkinson's disease, other heredodegenerative disorders and head injuries. $A d v$. Neurol. 45, 243-247.

Lee, P. H., Lee, G., and Paik, M. J. (2008). Polyunsaturated fatty acid levels in the cerebrospinal fluid of patients with Parkinson's disease and multiple system atrophy. Mov. Disord. 23, 309-310. doi: 10.1002/mds.21846

LeWitt, P. A., Li, J., Lu, M., Beach, T. G., Adler, C. H., and Guo, L. (2013). Arizona Parkinson's Disease Consortium. 3-hydroxykynurenine and other Parkinson's disease biomarkers discovered by metabolomic analysis. Mov. Disord. 28, 1653-1660. doi: 10.1002/mds. 25555

LeWitt, P., Schultz, L., Auinger, P., and Lu, M. (2011). Parkinson Study Group DATATOP Investigators. CSF xanthine, homovanillic acid, and their ratio as biomarkers of Parkinson's disease. Brain Res. 1408, 88-97. doi: 10.1016/j.brainres.2011.06.057

Lipman, I. J., and Papadopoulos, N. M. (1973). Cerebrospinal fluid N-acetyl neuraminic acid in Parkinson's disease, before and after L-dopa therapy. Dis. Nerv. Syst. 34, 59-62.

Liu, D. K. (1989). The concentration of homovanillic acid and leucine-enkephalin in the lumbar CSF of patients with Parkinson's disease before and after madopar treatment. Zhonghua Shen Jing Jing Shen Ke Za Zhi 22, 95-98; 126-127.

Liu, H., Iacono, R. P., Schoonenberg, T., Kuniyoshi, S., and Buchholz, J. (1999). A comparative study on neurochemistry of cerebrospinal fluid in advanced Parkinson's disease. Neurobiol. Dis. 6, 35-42. doi: 10.1006/nbdi.1998.0222

Loeffler, D. A., DeMaggio, A. J., Juneau, P. L., Brickman, C. M., Mashour, G. A., Finkelman, J. H., et al. (1994). Ceruloplasmin is increased in cerebrospinal fluid in Alzheimer's disease but not Parkinson's disease. Alzheimer Dis. Assoc. Disord. 8, 190-197. doi: 10.1097/00002093-199408030-00005

Lotstra, F., Verbanck, P. M., Gilles, C., Mendlewicz, J., and Vanderhaeghen, J. J. (1985). Reduced cholecystokinin levels in cerebrospinal fluid of parkinsonian and schizophrenic patients. Ann. N.Y. Acad. Sci. 448, 507-517. doi: 10.1111/j.1749-6632.1985.tb29944.x

Lovenberg, W., Levine, R. A., Robinson, D. S., Ebert, M., Williams, A. C., and Calne, D. B. (1979). Hydroxylase cofactor activity in cerebrospinal fluid of normal subjects and patients with Parkinson's disease. Science 204, 624-626. doi: $10.1126 /$ science. 432666

Lunardi, G., Galati, S., Tropepi, D., Moschella, V., Brusa, L., Pierantozzi, M., et al. (2009). Correlation between changes in CSF dopamine turnover and development of dyskinesia in Parkinson's disease. Parkinsonism Relat. Disord. 15, 383-389. doi: 10.1016/j.parkreldis.2008.10.001

Maarouf, C. L., Beach, T. G., Adler, C. H., Shill, H. A., Sabbagh, M. N. Wu, T., et al. (2012). Cerebrospinal fluid biomarkers of neuropathologically diagnosed Parkinson's disease subjects. Neurol Res. 34, 669-676. doi: 10.1179/1743132812Y.0000000063

Maetzler, W., Berg, D., Schalamberidze, N., Melms, A., Schott, K., Mueller, J. C., et al. (2007). Osteopontin is elevated in Parkinson's disease and its absence leads to reduced neurodegeneration in the MPTP model. Neurobiol. Dis. 25, 473-482 doi: 10.1016/j.nbd.2006.10.020

Maetzler, W., Tian, Y., Baur, S. M., Gauger, T., Odoj, B., Schmid, B., et al. (2012). Serum and cerebrospinal fluid levels of transthyretin in Lewy body disorders with and without dementia. PLOS ONE 7:e48042. doi: 10.1371/journal.pone.0048042

Mally, J., Szalai, G., and Stone, T. W. (1997). Changes in the concentration of amino acids in serum and cerebrospinal fluid of patients with Parkinson's disease. J. Neurol. Sci. 151, 159-162. doi: 10.1016/S0022-510X(97)00119-6

Mann, J. J., Stanley, M., Kaplan, R. D., Sweeney, J., and Neophytides, A. (1983). Central catecholamine metabolism in vivo and the cognitive and motor deficits in Parkinson's disease. J. Neurol. Neurosurg. Psychiatry 46, 905-910. doi: 10.1136/jnnp.46.10.905

Manyam, B. V. (1982). Low CSF gamma-aminobutyric acid levels in Parkinson's Disease. Effect of levodopa and carbidopa. Arch. Neurol. 39, 391-392 doi: 10.1001/archneur.1982.00510190009002

Manyam, B. V., and Tremblay, R. D. (1984). Free and conjugated GABA in human cerebrospinal fluid: effect of degenerative neurologic diseases and isoniazid. Brain Res. 307, 217-223. doi: 10.1016/0006-8993(84) 90475-X 
Manyam, B. V., Ferraro, T. N., and Hare, T. A. (1988). Cerebrospinal fluid amino compounds in Parkinson's disease. Alterations due to carbidopa/levodopa. Arch. Neurol. 45, 48-50. doi: 10.1001/archneur.1988.00520250054021

Manyam, B. V., Giacobini, E., and Colliver, J. A. (1990). Cerebrospinal fluid choline levels are decreased in Parkinson's disease. Ann. Neurol. 27, 683-685. doi: 10.1002/ana.410270616

Manyam, N. V., Katz, L., Hare, T. A., Gerber, J. C. 3rd., and Grossman, M. H. (1980). Levels of gamma-aminobutyric acid in cerebrospinal fluid in various neurologic disorders. Arch. Neurol. 37, 352-355. doi: 10.1001/archneur. 1980.00500550054006

Mariani, S., Ventriglia, M., Simonelli, I., Donno, S., Bucossi, S., Vernieri, F., et al. (2013). Fe and $\mathrm{Cu}$ do not differ in Parkinson's disease: replication study plus meta-analysis. Neurobiol. Aging 34, 632-633. doi: 10.1016/j.neurobiolaging.2012.05.015

Martignoni, E., Blandini, F., Petraglia, F., Pacchetti, C., Bono, G., and Nappi, G. (1992). Cerebrospinal fluid norepinephrine, 3-methoxy-4-hydroxyphenylglycol and neuropeptide Y levels in Parkinson's disease, multiple system atrophy and dementia of the Alzheimer type. J. Neural Transm. Park. Dis. Dement. Sect. 4 191-205. doi: 10.1007/BF02260903

Marttila, R. J., Lorentz, H., and Rinne, U. K. (1988). Oxygen toxicity protecting enzymes in Parkinson's disease. Increase of superoxide dismutase-like activity in the substantia nigra and basal nucleus. J. Neurol. Sci. 86, 321-331. doi: 10.1016/0022-510X(88)90108-6

Maruyama, W., Abe, T., Tohgi, H., Dostert, P., and Naoi, M. (1996). A dopaminergic neurotoxin, (R)-N-methylsalsolinol, increases in Parkinsonian cerebrospinal fluid. Ann. Neurol. 40, 119-122. doi: 10.1002/ana.410400120

Maruyama, W., Abe, T., Tohgi, H., and Naoi, M. (1999). An endogenous MPTPlike dopaminergic neurotoxin, $\mathrm{N}$-methyl(R)salsolinol, in the cerebrospinal fluid decreases with progression of Parkinson's disease. Neurosci. Lett. 262, 13-16. doi: 10.1016/S0304-3940(99)00003-8

Maruyama, W., Naoi, M., and Narabayashi, H. (1994). The effect of droxidopa on the monoamine metabolsim in the human brain. Rinsho Shinkeigaku 34 985-990.

Mashayekhi, F., Mirzajani, E., Naji, M., and Azari, M. (2010). Expression of insulinlike growth factor-1 and insulin-like growth factor binding proteins in the serum and cerebrospinal fluid of patients with Parkinson's disease. J. Clin. Neurosci. 17, 623-627. doi: 10.1016/j.jocn.2009.08.013

Mashige, F., Takai, N., Matsushima, Y., Ito, A., Takano, M., Tsuchiya, E., et al (1994). Simultaneous determination of catecholamines, serotonin, and their precursors and metabolites in body fluid by an HPLC system with multielectrode electrochemical detector. Rinsho Byori 42, 591-599.

Masson, H., Popescu, I., Strubel, D., Cramer, H., and Kuntzmann, F. (1990). Somatostatin-like immunoreactivity in the cerebrospinal fluid of aged patients with Parkinson's disease. The effect of dopatherapy. J. Am. Geriatr. Soc. 38, 19-24.

Matsubara, K., Kobayashi, S., Kobayashi, Y., Yamashita, K., Koide, H., Hatta, M., et al. (1995). beta-Carbolinium cations, endogenous MPP+ analogs, in the lumbar cerebrospinal fluid of patients with Parkinson's disease. Neurology 45 2240-2245. doi: 10.1212/WNL.45.12.2240

Matsui, H., Kato, T., Yamamoto, C., Fujita, K., and Nagatsu, T. (1981). Highly sensitive assay for dopamine-beta-hydroxylase activity in human cerebrospinal fluid by high performance liquid chromatography- electrochemical detection properties of the enzyme. J. Neurochem. 37, 289-296. doi: 10.1111/j.14714159.1981.tb00454.x

Mayeux, R., Stern, Y., Cote, L., and Williams, J. B. (1984). Altered serotonin metabolism in depressed patients with Parkinson's disease. Neurology 34, 642-646. doi: 10.1212/WNL.34.5.642

Mayeux, R., Stern, Y., Sano, M., Cote, L., and Williams, J. B. (1987). Clinical and biochemical correlates of bradyphrenia in Parkinson's disease. Neurology 37, 1130-1134. doi: 10.1212/WNL.37.7.1130

Mayeux, R., Stern, Y., Sano, M., Williams, J. B., and Cote, L. J. (1988). The relationship of serotonin to depression in Parkinson's disease. Mov. Disord. 3, 237-244. doi: $10.1002 / \mathrm{mds} .870030308$

Mayeux, R., Stern, Y., Williams, J. B., Cote, L., Frantz, A., and Dyrenfurth, I. (1986). Clinical and biochemical features of depression in Parkinson's disease. Am. J. Psychiatry 143, 756-759.

McLellan, D. L., Chalmers, R. J., and Johnson, R. H. (1975). Clinical and pharmacological evaluation of the effects of piribedil in patients with parkinsonism. Acto Neurol. Scand. 51, 74-82. doi: 10.1111/j.1600-0404.1975.tb01360.x
Mena, M. A., Aguado, E. G., and de Yebenes, J. G. (1984). Monoamine metabolites in human cerebrospinal fluid. HPLC/ED method. Acta Neurol. Scand. 69, 218-225. doi: 10.1111/j.1600-0404.1984.tb07804.x

Meyne, F., Gloeckner, S. F., Ciesielczyk, B., Heinemann, U., Krasnianski, A., Meissner, B., et al. (2009). Total prion protein levels in the cerebrospinal fluid are reduced in patients with various neurological disorders. J. Alzheimers Dis. 17, 863-873. doi: 10.3233/JAD-2009-1110

Mogi, M., and Nagatsu, T. (1999). Neurotrophins and cytokines in Parkinson's disease. Adv. Neurol. 80, 135-139.

Mogi, M., Harada, M., Kojima, K., Adachi, T., Narabayashi, H., Fujita, K., et al. (1989). Beta 2-microglobulin decrease in cerebrospinal fluid from Parkinsonian patients. Neurosci. Lett. 104, 241-246. doi: 10.1016/0304-3940(89)90361-3

Mogi, M., Harada, M., Kondo, T., Mizuno, Y., Narabayashi, H., Riederer, P., et al. (1996b). bcl-2 protein is increased in the brain from parkinsonian patients. Neurosci. Lett. 215, 137-139. doi: 10.1016/0304-3940(96)12961-X

Mogi, M., Harada, M., Kondo, T., Narabayashi, H., Riederer, P., and Nagatsu, T. (1995). Transforming growth factor-beta 1 levels are elevated in the striatum and in ventricular cerebrospinal fluid in Parkinson's disease. Neurosci. Lett. 193, 129-132. doi: 10.1016/0304-3940(95)11686-Q

Mogi, M., Harada, M., Narabayashi, H., Inagaki, H., Minami, M., and Nagatsu, T. (1996a). Interleukin (IL)-1 beta, IL-2, IL-4, IL-6 and transforming growth factor-alpha levels are elevated in ventricular cerebrospinal fluid in juvenile parkinsonism and Parkinson's disease. Neurosci. Lett. 211, 13-16. doi: 10.1016/0304-3940(96)12706-3

Mogi, M., Harada, M., Riederer, P., Narabayashi, H., Fujita, K., and Nagatsu, T. (1994). Tumor necrosis factor-alpha (TNF-alpha) increases both in the brain and in the cerebrospinal fluid from parkinsonian patients. Neurosci. Lett. 165, 208-210. doi: 10.1016/0304-3940(94)90746-3

Molina, J. A., Benito-León, J., Jiménez-Jiménez, F. J., Ortí-Pareja, M., Berbel, A., Tallón-Barranco, A., et al. (1997c). Tau protein concentrations in cerebrospinal fluid of non-demented Parkinson's disease patients. Neurosci. Lett. 238, 139-141. doi: 10.1016/S0304-3940(97)00858-6

Molina, J. A., de Bustos, F., Jiménez-Jiménez, F. J., Benito-León, J., Ortí-Pareja M., Gasalla, T., et al. (1997b). Cerebrospinal fluid levels of alpha-tocopherol (vitamin E) in Parkinson's disease. J. Neural Transm. 104, 1287-1293. doi: 10.1007/BF01294729

Molina, J. A., Jiménez-Jiménez, F. J., Gomez, P., Vargas, C., Navarro, J. A., OrtíPareja, M., et al. (1997a). Decreased cerebrospinal fluid levels of neutral and basic amino acids in patients with Parkinson's disease. J. Neurol. Sci. 150, 123-127. doi: 10.1016/S0022-510X(97)00069-5

Molina, J. A., Jiménez-Jiménez, F. J., Navarro, J. A., Vargas, C., Gómez, P., Benito-León, J., et al. (1996). Cerebrospinal fluid nitrate levels in patients with Parkinson's disease. Acta Neurol. Scand. 93, 123-126. doi: 10.1111/j.1600 0404.1996.tb00186.x

Molina, J. A., Jiménez-Jiménez, F. J., Ortí-Pareja, M., and Navarro, J. A. (1998). The role of nitric oxide in neurodegeneration: potential for pharmacological intervention. Drugs Aging 12, 251-259. doi: 10.2165/00002512-199812040-00001

Mollenhauer, B., Locascio, J. J., Schulz-Schaeffer, W., Sixel-Döring, F., Trenkwalder, C., and Schlossmacher, M. G. (2011). $\alpha$-Synuclein and tau concentrations in cerebrospinal fluid of patients presenting with parkinsonism: a cohort study. Lancet Neurol. 10, 230-240. doi: 10.1016/S1474-4422(11)70014-X

Mollenhauer, B., Trautmann, E., Taylor, P., Manninger, P., Sixel-Döring, F., Ebentheuer, J., et al. (2013). Total CSF $\alpha$-synuclein is lower in de novo Parkinson patients than in healthy subjects. Neurosci. Lett. 532, 44-48. doi: 10.1016/j.neulet.2012.11.004

Mollenhauer, B., Trenkwalder, C., von Ahsen, N., Bibl, M., Steinacker, P., Brechlin, P., et al. (2006). Beta-amlyoid 1-42 and tau-protein in cerebrospinal fluid of patients with Parkinson's disease dementia. Dement. Geriatr. Cogn. Disord. 22, 200-208. doi: 10.1159/000094871

Mondello, S., Constantinescu, R., Zetterberg, H., Andreasson, U., Holmberg, B. and Jeromin, A. (2014). CSF $\alpha$-synuclein and UCH-L1 levels in Parkinson's disease and atypical parkinsonian disorders. Parkinsonism Relat. Disord. 20, 382-387. doi: 10.1016/j.parkreldis.2014.01.011

Mones, R. J. (1973). An analysis of six patients with Parkinson's disease who have been unresponsive to L-dopa therapy. J. Neurol. Neurosurg. Psychiatry 36, 362-367. doi: 10.1136/jnnp.36.3.362

Mones, R. J., Wilk, S., Green, J., and Jutkowitz, R. (1972). A study of spinal fluid homovanillic acid (HVA) in patients with diseases of the nervous system. Mt Sinai J. Med. 39, 478-485. 
Montine, T. J., Shi, M., Quinn, J. F., Peskind, E. R., Craft, S., Ginghina, C., et al. (2010). CSF A $\beta(42)$ and tau in Parkinson's disease with cognitive impairment. Mov. Disord. 25, 2682-2685. doi: 10.1002/mds.23287

Moser, A., and Kömpf, D. (1992). Presence of methyl-6,7-dihydroxy-1,2,3,4tetrahydroisoquinolines, derivatives of the neurotoxin isoquinoline, in parkinsonian lumbar CSF. Life Sci. 50, 1885-1891. doi: 10.1016/0024-3205(92)90549-5

Moser, A., Scholz, J., Nobbe, F., Vieregge, P., Böhme, V., and Bamberg, H. (1995). Presence of N-methyl-norsalsolinol in the CSF: correlations with dopamine metabolites of patients with Parkinson's disease. J. Neurol. Sci. 131, 183-189. doi: 10.1016/0022-510X(95)00110-N

Moser, A., Siebecker, F., Vieregge, P., Jaskowski, P., and Kömpf, D. (1996). Salsolinol, catecholamine metabolites, and visual hallucinations in L-dopa treated patients with Parkinson's disease. J. Neural Transm. 103, 421-432. doi: 10.1007/BF01276418

Moussa, Z., Raftopoulos, C., Przedborski, S., and Hildebrand, J. (1992). Lack of changes in ventricular cerebrospinal fluid concentrations of homovanillic acid following acute challenge with levodopa. Ann. Neurol. 31, 113-115. doi: 10.1002/ana.410310124

Müller, T., Blum-Degen, D., Przuntek, H., and Kuhn, W. (1998). Interleukin-6 levels in cerebrospinal fluid inversely correlate to severity of Parkinson's disease. Acta Neurol. Scand. 98, 142-144. doi: 10.1111/j.1600-0404.1998.tb01736.x

Müller, T., Przuntek, H., Kuhn, W., Baum, S. S., and Rommelspacher, H. (1999a). No increase of synthesis of (R)salsolinol in Parkinson's disease. Mov. Disord. 14, 514-515.

Müller, T., Sällström Baum, S., Häussermann, P., Przuntek, H., Rommelspacher, H., and Kuhn, W. (1999b). R- and S-salsolinol are not increased in cerebrospinal fluid of Parkinsonian patients. J. Neurol. Sci. 164, 158-162. doi: 10.1016/S0022510X(99)00058-1

Naoi, M., and Maruyama, W. (1999). N-methyl(R)salsolinol, a dopamine neurotoxin, in Parkinson's disease. Adv. Neurol. 80, 259-264.

Nappi, G., Petraglia, F., Martignoni, E., Facchinetti, F., Bono, G., and Genazzani, A. R. (1985). beta-Endorphin cerebrospinal fluid decrease in untreated parkinsonian patients. Neurology 35, 1371-1374. doi: 10.1212/WNL.35.9.1371

Nasr, A., Bertrand, N., Giroud, M., Septien, L., Gras, P., Dumas, R., et al. (1993). Cerebrospinal fluid choline levels in Parkinson's disease. Ann. Neurol. 34, 114-115. doi: 10.1002/ana.410340122

Navarro, J. A., Jiménez-Jiménez, F. J., Molina, J. A., Benito-León, J., Cisneros, E., Gasalla, T., et al. (1998). Cerebrospinal fluid cyclic guanosine 3'5' monophosphate levels in Parkinson's disease. J. Neurol. Sci. 155, 92-94. doi: 10.1016/S0022-510X(97)00267-0

Nielsen, H. M., Hall, S., Surova, Y., Nägga, K., Nilsson, C., Londos, E., et al. (2014). Low levels of soluble NG2 in cerebrospinal fluid from patients with dementia with Lewy bodies. J. Alzheimers Dis. 40, 343-350. doi: 10.3233/JAD-132246

Nishi, K., Kondo, T., Narabayashi, H., Takubo, H., Muramoto, S., and Araki, H. (1989). Unresponsiveness to L-DOPA in parkinsonian patients: a study of homovanillic acid concentration in the cerebrospinal fluid. J. Neurol. Sci. 92, 65-70. doi: 10.1016/0022-510X(89)90175-5

Nutu, M., Bourgeois, P., Zetterberg, H., Portelius, E., Andreasson, U., Parent, S., et al. (2013b). A $\beta 1-15 / 16$ as a potential diagnostic marker in neurodegenerative diseases. Neuromolecular Med. 15, 169-179. doi: 10.1007/s12017-012-8208-8

Nutu, M., Zetterberg, H., Londos, E., Minthon, L., Nägga, K., Blennow, K., et al. (2013a). Evaluation of the cerebrospinal fluid amyloid- $\beta 1-42 /$ amyloid$\beta 1-40$ ratio measured by alpha-LISA to distinguish Alzheimer's disease from other dementia disorders. Dement. Geriatr. Cogn. Disord. 36, 99-110. doi: 10.1159/000353442

Oeckl, P., Steinacker, P., Lehnert, S., Jesse, S., Kretzschmar, H. A., Ludolph, A. C., et al. (2012). CSF concentrations of cAMP and cGMP are lower in patients with Creutzfeldt-Jakob disease but not Parkinson's disease and amyotrophic lateral sclerosis. PLoS ONE 7:e32664. doi: 10.1371/journal.pone.0032664

Ohrfelt, A., Grognet, P., Andreasen, N., Wallin, A., Vanmechelen, E., Blennow, K., et al. (2009). Cerebrospinal fluid alpha-synuclein in neurodegenerative disorders-a marker of synapse loss? Neurosci. Lett. 450, 332-335. doi: 10.1016/i.neulet.2008.11.015

Olsson, B., Constantinescu, R., Holmberg, B., Andreasen, N., Blennow, K., and Zetterberg, H. (2013). The glial marker YKL-40 is decreased in synucleinopathies. Mov. Disord. 28, 1882-1885. doi: 10.1002/mds.25589

Olsson, J. E., Forsling, M. L., Lindvall, B., and Akerlund, M. (1987). Cerebrospinal fluid arginine vasopressin in Parkinson's disease, dementia, and other degenerative disorders. Adv. Neurol. 45, 239-242.
Olsson, R., and Roos, B. E. (1968). Concentrations of 5-hydroxyindoleacetic acid and homovanillic acid in the cerebrospinal fluid after treatment with probenecid in patients with Parkinson's disease. Nature 219, 502-503. doi: 10.1038/219502a0

Paik, M. J., Ahn, Y. H., Lee, P. H., Kang, H., Park, C. B., Choi, S., et al. (2010). Polyamine patterns in the cerebrospinal fluid of patients with Parkinson's disease and multiple system atrophy. Clin. Chim. Acta 411, 1532-1535. doi: 10.1016/j.cca.2010.05.034

Pålhagen, S., Qi, H., Mårtensson, B., Wålinder, J., Granérus, A. K., and Svenningsson, P. (2010). Monoamines, BDNF, IL-6 and corticosterone in CSF in patients with Parkinson's disease and major depression. J. Neurol. 257, 524-532. doi: 10.1007/s00415-009-5353-6

Pall, H. S., Brailsford, S., Williams, A. C., Lunec, J., and Blake, D. R. (1990) Ferritin in the cerebrospinal fluid of patients with Parkinson's disease. J. Neurol. Neurosurg. Psychiatry 53, 803. doi: 10.1136/jnnp.53.9.803

Pall, H. S., Williams, A. C., Blake, D. R., Lunec, J., Gutteridge, J. M., Hall, M., et al. (1987). Raised cerebrospinal-fluid copper concentration in Parkinson's disease. Lancet 2, 238-241. doi: 10.1016/S0140-6736(87)90827-0

Pan, B. Y., Cheng, Q. L., He, Z. X., and Su, C. C. (1997). “Transition metals in serum and CSF of patients with Parkinson's disease," in Poster P125, XIIth International Symposium on Parkinson's disease, London, March 23-26. Mov. Disord. 12(Suppl. 1), 33.

Pankonin, M. S., Sohi, J., Kamholz, J., and Loeb, J. A. (2009). Differential distribution of neuregulin in human brain and spinal fluid. Brain Res. 1258, 1-11. doi: 10.1016/j.brainres.2008.12.047

Papeschi, R., Molina-Negro, P., Sourkes, T. L., and Erba, G. (1972). The concentration of homovanillic and 5-hydroxyindoleacetic acids in ventricular and lumbar CSF. Studies in patients with extrapyramidal disorders, epilepsy, and other diseases. Neurology 22, 1151-1159. doi: 10.1212/WNL.22.11.1151

Papeschi, R., Molina-Negro, P., Sourkes, T. L., Hardy, J., and Bertrand, C. (1970). Concentration of homovanillic acid in the ventricular fluid of patients with Parkinson's disease and other dyskinesias. Neurology 20, 991-995. doi: 10.1212/WNL.20.10.991

Park, M. J., Cheon, S. M., Bae, H. R., Kim, S. H., and Kim, J. W. (2011). Elevated levels of $\alpha$-synuclein oligomer in the cerebrospinal fluid of drug-naïve patients with Parkinson's disease. J. Clin. Neurol. 7, 215-222. doi: 10.3988/jcn.2011.7.4.215

Parnetti, L., Chiasserini, D., Bellomo, G., Giannandrea, D., De Carlo, C., Qureshi, M. M., et al. (2011). Cerebrospinal fluid Tau/ $\alpha$-synuclein ratio in Parkinson's disease and degenerative dementias. Mov. Disord. 26, 1428-1435. doi: $10.1002 / \mathrm{mds} .23670$

Parnetti, L., Chiasserini, D., Persichetti, E., Eusebi, P., Varghese, S., Qureshi, M. M., et al. (2014a). Cerebrospinal fluid lysosomal enzymes and $\alpha$-synuclein in Parkinson's disease. Mov. Disord. 29, 1019-1027. doi: 10.1002/mds.25772

Parnetti, L., Farotti, L., Eusebi, P., Chiasserini, D., De Carlo, C., Giannandrea, D., et al. (2014b). Differential role of CSF alpha-synuclein species, tau, and A 342 in Parkinson's Disease. Front. Aging Neurosci. 6:53. doi: 10.3389/fnagi.2014.00053

Parnetti, L., Tiraboschi, P., Lanari, A., Peducci, M., Padiglioni, C., D’Amore, C., et al. (2008). Cerebrospinal fluid biomarkers in Parkinson's disease with dementia and dementia with Lewy bodies. Biol. Psychiatry 64, 850-855. doi: 10.1016/j.biopsych.2008.02.016

Perschak, H., Amsler, U., Vischer, A., Siegfried, J., and Cuénod, M. (1987). Ventricular cerebrospinal fluid concentrations of putative amino acid transmitters in Parkinson's disease and other disorders. Hum. Neurobiol. 6, 191-194.

Pezzoli, G., Panerai, A. E., Di Giulio, A., Longo, A., Passerini, D., and Carenzi, A. (1984). Methionine-enkephalin, substance P, and homovanillic acid in the CSF of parkinsonian patients. Neurology 34, 516-519. doi: 10.1212/WNL.34.4.516

Pirttila, T., Mehta, P. D., Frey, H., and Wisniewski, H. M. (1994). Alpha 1antichymotrypsin and IL-1 beta are not increased in CSF or serum in Alzheimer's disease. Neurobiol. Aging 15, 313-317.

Pisani, A., Fezza, F., Galati, S., Battista, N., Napolitano, S., Finazzi-Agrò, A., et al. (2005). High endogenous cannabinoid levels in the cerebrospinal fluid of untreated Parkinson's disease patients. Ann. Neurol. 57, 777-779. doi: 10.1002/ana.20462

Pisani, V., Moschella, V., Bari, M., Fezza, F., Galati, S., Bernardi, G., et al. (2010). Dynamic changes of anandamide in the cerebrospinal fluid of Parkinson's disease patients. Mov. Disord. 25, 920-924. doi: 10.1002/mds.23014

Poewe, W., Benke, T., Karamat, E., Schelosky, L., Wagner, M., and Sperk, G. (1990). CSF somatostatin-like immunoreactivity in dementia of Parkinson's disease. J. Neurol. Neurosurg. Psychiatry 53, 1105-1106. doi: 10.1136/jnnp.53.12.1105-a 
Prell, G. D., and Green, J. P. (1991). Histamine metabolites and prosmethylimidazoleacetic acid in human cerebrospinal fluid. Agents Actions Suppl. 33, 343-363.

Prell, G. D., Khandelwal, J. K., Burns, R. S., Blandina, P., Morrishow, A. M., and Green, J. P. (1991). Levels of pros-methylimidazoleacetic acid: correlation with severity of Parkinson's disease in CSF of patients and with the depletion of striatal dopamine and its metabolites in MPTP-treated mice. J. Neural Transm. Park. Dis. Dement. Sect. 3, 109-125. doi: 10.1007/BF02260886

Přikrylová Vranová, H., Mareš, J., Hluštík, P., Nevrlý, M., Stejskal, D., Zapletalová, J., et al. (2012). Tau protein and beta- amyloid(1-42) CSF levels in different phenotypes of Parkinson's disease. J. Neural Transm. 119, 353-362. doi: 10.1007/s00702-011-0708-4

Přikrylová Vranová, H., Mareš, J., Nevrlý, M., Stejskal, D., Zapletalová, J., Hluštík, P., et al. (2010). CSF markers of neurodegeneration in Parkinson's disease. J. Neural Transm. 117, 1177-1181. doi: 10.1007/s00702-010-0462-Z

Pullar, I. A., Dowson, J. H., Ahmed, R., Chow, R., and Gillingham, F. J. (1972). Biochemical investigations in Parkinsonism. A study of the metabolites of the biogenic amines in the lumbar CSF. Confin. Neurol. 34, 143-148 doi 10.1159/000103047

Qureshi, G. A., Baig, S., Bednar, I., Södersten, P., Forsberg, G., and Siden, A. (1995). Increased cerebrospinal fluid concentration of nitrite in Parkinson's disease. Neuroreport 6, 1642-1644. doi: 10.1097/00001756-199508000-00013

Qureshi, G. A., Qureshi, A. A., Memon, S. A., and Parvez, S. H. (2006). Impact of selenium, iron, copper and zinc in on/off Parkinson's patients on L-dopa therapy. J. Neural Transm. Suppl. 71, 229-236. doi: 10.1007/978-3-211-33328-0_24

Rainero, I., Kaye, J. A., May, C., Durso, R., Katz, D. I., Albert, M. L., et al. (1988). Alpha-melanocyte-stimulating hormonelike immunoreactivity is increased in cerebrospinal fluid of patients with Parkinson's disease. Arch. Neurol. 45, 1224-1227. doi: 10.1001/archneur.1988.00520350062017

Rinne, U. K., Marttila, R., and Sonninen, V. (1977). Brain dopamine turnover and the relief of parkinsonism. Arch. Neurol. 34, 626-629. doi: 10.1001/archneur.1977.00500220060010

Rinne, U. K., and Sonninen, V. (1972). Acid monoamine metabolites in the cerebrospinal fluid of patients with Parkinson's disease. Neurology 22, 62-67. doi: 10.1212/WNL.22.1.62

Rinne, U. K., Sonninen, V., and Marttila, R. (1975). Dopaminergic agonist effects on Parkinsonian clinical features and brain monamine metabolism. Adv. Neurol. 9, 383-392.

Rinne, U. K., Sonninen, V., and Siirtola, T. (1973). Acid monoamine metabolites in the cerebrospinal fluid of Parkinsonian patients treated with levodopa alone or combined with a decarboxylase inhibitor. Eur. Neurol. 9, 349-362. doi: $10.1159 / 000114243$

Rota, E., Bellone, G., Rocca, P., Bergamasco, B., Emanuelli, G., and Ferrero, P. (2006). Increased intrathecal TGF-beta1, but not IL-12, IFN-gamma and IL-10 levels in Alzheimer's disease patients. Neurol. Sci. 27, 33-39. doi: 10.1007/s10072-006-0562-6

Ruberg, M., Rieger, F., Villageois, A., Bonnet, A. M., and Agid, Y. (1986). Acetylcholinesterase and butyrylcholinesterase in frontal cortex and cerebrospinal fluid of demented and non-demented patients with Parkinson's disease. Brain Res. 362, 83-91. doi: 10.1016/0006-8993(86)91401-0

Salehi, Z., and Mashayekhi, F. (2009). Brain-derived neurotrophic factor concentrations in the cerebrospinal fluid of patients with Parkinson's disease. J. Clin. Neurosci. 16, 90-93. doi: 10.1016/j.jocn.2008.03.010

Selley, M. L. (1998). (E)-4-hydroxy-2-nonenal may be involved in the pathogenesis of Parkinson's disease. Free Radic. Biol. Med. 25, 169-174. doi: 10.1016/S08915849(98)00021-5

Sharpless, N. S., Thal, L. J., Perlow, M. J., Tabaddor, K., Waltz, J. M., Shapiro, K. N., et al. (1984). Vasoactive intestinal peptide in cerebrospinal fluid. Peptides 5 , 429-433. doi: 10.1016/0196-9781(84)90248-1

Shi, M., Bradner, J., Hancock, A. M., Chung, K. A., Quinn, J. F., Peskind, E. R., et al. (2011). Cerebrospinal fluid biomarkers for Parkinson's disease diagnosis and progression. Ann. Neurol. 69, 570-580. doi: 10.1002/ana.22311

Shi, M., Furay, A. R., Sossi, V., Aasly, J. O., Armaly, J., Wang, Y., et al. (2012). DJ-1 and $\alpha$ SYN in LRRK2 CSF do not correlate with striatal dopaminergic function. Neurobiol. Aging 33, 836 e5-e7. doi: 10.1016/j.neurobiolaging.2011.09.015

Shukla, R., Rajani, M., Srivastava, N., Barthwal, M. K., and Dikshit, M. (2006). Nitrite and malondialdehyde content in cerebrospinal fluid of patients with Parkinson's disease. Int. J. Neurosci. 116, 1391-1402. doi: $10.1080 / 00207450500513989$
Siderowf, A., Xie, S. X., Hurtig, H., Weintraub, D., Duda, J., Chen-Plotkin, A., et al. (2010). CSF amyloid \{beta\} 1-42 predicts cognitive decline in Parkinson disease. Neurology 75, 1055-1061. doi: 10.1212/WNL.0b013e3181f39a78

Sirviö, J., Soininen, H. S., Kutvonen, R., Hyttinen, J. M., Helkala, E. L., and Riekkinen, P. J. (1987). Acetyl- and butyrylcholinesterase activity in the cerebrospinal fluid of patients with Parkinson's disease. J. Neurol. Sci. 81, 273-279. doi: 10.1016/0022-510X(87)90102-X

Sjögren, M., Davidsson, P., Wallin, A., Granérus, A. K., Grundström, E., Askmark, H., et al. (2002). Decreased CSF-beta-amyloid 42 in Alzheimer's disease and amyotrophic lateral sclerosis may reflect mismetabolism of beta-amyloid induced by disparate mechanisms. Dement. Geriatr. Cogn. Disord. 13, 112-118. doi: $10.1159 / 000048642$

Steen, S. N., and Thomas, J. S. (1962). Glutamic oxaloacetic transaminase in serum and cerebrospinal fluid in parkinsonism. JAMA 180, 836-837. doi: 10.1001/jama.1962.03050230038017

Stewart, T., Liu, C., Ginghina, C., Cain, K. C., Auinger, P., Cholerton, B., et al. (2014). Cerebrospinal fluid $\alpha$-synuclein predicts cognitive decline in parkinson disease progression in the DATATOP cohort. Am. J. Pathol. 184, 966-975. doi: 10.1016/j.ajpath.2013.12.007

Strittmatter, M. M., and Cramer, H. (1992). Parkinson's disease and dementia: clinical and neurochemical correlations. Neuroreport 3, 413-416. doi: 10.1097/00001756-199205000-00009

Strittmatter, M., Hamann, G. F., Strubel, D., Cramer, H., and Schimrigk, K. (1996). Somatostatin-like immunoreactivity, its molecular forms and monoaminergic metabolites in aged and demented patients with Parkinson's disease-effect of L-Dopa. J. Neural Transm. 103, 591-602. doi: 10.1007/BF01273156

Suemaru, S., Suemaru, K., Kawai, K., Miyata, S., Nobukuni, K., Ihara, Y., et al. (1995). Cerebrospinal fluid corticotropin-releasing hormone in neurodegenerative diseases: reduction in spinocerebellar degeneration. Life Sci. 57, 2231-2235. doi: 10.1016/0024-3205(95)02215-5

Sundquist, J., Forsling, M. L., Olsson, J. E., and Akerlund, M. (1983). Cerebrospinal fluid arginine vasopressin in degenerative disorders and other neurological diseases. J. Neurol. Neurosurg. Psychiatry 46, 14-17. doi: 10.1136/jnnp.46.1.14

Tabaddor, K., Wolfson, L. I., and Sharpless, N. S. (1978). Ventricular fluid homovanillic acid and 5-hydroxyindoleacetic acid concentrations in patients with movement disorders. Neurology 28, 1249-1253. doi: 10.1212/WNL.28.12.1249

Takahashi, S., Takahashi, J., Osawa, N., Abe, T., Yonezawa, H., Sera, K., et al. (1994). [Trace elements analysis of serum and cerebrospinal fluid with PIXE-effect of age and changes in parkinsonian patients]. Nihon Ronen Igakkai Zasshi 31, 865-871. doi: 10.3143/geriatrics.31.865

Tateno, F., Sakakibara, R., Kawai, T., Kishi, M., and Murano, T. (2012). Alpha-synuclein in the cerebrospinal fluid differentiates synucleinopathies (Parkinson Disease, dementia with Lewy bodies, multiple system atrophy) from Alzheimer disease. Alzheimer Dis. Assoc. Disord. 26, 213-216. doi: 10.1097/WAD.0b013e31823899cc

Teelken, A. W., van den Berg, G. A., Muskiet, F. A., Staal-Schreinemachers, A. L., Wolthers, B. G., and Lakke, J. P. (1989). Catecholamine metabolism during additional administration of DL-threo-3,4-dihydroxyphenylserine to patients with Parkinson's disease. J. Neural Transm. Park. Dis. Dement. Sect. 1, 177-188. doi: 10.1007/BF02248667

Teychenné, P. F., Ziegler, M. G., Lake, C. R., and Enna, S. J. (1982). Low CSF GABA in Parkinsonian patients who respond poorly to therapy or suffer from the "onoff" phenomenon. Ann. Neurol. 11, 76-79. doi: 10.1002/ana.410110113

Tohgi, H., Abe, T., Hashiguchi, K., Takahashi, S., Nozaki, Y., and Kikuchi, T. (1991c). A significant reduction of putative transmitter amino acids in cerebrospinal fluid of patiens with Parkinson's disease and spinocerebellar degeneration. Neurosci. Lett. 126, 155-158. doi: 10.1016/0304-3940(91)90542-2

Tohgi, H., Abe, T., Kikuchi, T., Takahashi, S., and Nozaki, Y. (1991a). The significance of 3-O-methyldopa concentrations in the cerebrospinal fluid in the pathogenesis of wearing-off phenomenon in Parkinson's disease. Neurosci. Lett. 132, 19-22. doi: 10.1016/0304-3940(91)90422-P

Tohgi, H., Abe, T., Saheki, M., Hamato, F., Sasaki, K., and Takahashi, S. (1995b). Reduced and oxidized forms of glutathione and alpha-tocopherol in the cerebrospinal fluid of parkinsonian patients: comparison between before and after L-dopa treatment. Neurosci. Lett. 184, 21-24. doi: 10.1016/03043940(94)11158-F

Tohgi, H., Abe, T., Saheki, M., Yamazaki, K., and Murata, T. (1997). Concentration of catecholamines and indoleamines in the cerebrospinal fluid of patients 
with vascular parkinsonism compared to Parkinson's disease patients. J. Neural Transm. 104, 441-449. doi: 10.1007/BF01277662

Tohgi, H., Abe, T., and Takahashi, S. (1993d). The effects of L-threo-3,4dihydroxyphenylserine on the total norepinephrine and dopamine concentrations in the cerebrospinal fluid and freezing gait in parkinsonian patients. J. Neural Transm. Park. Dis. Dement. Sect. 5, 27-34. doi: 10.1007/BF02260912

Tohgi, H., Abe, T., Takahashi, S., and Kikuchi, T. (1993e). The urate and xanthine concentrations in the cerebrospinal fluid in patients with vascular dementia of the Binswanger type, Alzheimer type dementia, and Parkinson's disease. J. Neural Transm. Park. Dis. Dement. Sect. 6, 119-126. doi: 10.1007/BF022 61005

Tohgi, H., Abe, T., Takahashi, S., Nozaki, Y., and Kikuchi, T. (1991b). Concentrations of tyrosine, L-dihydroxyphenylalanine, dopamine, and 3-Omethyldopa in the cerebrospinal fluid of Parkinson's disease. Neurosci. Lett. 127, 212-214. doi: 10.1016/0304-3940(91)90796-V

Tohgi, H., Abe, T., Takahashi, S., Takahashi, J., and Hamato, H. (1993b). Concentrations of serotonin and its related substances in the cerebrospinal fluid of parkinsonian patients and their relations to the severity of symptoms. Neurosci. Lett. 150, 71-74. doi: 10.1016/0304-3940(93)90111-W

Tohgi, H., Abe, T., Takahashi, S., Takahashi, J., and Hamato, H. (1993c). Alterations in the concentration of serotonergic and dopaminergic substances in the cerebrospinal fluid of patients with Parkinson's disease, and their changes after L-dopa administration. Neurosci. Lett. 159, 135-138. doi: 10.1016/03043940(93)90817-5

Tohgi, H., Abe, T., Takahashi, S., Takahashi, J., Nozaki, Y., Ueno, M., et al. (1993a). Monoamine metabolism in the cerebrospinal fluid in Parkinson's disease: relationship to clinical symptoms and subsequent therapeutic outcomes. J. Neural Transm. Park. Dis. Dement. Sect. 5, 17-26. doi: 10.1007/BF02260911

Tohgi, H., Abe, T., Takahashi, S., Takahashi, J., Ueno, M., and Nozaki, Y. (1990). Effect of a synthetic norepinephrine precursor, L-threo-3,4dihydroxyphenylserine on the total norepinephrine concentration in the cerebrospinal fluid of parkinsonian patients. Neurosci. Lett. 116, 194-197. doi: 10.1016/0304-3940(90)90409-3

Tohgi, H., Abe, T., Yamazaki, K., Saheki, M., Takahashi, S., and Tsukamoto, Y. (1995a). Effects of the catechol-O-methyltransferase inhibitor tolcapone in Parkinson's disease: correlations between concentrations of dopaminergic substances in the plasma and cerebrospinal fluid and clinical improvement. Neurosci. Lett. 192, 165-168. doi: 10.1016/0304-3940(95)11636-B

Tokuda, T., Qureshi, M. M., Ardah, M. T., Varghese, S., Shehab, S. A., Kasai, T., et al. (2010). Detection of elevated levels of $\alpha$-synuclein oligomers in CSF from patients with Parkinson disease. Neurology 75, 1766-1772. doi: 10.1212/WNL.0b013e3181fd613b

Tokuda, T., Salem, S. A., Allsop, D., Mizuno, T., Nakagawa, M., Qureshi, M. M., et al. (2006). Decreased alpha-synuclein in cerebrospinal fluid of aged individuals and subjects with Parkinson's disease. Biochem. Biophys. Res. Commun. 349, 162-166. doi: 10.1016/j.bbrc.2006.08.024

Trupp, M., Jonsson, P., Ohrfelt, A., Zetterberg, H., Obudulu, O., Malm, L., et al. (2014). Metabolite and peptide levels in plasma and CSF differentiating healthy controls from patients with newly diagnosed Parkinson's disease. J. Parkinsons Dis. 4, 549-560. doi: 10.3233/JPD-140389

Turkka, J. T., Juujärvi, K. K., and Myllylä, V. V. (1987). Correlation of autonomic dysfunction to CSF concentrations of noradrenaline and 3-methoxy4-hydroxyphenylglycol in Parkinson's disease. Eur. Neurol. 26, 29-34. doi: $10.1159 / 000116308$

van Dijk, K. D., Bidinosti, M., Weiss, A., Raijmakers, P., Berendse, H. W., and van de Berg, W. D. (2014). Reduced $\alpha$-synuclein levels in cerebrospinal fluid in Parkinson's disease are unrelated to clinical and imaging measures of disease severity. Eur. J. Neurol. 21, 388-394. doi: 10.1111/ene.12176

van Dijk, K. D., Jongbloed, W., Heijst, J. A., Teunissen, C. E., Groenewegen, H. J., Berendse, H. W., et al. (2013a). Cerebrospinal fluid and plasma clusterin levels in Parkinson's disease. Parkinsonism Relat. Disord. 19, 1079-1083. doi: 10.1016/j.parkreldis.2013.07.016

van Dijk, K. D., Persichetti, E., Chiasserini, D., Eusebi, P., Beccari, T., Calabresi, P., et al. (2013b). Changes in endolysosomal enzyme activities in cerebrospinal fluid of patients with Parkinson's disease. Mov. Disord. 28, 747-754. doi: 10.1002/mds. 25495

Van Sande, M., Caers, J., and Lowenthal, A. (1971). Cerebrospinal fluid amino acids in extrapyramidal disorders before and after L-DOPA treatment. Z. Neurol. 199, $24-29$. van Woert, M. H., and Bowers, M. B. Jr. (1970). Homovanillic acid (HVA) and 5-hydroxyindoleacetic acid (5HIAA) during L-dopa therapy of Parkinson's disease. Neurology 20, 377.

Vawter, M. P., Dillon-Carter, O., Tourtellotte, W. W., Carvey, P., and Freed, W. J. (1996). TGFbetal and TGFbeta2 concentrations are elevated in Parkinson's disease in ventricular cerebrospinal fluid. Exp. Neurol. 142, 313-322. doi: 10.1006/exnr.1996.0200

Vermes, I., Steur, E. N., Jirikowski, G. F., and Haanen, C. (2004). Elevated concentration of cerebrospinal fluid tissue transglutaminase in Parkinson's disease indicating apoptosis. Mov. Disord. 19, 1252-1254. doi: 10.1002/mds.20197

Vermes, I., Steur, E. N., Reutelingsperger, C., and Haanen, C. (1999). Decreased concentration of annexin $\mathrm{V}$ in parkinsonian cerebrospinal fluid: speculation on the underlying cause. Mov. Disord. 14, 1008-1010.

Volicer, L., Beal, M. F., Direnfeld, L. K., Marquis, J. K., and Albert, M. L. (1986). CSF cyclic nucleotides and somatostatin in Parkinson's disease. Neurology 36, 89-92. doi: 10.1212/WNL.36.1.89

Volicer, L., Direnfeld, L. K., Freedman, M., Albert, M. L., Langlias, P. J., and Bird, E. D. (1985). Serotonin and 5-hydroxyindoleacetic acid in CSF. Difference in Parkinson's disease and dementia of the Alzheimer's type. Arch. Neurol. 42, 127-129. doi: 10.1001/archneur.1985.04060020037011

Voto Bernales, J., Cruz, G. A., and Davila, E. (1973). [Determination of homovanillic acid in the cerebrospinal fluid of Parkinson's disease patients and control group]. Rev. Neuropsiquiatr. 36, 46-52 [Article in Spanish].

Vranová, H. P., Hényková, E., Kaiserová, M., Menšíková, K., Vaštík, M., Mareš, J., et al. (2014). Tau protein, beta-amyloid1-42 and clusterin CSF levels in the differential diagnosis of Parkinsonian syndrome with dementia. J. Neurol. Sci. 343, 102-104. doi: 10.1016/j.jns.2014.05.052

Wang, E. S., Sun, Y., Guo, J. G., Gao, X., Hu, J. W., Zhou, L., et al. (2010). Tetranectin and apolipoprotein A-I in cerebrospinal fluid as potential biomarkers for Parkinson's disease. Acta Neurol. Scand. 122, 350-359. doi: 10.1111/j.16000404.2009.01318.x

Wang, Y., Hancock, A. M., Bradner, J., Chung, K. A., Quinn, J. F., Peskind, E. R., et al. (2011). Complement 3 and factor $h$ in human cerebrospinal fluid in Parkinson's disease, Alzheimer's disease, and multiple-system atrophy. Am. J. Pathol. 178, 1509-1516. doi: 10.1016/j.ajpath.2011.01.006

Wang, Y., Shi, M., Chung, K. A., Zabetian, C. P., Leverenz, J. B., Berg, D., et al. (2012). Phosphorylated $\alpha$-synuclein in Parkinson's disease. Sci. Transl. Med. 4, 121ra20. doi: 10.1126/scitranslmed.3002566

Waragai, M., Wei, J., Fujita, M., Nakai, M., Ho, G. J., Masliah, E., et al. (2006). Increased level of DJ-1 in the cerebrospinal fluids of sporadic Parkinson's disease. Biochem. Biophys. Res. Commun. 345, 967-972. doi: 10.1016/j.bbrc.2006.05.011

Weiner, W. J., and Klawans, H. L. Jr. (1973). Failure of cerebrospinal fluid homovanillic acid to predict levodopa response in Parkinson's disease. J. Neurol. Neurosurg. Psychiatry 36, 747-752. doi: 10.1136/jnnp.36.5.747

Weiner, W., Harrison, W., and Klawans, H. (1969). L-dopa and cerebrospinal fluid homovanillic acid in Parkinsonism. Life Sci. 8, 971-976. doi: 10.1016/00243205(69)90428-7

Weiss, J., Gründig, E., and Gerstenbrand, F. (1975). [The activity of aminotransferases in serum and cerebrospinal fluid in neurological diseases (author's transl)]. Wien. Klin. Wochenschr. 87, 799-803.

Welch, M. J., Markham, C. H., and Jenden, D. J. (1976). Acetylcholine and choline in cerebrospinal fluid of patients with Parkinson's disease and Huntington's chorea. J. Neurol. Neurosurg. Psychiatry 39, 367-374. doi: 10.1136/jnnp.39.4.367

Wennström, M., Surova, Y., Hall, S., Nilsson, C., Minthon, L., Boström, F., et al. (2013). Low CSF levels of both $\alpha$-synuclein and the $\alpha$-synuclein cleaving enzyme neurosin in patients with synucleinopathy. PLoS ONE 8:e53250. doi: 10.1371/journal.pone.0053250

Widner, B., Leblhuber, F., and Fuchs, D. (2002). Increased neopterin production and tryptophan degradation in advanced Parkinson's disease. J. Neural Transm. 109, 181-189. doi: 10.1007/s007020200014

Wienecke, M., Werth, E., Poryazova, R., Baumann-Vogel, H., Bassetti, C. L., Weller, M., et al. (2012). Progressive dopamine and hypocretin deficiencies in Parkinson's disease: is there an impact on sleep and wakefulness? J. Sleep Res. 21, 710-717. doi: 10.1111/j.1365-2869.2012.01027.x

Wilk, S., and Mones, R. (1971). Cerebrospinal fluid levels of 3-methoxy-4hydroxyphenylethylene glycol in Parkinsonism before and after treatment with L-dopa. J. Neurochem. 18, 1771-1773. doi: 10.1111/j.1471-4159.1971. tb03753.x 
Williams, A., Ballenger, J., Levine, R., Lovenberg, W., and Calne, D. (1980b). Aging and CSF hydroxylase cofactor. Neurology 30, 1244-1246. doi: 10.1212/WNL.30.11.1244

Williams, A. C., Levine, R. A., Chase, T. N., Lovenberg, W., and Calne, D. B. (1980a). CFS hydroxylase cofactor levels in some neurological diseases. J. Neurol. Neurosurg. Psychiatry 43, 735-738. doi: 10.1136/jnnp. 43.8.735

Woulfe, J. M., Duke, R., Middeldorp, J. M., Stevens, S., Vervoort, M., Hashimoto, M., et al. (2002). Absence of elevated anti-alpha-synuclein and anti-EBV latent membrane protein antibodies in PD. Neurology 58, 1435-1436. doi: 10.1212/WNL.58.9.1435

Yaksh, T. L., Carmichael, S. W., Stoddard, S. L., Tyce, G. M., Kelly, P. J., Lucas, D., et al. (1990). Measurement of lumbar CSF levels of met-enkephalin, encrypted met-enkephalin, and neuropeptide $\mathrm{Y}$ in normal patients and in patients with Parkinson's disease before and after autologous transplantation of adrenal medulla into the caudate nucleus. J. Lab. Clin. Med. 115, 346-351

Yamada, H., Otsuka, M., Fujimoto, K., Kawashima, K., and Yoshida, M. (1996). Determination of acetylcholine concentration in cerebrospinal fluid of patients with neurologic diseases. Acta Neurol. Scand. 93, 76-78. doi: 10.1111/j.16000404.1996.tb00175.x

Yamada, T., Chong, J. K., Asahina, M., Koguchi, Y., and Hirayama, K. (1993). Concentration of neural thread protein in cerebrospinal fluid from progressive supranuclear palsy and Parkinson's disease. Jpn. J. Psychiatry Neurol. 47, 631-635.

Yamada, T., Moroo, I., Koguchi, Y., Asahina, M., and Hirayama, K. (1994). Increased concentration of C4d complement protein in the cerebrospinal fluids in progressive supranuclear palsy. Acta Neurol. Scand. 89, 42-46. doi: 10.1111/j.1600-0404.1994.tb01631.x

Yamamoto, M., Ogawa, N., and Ujike, H. (1986). Effect of L-threo-3,4dihydroxyphenylserine chronic administration on cerebrospinal fluid and plasma free 3-methoxy-4-hydroxy-phenylglycol concentration in patients with Parkinson's disease. J. Neurol. Sci. 73, 39-44. doi: 10.1016/0022-510X(86) 90061-4

Yamamoto-Watanabe, Y., Watanabe, M., Jackson, M., Akimoto, H., Sugimoto, K., Yasujima, M., et al. (2010). Quantification of cystatin C in cerebrospinal fluid from various neurological disorders and correlation with G73A polymorphism in CST3. Brain Res. 1361, 140-145. doi: 10.1016/j.brainres.2010.09.033

Yasui, K., Inoue, Y., Kanbayashi, T., Nomura, T., Kusumi, M., and Nakashima, K. (2006). CSF orexin levels of Parkinson's disease, dementia with Lewy bodies, progressive supranuclear palsy and corticobasal degeneration. J. Neurol. Sci. 250, 120-123. doi: 10.1016/j.jns.2006.08.004
Yoshinaga, J., Sasaki, T., Ideshita, H., Hikiji, A., and Kuwaki, T. (1989). Acetylcholinesterase activity in CSF in senile dementia of Alzheimer type, vascular dementia, and Parkinson's disease. Rinsho Shinkeigaku 29, 376-378.

Zhang, J., Mattison, H. A., Liu, C., Ginghina, C., Auinger, P., McDermott, M. P., et al. (2013). Longitudinal assessment of tau and amyloid beta in cerebrospinal fluid of Parkinson disease. Acta Neuropathol. 126, 671-682. doi: 10.1007/s00401-013-1121-x

Zhang, J., Sokal, I., Peskind, E. R., Quinn, J. F., Jankovic, J., Kenney, C., et al. (2008). CSF multianalyte profile distinguishes Alzheimer and Parkinson diseases. Am. J. Clin. Pathol. 129, 526-529. doi: 10.1309/W01Y0B808EMEH12L

Zhou, G., Shoji, H., Yamada, S., and Matsuishi, T. (1997). Decreased betaphenylethylamine in CSF in Parkinson's disease. J. Neurol. Neurosurg. Psychiatry 63, 754-758. doi: 10.1136/jnnp.63.6.754

Zubenko, G. S., Marquis, J. K., Volicer, L., Direnfeld, L. K., Langlais, P. J., and Nixon, R. A. (1986). Cerebrospinal fluid levels of angiotensin-converting enzyme, acetylcholinesterase, and dopamine metabolites in dementia associated with Alzheimer's disease and Parkinson's disease: a correlative study. Biol. Psychiatry 21, 1365-1381. doi: 10.1016/0006-3223(86)90328-8

Zubenko, G. S., Volicer, L., Direnfeld, L. K., Freeman, M., Langlais, P. J., and Nixon, R. A. (1985). Cerebrospinal fluid levels of angiotensin-converting enzyme in Alzheimer's disease, Parkinson's disease and progressive supranuclear palsy. Brain Res. 328, 215-221. doi: 10.1016/0006-8993(85)91032-7

Conflict of Interest Statement: The authors declare that the research was conducted in the absence of any commercial or financial relationships that could be construed as a potential conflict of interest.

Received: 30 June 2014; accepted: 20 October 2014; published online: 11 November 2014.

Citation: Jiménez-Jiménez FJ, Alonso-Navarro H, García-Martín E and Agúndez JAG (2014) Cerebrospinal fluid biochemical studies in patients with Parkinson's disease: toward a potential search for biomarkers for this disease. Front. Cell. Neurosci. 8:369. doi: $10.3389 /$ fncel.2014.00369

This article was submitted to the journal Frontiers in Cellular Neuroscience.

Copyright (c) 2014 Jiménez-Jiménez, Alonso-Navarro, García-Martín and Agúndez. This is an open-access article distributed under the terms of the Creative Commons Attribution License (CC BY). The use, distribution or reproduction in other forums is permitted, provided the original author(s) or licensor are credited and that the original publication in this journal is cited, in accordance with accepted academic practice. No use, distribution or reproduction is permitted which does not comply with these terms. 